OPEN ACCESS

Edited by: Jiehui Jiang,

Shanghai University, China

Reviewed by: Parnetti Lucilla,

University of Perugia, Italy Ville Leinonen,

University of Eastern Finland, Finland

*Correspondence:

Christiana Bjorkl

christiana.bjorkli@ntnu.no

Received: 31 May 2020

Accepted: 06 August 2020

Published: 02 September 2020

Citation:

Bjorkli C, Sandvig A and Sandvig I (2020) Bridging the Gap Between

Fluid Biomarkers for Alzheimer's

Disease, Model Systems,

and Patients.

Front. Aging Neurosci. 12:272.

doi: 10.3389/fnagi.2020.00272

\section{Bridging the Gap Between Fluid Biomarkers for Alzheimer's Disease, Model Systems, and Patients}

\author{
Christiana Bjorkli ${ }^{*}$, Axel Sandvig ${ }^{1,2,3}$ and loanna Sandvig ${ }^{1}$ \\ ${ }^{1}$ Sandvig Group, Department of Neuromedicine and Movement Science, Faculty of Medicine and Health Sciences, \\ Norwegian University of Science and Technology, Trondheim, Norway, ${ }^{2}$ Institute of Neuromedicine and Movement Science, \\ Department of Neurology, St. Olavs Hospital, Trondheim, Norway, ${ }^{3}$ Department of Pharmacology and Clinical \\ Neurosciences, Division of Neuro, Head, and Neck, University Hospital of Umeå, Umeå, Sweden
}

Alzheimer's disease (AD) is a debilitating neurodegenerative disease characterized by the accumulation of two proteins in fibrillar form: amyloid- $\beta(A \beta)$ and tau. Despite decades of intensive research, we cannot yet pinpoint the exact cause of the disease or unequivocally determine the exact mechanism(s) underlying its progression. This confounds early diagnosis and treatment of the disease. Cerebrospinal fluid (CSF) biomarkers, which can reveal ongoing biochemical changes in the brain, can help monitor developing AD pathology prior to clinical diagnosis. Here we review preclinical and clinical investigations of commonly used biomarkers in animals and patients with $A D$, which can bridge translation from model systems into the clinic. The core $A D$ biomarkers have been found to translate well across species, whereas biomarkers of neuroinflammation translate to a lesser extent. Nevertheless, there is no absolute equivalence between biomarkers in human $A D$ patients and those examined in preclinical models in terms of revealing key pathological hallmarks of the disease. In this review, we provide an overview of current but also novel AD biomarkers and how they relate to key constituents of the pathological cascade, highlighting confounding factors and pitfalls in interpretation, and also provide recommendations for standardized procedures during sample collection to enhance the translational validity of preclinical AD models.

\section{Keywords: Alzheimer's disease, translational research, biomarkers, cerebrospinal fluid, screening tools}

\section{INTRODUCTION}

Due to an increasingly elderly population, patients with Alzheimer's disease (AD) constitute a growing public health problem, thus developing methods for early diagnosis of the disease will become pertinent as there of yet exists no cure. The disease typically manifests through a progressive decline in cognitive and behavioral functions that severely impact the ability of AD patients to independently perform daily tasks. As a result, the associated socioeconomic cost and burden to the healthcare system are very high, with annual healthcare expenditure exceeding billions of dollars. Based on the early findings by Alzheimer et al. (1995), we now know that the neuropathological hallmarks of AD include intracellular neurofibrillary tangles (NFTs) composed of misfolded tau protein, and extracellular amyloid plaques comprising aggregated amyloid- $\beta(A \beta)$. The pathological 
protein accumulation in $\mathrm{AD}$ follows a predictable spatiotemporal pattern where certain areas become affected before others, including the entorhinal cortex (EC) and the hippocampus (Serrano-Pozo et al., 2011). In late stage AD, up to $90 \%$ of cells are lost in EC layer II (Gomez-Isla et al., 1996). The initial A $\beta$ deposits present as plaques in the temporal neocortex, before progressing to the EC and the hippocampus (Box 1; Thal et al., 2002). Meanwhile, initial tangle formation begins in the most lateral portions of EC layer II, followed by the hippocampus, before appearing in areas of the neocortex (Box 1; Braak and Braak, 1991). The anatomical and temporal progression of $A \beta$ and tau pathology, and subsequently neurodegeneration, has led to the postulation that $A \beta$ acts as an initiator of the disease progression that results in tau-mediated neurodegeneration (Freudenberg-Hua et al., 2018).

Many variants of the amyloid cascade hypothesis have been proposed over the years; and this hypothesis argues that the deposition of $A \beta$ is the initial and causative step for developing AD (Hardy and Higgins, 1992). According to this hypothesis, $A \beta$ deposition causes disruption of calcium homeostasis in cells, resulting in molecular lesions, NFTs, oxidative stress, inflammation, excitotoxicity, and eventually cell death. The main counter argument for this hypothesis has been that amyloid plaque burden has a low correlation with the severity of clinical symptoms of AD, unlike that of NFTs and neurodegeneration (Terry et al., 1991; Arriagada et al., 1992). In line with this, amyloid plaque deposition commonly plateaus with time, despite declining cognition in AD (Engler et al., 2006). Therefore, the majority in the AD research field now focus on soluble, intracellular $A \beta$ oligomers as a possible initiator of the development of the disease (Figure 1).

Amyloid- $\beta$ can exist in multiple assembly forms, ranging from monomeric to oligomeric and fibrillar forms (Figure 1). As a monomer, $A \beta$ does not seem to be toxic, whereas oligomeric or fibrillar forms have been found to be potent blockers of longterm potentiation (LaFerla et al., 2007). Research suggests that levels of soluble $A \beta$ oligomers are better correlated with disease severity than amyloid plaques mainly consisting of insoluble A $\beta$ fibrillar species (Arriagada et al., 1992; Lue et al., 1999; McLean et al., 1999; Naslund et al., 2000; Haass and Selkoe, 2007). When produced intracellularly, $A \beta$ oligomers expose flexible hydrophobic surfaces that might contribute to trapping vital proteins and, in this way, they can subtly damage and predispose vulnerable neurons to the formation of intracellular tau aggregates (Campioni et al., 2010). Thus, tau pathology in $\mathrm{AD}$ appears to be a downstream, effect of the presence of $A \beta$ oligomers (Figure 1). In line with this, a link has been made between increased amounts of intracellular $A \beta$ and neurodegeneration, while clearing of intracellular $\mathrm{A} \beta$ has been shown to revert AD-related memory deficits in animals modeling AD (Billings et al., 2005). An explanation for the weak correlation between cognitive decline and plaque load could be that insoluble fibrillar $A \beta$ species might serve as reservoirs for smaller oligomeric $A \beta$, thus sequestering these away from neurons (Mucke and Selkoe, 2012; Figure 1).

The manner in which pathology progresses in model systems and human patients with $\mathrm{AD}$ has mostly been investigated separately resulting in little or poor translational value. As such, the translational aspect of staging the $\mathrm{AD}$ molecular disease cascade between preclinical models and human $\mathrm{AD}$ patients has remained inadequate. Despite intense investigation into disease cause and mechanisms of neurodegeneration, there is currently no cure or unequivocal evidence as to the exact nature of its underlying cause. Still, there seems to be consensus as to the fact that the success of treatments is primarily contingent on whether they can target disease-related pathology at early onset. This suggests that we are urgently in need of better tools for early onset diagnosis, before evolving pathology severely affects brain function, as well as better tools for monitoring pathological progression.

This effectively means, to translate discoveries made in preclinical models to the clinic, we must bridge the gap between model systems and patients with $\mathrm{AD}$ by improving the robustness and predictive validity of screening tools. For instance, the current dominant view is that $A \beta 42$ accumulates extracellularly first, and thereby leads to the formation of amyloid plaques. However, several studies of brain tissue from animal models and human patients have begun to challenge this notion. In this paper, we explore potential early screening tools for the diagnosis of $\mathrm{AD}$ and also provide links between the extensive research done in preclinical models to human clinical applications. Specifically, we review how screening in $\mathrm{AD}$ patients can become more precise by the use of novel cerebrospinal fluid (CSF) biomarkers and by following recommendations for standardized procedures during CSF sample collections. We also focus on how intracellular events of $\mathrm{A} \beta$ and tau aggregation eventually lead to extracellular deposition and the presence of neuropathological hallmarks, and how current tools can predict, diagnose and potentially treat models and patients at various timepoints of the disease.

\section{AD BIOMARKERS - TYPE AND DEFINITION}

When defining an $\mathrm{AD}$ biomarker, many agree that it is a measurable indicator within a patient that can help to test and monitor the progress of pathology (Hane et al., 2017). The ideal fluid biomarker for $\mathrm{AD}$ would be consistent, reproducible, noninvasive, simple to measure, inexpensive, and easy to implement into the clinic and the primary care setting (Davies et al., 1998; Wang et al., 2012; Bjerke and Engelborghs, 2018; Molinuevo et al., 2018). Such biomarkers should be able to identify the clinical disease stage of the patient and also monitor treatment effects. Conventionally, patients with overt dementia are diagnosed with around $85 \%$ specificity (but at much lower rates in patients with early stage $\mathrm{AD}$ ), but the ideal biomarker should exceed this rate (Davies et al., 1998). There is thus an urgent need for a specific marker for early detection in these patients. Various biomarkers that can detect early $\mathrm{AD}$ in both preclinical models and patients have been proposed. For instance, it would be preferable to have a biomarker that can detect intracellular events prior to the deposition of amyloid plaques and NFTs. In line 


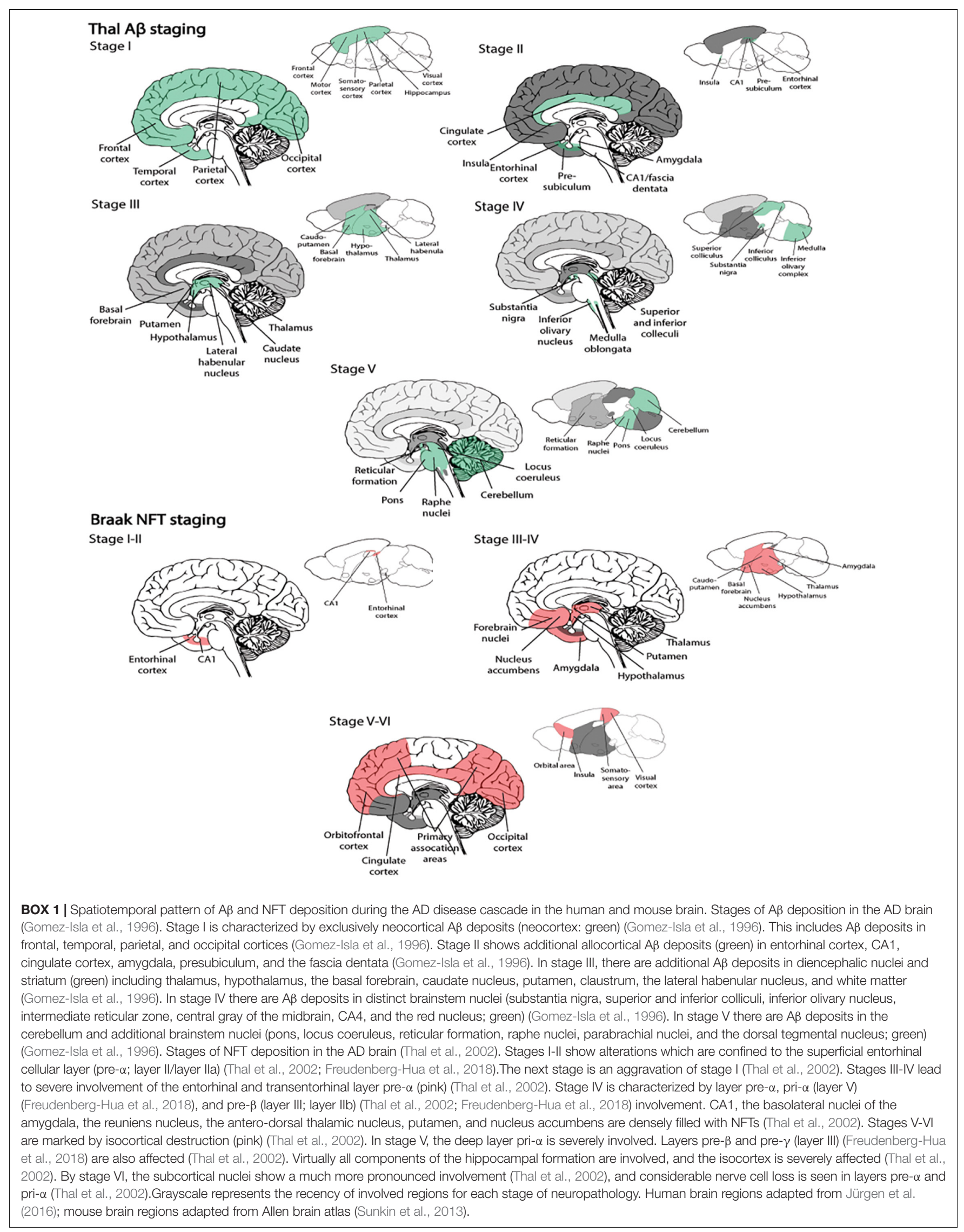




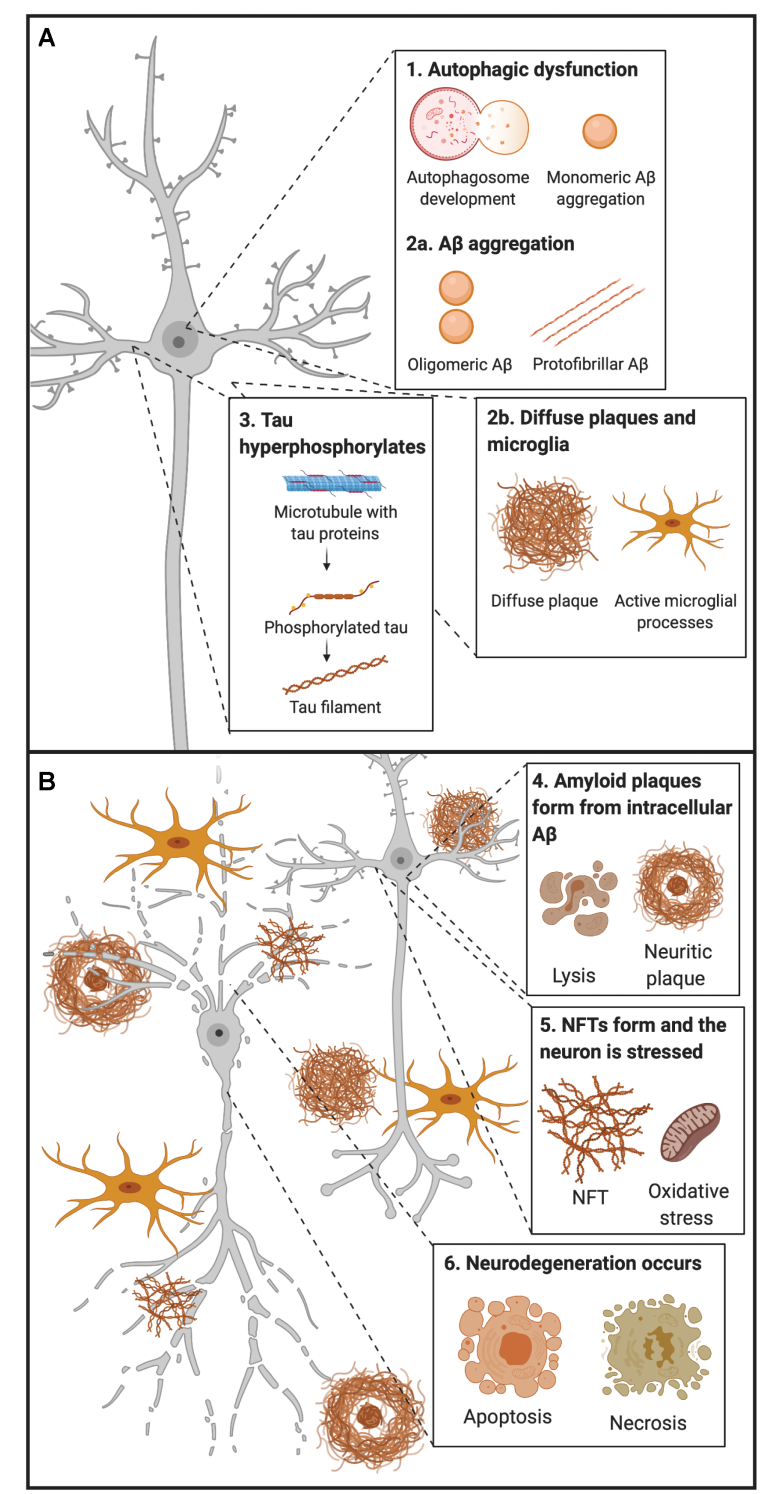

FIGURE 1 | Early and late timepoints of neuropathological development in AD. (A) Early molecular abnormalities leading to the development of neuropathological hallmarks in AD. First, disruption of endocytic and autophagic systems may lead to, or simultaneously become disrupted, as monomeric $A \beta$ aggregates. Following, monomeric $A \beta$ aggregates into oligomeric and protofibrillar forms. At the same time, diffuse amyloid plaques may be present extracellularly and begin to sequester $A \beta$ from synapses, leading to microglial activation (and other inflammatory responses). Next, tau proteins become hyperphosphorylated and move from the axon to the somatodendritic compartment of the neuron. (B) Late molecular abnormalities in $\mathrm{AD}$. While diffuse plaques are present extracellularly and may become neuritic by sequestering $A \beta$ peptides from the synapse, a lysis event of the neuron occurs, and intracellular protofibrillar $A \beta$ is deposited into the extracellular space leading to the development of neuritic plaques (composed of fibrillar $A \beta$ ). Other amyloid plaques in close vicinity may sequester $A \beta$ peptides between each other, leading to the increased accumulation of neuritic plaques. Next, hyperphosphorylated tau from paired helical filaments form NFTs which results in excitotoxicity and oxidative stress. Ultimately neurodegeneration of the neuron occurs, primarily by necrosis, but apoptosis may also occur from some intracellular processes. A $\beta$, amyloid- $\beta$; NFT, neurofibrillary tangle. with this, when diagnosing patients based on physical symptoms, reduced memory recall manifests in many diseases other than $\mathrm{AD}$ (Hane et al., 2017), highlighting the need for preclinical markers specific to $\mathrm{AD}$.

Furthermore, $\mathrm{AD}$ has a long preclinical phase (Figure 2) consisting of three stages. In the first stage, monomeric and oligomeric $A \beta$ aggregates inside neurons and subsequently onto neuronal surfaces and synapses as the concentration in the CSF reservoir diminishes. At this stage, current methods cannot detect the changes caused by $A \beta$ aggregation in neurons and synapses (Hane et al., 2017). During the second stage, certain CSF biomarkers such as increased CSF tau, hypometabolism in the posterior cingulate, and cortical thinning become detectable (Hane et al., 2017). In the third stage, the patient experiences subtle symptoms while CSF A $\beta$ decreases and CSF tau increases (Hane et al., 2017). Therefore, biomarker trajectories may differ as a function of the stage to which patients belong along the neuropathological cascade.

\section{Neuroimaging Biomarkers in AD Imaging Amyloid and Tau Burden}

Substantial advances have been made in the detection $A D$ biomarkers using neuroimaging. In terms of imaging amyloid burden, positron emission tomography (PET) scans with radiolabeled tracers specific to $A \beta$ have become fairly common in $\mathrm{AD}$ research. PET amyloid ligands allows for quantification of amyloid deposition in patients, and binding of these ligands predates the development of clinical symptoms of $\mathrm{AD}$ by $7-$ 15 years (Jack et al., 2013; Roe et al., 2013). [ $\left.{ }_{11} \mathrm{C}\right]$ Pittsburgh Compound-B ( $\mathrm{PiB})$, a derivative of the fluorescent benzothiazole dye thioflavin $T$, enables for non-invasive imaging of fibrillar $A \beta$ deposits (Klunk et al., 2004; Johnson et al., 2009). Importantly, this imaging tool is only able to detect extracellular $A \beta$ deposition, and not intracellular $A \beta$ accumulation. The Alzheimer's Disease Neuroimaging Initiative (ADNI) suggests that $\mathrm{PiB}$ can predict cognitive decline and brain atrophy in patients with mild cognitive impairment ( $\mathrm{MCI}$; represents a transition toward diagnosable dementia) (Weiner et al., 2010). Amyloid imaging is now usually performed by the use of fluorine-based tracers $\left({ }_{18} \mathrm{~F}\right.$ or $\left.\mathrm{FDG}\right)$ and points to the parietal cortices as the earliest sites of amyloid deposition (Figure 2; Dickerson et al., 2009). The specific brain regions (posterior cingulate, retrosplenial cortex, and precuneus) are heavily connected with the medial temporal lobes (MTLs) (Ranganath and Ritchey, 2012), which are sites of early AD-related neuropathology. Tau imaging, by the use of selective PET tracers, is able to detect tau depositions that follow Braak staging of NFT pathology (Figure 2; Schöll et al., 2015; Cho et al., 2016; Maass et al., 2017). PET ligands have also been developed that are specific for paired-helical filament tau (Leuzy et al., 2019; Scholl et al., 2019). Post-mortem studies of $\mathrm{AD}$ patients indicate that, unlike amyloid plaque deposition, NFT density correlates with neurodegeneration and cognitive impairment (Duyckaerts et al., 1987; Braak and Braak, 1997). However, disentangling primary age-related tauopathy (PART) and $\mathrm{AD}$ may be a great challenge as there is considerable overlap in the MTL. 


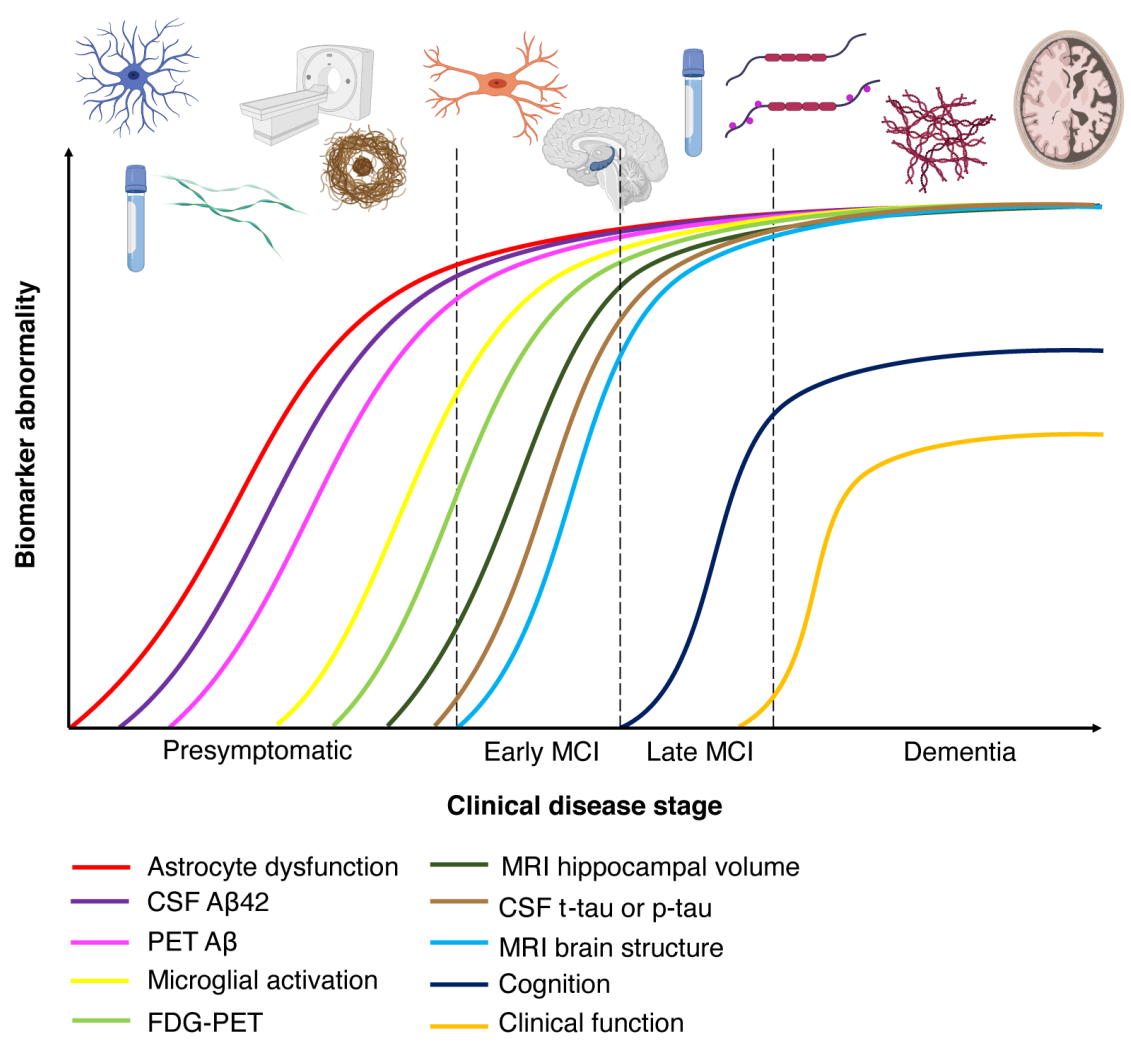

FIGURE 2 | Chronobiological biomarkers to Alzheimer's disease clinical stage. This disease model displays that biomarkers become abnormal in a temporally ordered manner as the disease progresses (Jack et al., 2010). Amyloid plaque biomarkers are dynamic early in the disease, prior to the appearance of clinical symptoms, and have largely reached a plateau by the time clinical symptoms appear (Jack et al., 2010). Biomarkers of neuronal injury, dysfunction, and degeneration are dynamic later in the disease and correlate with clinical symptom severity. MRI is the last biomarker to become aberrant. None of the biomarkers are static, and rates of change in each biomarker vary over time and follow a non-linear time-course, which is hypothesized to be sigmoid shaped (Jack et al., 2010). A sigmoid shape as a function of time implies that the maximum effect of each biomarker varies over the course of disease progression (Jack et al., 2010). Figure adapted with permission from Leclerc and Abulrob (2013). MCl, mild cognitive impairment; CSF, cerebrospinal fluid; A $\beta$, amyloid- $\beta$; PET, positron emission tomography; FDG, fluorine-based tracers; MRI, magnetic resonance imaging; t-tau, total tau; p-tau, phosphorylated tau.

\section{FDG-PET - Cerebral Glucose Hypometabolism}

Positron emission tomography imaging has been used to examine brain glucose abnormalities in aging, MCI and $\mathrm{AD}$ (de Leon et al., 1983). FDG can be used as a metabolic marker and reduced hippocampal metabolism has been observed in patients with MCI and AD (Mosconi et al., 2005; Figure 2). FDG-PET is a sensitive biomarker for neuronal and synaptic degeneration (Zimmer et al., 2017), and in line with this, research indicates that cerebral glucose hypometabolism is a downstream marker of neurodegeneration. Thus, this imaging method is able to detect patients at a later timepoint in the course of AD. Studies (Kuhl et al., 1982) have demonstrated that in older ages cerebral glucose metabolism decreases, and that the MTLs, the posterior cingulate cortex and the precuneus show the least age-dependent change. These regions express significant hypometabolism in $\mathrm{AD}$ (Márquez and Yassa, 2019), and Mosconi et al. (2008) showed that FDG-PET could be used to differentiate healthy subjects from AD patients with 98 to $99 \%$ specificity. Recent work by ADNI 2 PET Core has examined how FDG-PET and amyloid PET can be combined to track progression of AD. For instance, they demonstrated that amyloid PET is negatively associated with temporoparietal metabolism (Landau et al., 2012). Amyloid PET is associated with cognitive change in healthy subjects, whereas FDG-PET imaging is able to demonstrate cognitive change in MCI patients (Jagust et al., 2015). This is consistent with the spatiotemporal progression model of $\mathrm{AD}$ (Figure 2), where amyloid progression precedes neurodegeneration.

\section{Imaging Connectivity - Resting-State Functional Magnetic Resonance Imaging}

Functional magnetic resonance imaging (fMRI) techniques use blood-oxygenation-level-dependent (BOLD) contrast, which is associated with neuronal population activity. Resting-state fMRI studies examine the correlation of the BOLD signal and anatomical regions of interest at a temporal scale by analyzing spontaneous fluctuations in brain connectivity (Biswal et al., 1995; Fox and Raichle, 2007). In preclinical stages of AD, resting-state fMRI signals have been linked to metabolic changes (indexed by PET) and found to precede neurodegeneration (Sheline and Raichle, 2013). Therefore, this imaging tool is able to detect patients at some point immediately before or after amyloid plaque deposition, prior to the development of NFTs 
and associated neurodegeneration. Most of these analyses have focused on the default mode network (Gusnard et al., 2001; Raichle et al., 2001), a network consisting of the MTL, the medial prefrontal cortex, posterior cingulate cortex, anterior cingulate cortex, parietal cortex, and precuneus (Greicius and Menon, 2004; Buckner et al., 2008). These regions overlap with the spatial pattern of amyloid and tau pathology (Buckner et al., 2008). In addition to changes in the default mode network, some studies have suggested that connectivity within the MTL may also be disrupted in AD (Yassa et al., 2011), such as the connectivity between EC and hippocampus [dentate gyrus (DG) and cornu ammonis field 3 (CA3)].

\section{Cortical Thinning and Volume Loss - Structural MRI}

Compared with functional imaging modalities, structural MRI provides an overview of anatomical changes in high resolution. Research has shown that in $\mathrm{AD}$ patients there is a decrease in brain volume associated with cortical thinning and gyral loss (Figure 2; Uylings and de Brabander, 2002), especially in the prefrontal cortex and hippocampus (Jack et al., 2000; Raz et al., 2005). Thus, this imaging tool can detect patients in which neurodegeneration has begun to occur. Studies in aged rodents and monkeys have demonstrated that hippocampal cells do not undergo frank cell loss with healthy aging (Rapp and Gallagher, 1996; Rasmussen et al., 1996; Rapp et al., 2002); in contrast, this is observed in the prefrontal cortex (Peters et al., 1994; Smith et al., 2004; Stranahan et al., 2012). Recently, cortical thinning of the EC has been shown to be a sensitive marker for structural alterations in both patients with MCI and AD (Holland et al., 2012a). EC thickness has been found to diminish prior to, and thereby predict, hippocampal atrophy (Desikan et al., 2010, 2011, 2012; Eskildsen et al., 2013). Several recent studies using the ADNI data have shown that older adults with CSF A $\beta$ and phosphorylatedtau (p-tau) present with volume loss in EC (Desikan et al., 2012; Holland et al., 2012b).

\section{White Matter Integrity - Diffusion Tensor Imaging}

Studies using diffusion tensor imaging (DTI) in MCI and AD patients show a decrease in brain white matter integrity but with most prominent changes in MTLs (Bozzali et al., 2002; Naggara et al., 2006; Xie et al., 2006; Huang et al., 2007; Chua et al., 2008). DTI studies have focused primarily on the fornix as this region links the limbic system with the rest of the brain. Fornix lesions have been found to reproduce memory and learning deficits linked to hippocampal damage in rats (Sutherland et al., 1982; McDonald and White, 1993) and monkeys (Gaffan et al., 1984; Gaffan, 1992, 1994). The perforant path connects EC layer II neurons to the hippocampal DG and CA3 (Witter, 2007) and is critical for normal hippocampal function (Hyman et al., 1986). The integrity of this pathway is reduced in aged rats with memory loss (Geinisman et al., 1992; Smith et al., 2000). Perforant path lesions also result in EC layer II neuronal loss (Peterson et al., 1994), i.e., at the site where neurodegeneration is first observed in $\mathrm{AD}$ patients. Thus, similarly to structural MRI, this imaging tool can detect AD patients at the timepoint at which neurodegeneration has occurred. In vivo biomarkers, such as those derived from brain imaging, are crucial for accurate diagnosis of $\mathrm{AD}$, but does not support diagnosis during preclinical stages. Additionally, molecular imaging is expensive and not easily accessible to the clinical population.

\section{CSF Biomarkers in AD}

The current approach to diagnosing $\mathrm{AD}$ patients involves assessing patient history, clinical examinations, and detection of underlying pathology using biomarkers during stages of the disease (Ramesh et al., 2018b), with the latter having a diagnostic accuracy between 82 and 84\% (Engelborghs et al., 2008). The clinical staging of AD usually lasts about 9-10 years (Heyman et al., 1996), however, researchers have found that the neuropathology of AD starts 20-30 years before the onset of clinical symptoms (Selkoe, 2001; Sperling et al., 2011). Thus, it is likely that, with current means, clinical diagnosis is only feasible at a late stage of the disease. Imaging tools are invaluable methods to diagnose $\mathrm{AD}$ patients, but additional methods are needed to detect AD pathology at an earlier stage of the disease cascade, where intervention may be able to delay, even, halt disease progression. By developing better screening and detection tools, early interventions at the preclinical stages of the disease should be possible.

Clearance of abnormal proteins by drainage into the CSF is an endogenous neuroprotective function of the brain. Clinical AD diagnosis is conducted by sampling CSF and analyzing aberrant protein levels within the sample. CSF fills the ventricular system in the brain and spinal cord (Barten et al., 2017) and research evidence suggests that the composition of CSF at any given time reflects true biochemical changes that occur in the brain (Lee et al., 2019). Most of the CSF is generated by the choroid plexus but a significant fraction derives from the interstitial fluid (ISF) in the brain and spinal cord parenchyma. ISF is the circulating CSF that bathes brain tissue (Barten et al., 2017), whereas the choroid plexus connects to nearby permeable capillaries with tight junctions and produces CSF using the aquaporin-1 water channel as well as directional ionic transporters (Speake et al., 2001; Brinker et al., 2014). In terms of CSF production and volume, studies have shown that it can change with age, disease, and time of day. For instance, CSF production increases from 0.4 to $1.4 \mu \mathrm{L} / \mathrm{min}$ between 8 and 12 weeks of age in the rat (Karimy et al., 2015). Interestingly, CSF volume has been found to increase during neurodegeneration (Barten et al., 2017), which may be related to the increase in atrophy and substance loss of the brain. It is therefore vital to keep these changes in CSF production in mind when comparing healthy subjects to $\mathrm{AD}$ patients, and when comparing preclinical with clinical findings.

\section{Temporal Course of AD Biomarkers}

Amyloid- $\beta$ level changes is the first biomarker abnormality seen in $\mathrm{AD}$ patients, which can either be in the form of an upregulation in plasma and CSF in cognitively normal individuals (Figure 2). The increased levels seen in CSF $A \beta 40$ and $A \beta 42$ in $A D$ patients is thought to reflect extracellular $A \beta$ deposits prior to the accumulation of amyloid plaques (Murphy and LeVine, 2010). However, it is important to note that $A \beta$ oligomers can form intracellularly before being deposited extracellularly, and currently this cannot be detected with existing biomarkers. 
Moreover, A $\beta$ deposition detected by PET ligands can be seen as early as 15 years prior to onset of AD symptoms (Figure 2; Shen et al., 2018). The next stage of biomarker alteration include neuronal injury, shown by increased levels of CSF total tau protein ( $\mathrm{t}$-tau) and tau phosphorylated at threonine 181 ( $\mathrm{p}$ tau181/p-tau), and brain atrophy revealed by structural MRI, and synaptic loss and neurodegeneration detected by DTI or FDG-PET (Figures 2, 3; Shen et al., 2018).

\section{Core CSF Biomarkers for Diagnosis}

Currently, CSF biomarkers are the only variety of fluid markers used for diagnosis of early $\mathrm{AD}$, however, they have proven difficult to implement in the clinic due to their limited accessibility and the invasive nature of CSF collection (Lee et al., 2019). There are three core CSF biomarkers for AD diagnosis; $\mathrm{A} \beta 42$, t-tau, and p-tau (Shen et al., 2018). Using a combination of the core $\mathrm{AD}$ biomarkers is a better approach compared to using the biomarkers individually, especially for differential diagnosis (Engelborghs et al., 2008). Lower concentrations of CSF A $\beta 42$ and higher concentrations of $t$-tau have been used to distinguish $\mathrm{AD}$ patients from healthy age-matched controls and to predict the conversion of MCI to AD (Frölich et al., 2017). To develop a non-invasive and effective measure of preclinical stages in $\mathrm{AD}$, early abnormal AD biomarkers in preclinical models and patients need to be translated and assessed, followed by methodological developments of screening tools that are successful in system models that mirror the disease progression seen in patients.

\section{CLASSIFICATION OF AD BIOMARKERS}

Alzheimer's disease biomarkers may be open to different interpretations, however, there is an international classification system proposed by the National Institute of Aging (NIH) and the Alzheimer's Association (NIA-AA) that can aid in grouping them. In 2018, CSF biomarkers could be used in conjunction with neuroimaging for the first time to diagnose $\mathrm{AD}$ patients (Lee et al., 2019). The $A / T / N$ system (Table 1) is a suggested grouping by Jack et al. (2016) based on the framework from the NIH and NIA-AA, where the $A$ refers to the $A \beta$ pathology measured either by PET or CSF $\mathrm{A} \beta 42$, the $T$ represents tangle pathology and is assessed by either PET or CSF p-tau, and the $N$ stands for neurodegeneration or neuronal injury detected by either FDG-PET, structural MRI, or CSF t-tau (Jack et al., 2016). Imaging techniques have found amyloid PET to be most reliable, whereas MRI and FDG-PET scans often are unable to distinguish $\mathrm{AD}$ more from other neurodegenerative disorders (Johnson et al., 2012). It is important to note that fluid biomarkers are more available and affordable compared to MRI and PET (Lee et al., 2019).

\section{$A \beta$ as a Biomarker for $A D$}

Amyloid- $\beta$ production occurs at the C-terminal fragment of amyloid precursor protein (APP) by cleavage of APP by $\beta$-secretase (BACE1) to form C99, followed by cleavage of C99 by presenilin (PSEN) 1 or PSEN2, two enzymatic components of $\gamma$-secretase (Haass and De Strooper, 1999). Following
TABLE 1 | AT(N) biomarker grouping of the NIA-AA framework.

\begin{tabular}{lll}
\hline Biomarker class & CSF marker & Imaging marker \\
\hline Amyloid $(\mathrm{A})$ & CSF $\mathrm{A} \beta 42$ or & Amyloid PET \\
& A $\beta 42:$ A $\beta 40$ ratio & \\
Tau $(T)$ & CSF p-tau & Tau PET \\
Neurodegeneration $(N)$ & CSF t-tau & Anatomic MRl; \\
& & FDG-PET
\end{tabular}

Adapted from Jack et al. (2016). NIH, National Institute on Aging; NIA$A A$, Alzheimer's Association; CSF, cerebrospinal fluid; $A \beta$, amyloid- $\beta$; $p$-tau, phosphorylated tau; t-tau, total tau; PET, positron emission tomography; MRl, magnetic resonance imaging; FDG, fluorine-based tracers.

production, $\mathrm{A} \beta 42$ aggregates and accumulates intracellularly and/or extracellularly until a critical threshold is reached, where CSF A $\beta 42$ decreases as the peptide sequesters in amyloid plaques in the brain parenchyma (Cirrito et al., 2003; Hong et al., 2011). The long delay in the emergence of plaque deposits even in the presence of increased $A \beta 42$, suggests an initial slow process where monomeric $A \beta$ forms small aggregates, followed by further A $\beta$ polymerization (Harper and Lansbury, 1997). The AD field cannot yet explain exactly how $A \beta$ pathology initiates, but further research on the generation of intracellular $A \beta$ monomers, their recycling, and their aggregation into oligomeric $\mathrm{A} \beta$ may yield some answers.

One of the most widely used biomarkers in $\mathrm{AD}$ diagnostic research is the measurement of $A \beta 42$ and $A \beta 40$ in CSF (Figure 3; Rogeberg et al., 2015). Although $A \beta 40$ is present at about 1020 times higher concentration in CSF, A $\beta 42$ is more prone to aggregate and shown to correlate better with $\mathrm{AD}$ neuropathology (Mehta et al., 2001; Hellstrand et al., 2010; Murphy and LeVine, 2010; Savage et al., 2014). It has been found that cognitively normal older adults that developed dementia in older ages had low CSF $A \beta 42$ but not $A \beta 40$ levels (Blennow et al., 2015). These findings can be explained in part by how $\mathrm{A} \beta$ aggregates to form soluble oligomers, which can exist in multiple forms and are neurotoxic (Haass and Selkoe, 2007), and which finally conform to diffuse and dense plaques. Recent studies support the notion that accumulation of the $A \beta$ peptide arises from an imbalance in the production and clearance of $A \beta$ and that the ability to clear A $\beta$ diminishes with age (Wildsmith et al., 2013). An attractive early biomarker for AD is CSF $\mathrm{A} \beta 42$, given that both CSF t-tau and p-tau changes occur at a later time point in the disease process closer to clinically detectable dementia (Buchhave et al., 2012). Furthermore, measurement of the CSF A $\beta 42: A \beta 40$ ratio is superior to $A \beta 42$ alone when distinguishing between MCI patients who progress and those that do not progress to AD dementia (Hansson et al., 2007; Lee et al., 2019). When comparing $A \beta$ fluid biomarkers and imaging biomarkers, studies have shown that CSF A $\beta 42$ can detect amyloid pathology earlier than amyloid PET imaging (Figure 3; Palmqvist et al., 2016).

There appears to be a lack of consensus regarding CSF A $\beta$ concentrations in $\mathrm{AD}$ patients. For instance, researchers have found that CSF A $\beta 42$ concentrations increase (Nakamura et al., 1994; Bouwman et al., 2007), decrease (Kanai et al., 1998; Tapiola et al., 2000; Wahlund and Blennow, 2003; Mollenhauer et al., 2005; de Leon et al., 2006; Beckett et al., 2010), or experience 


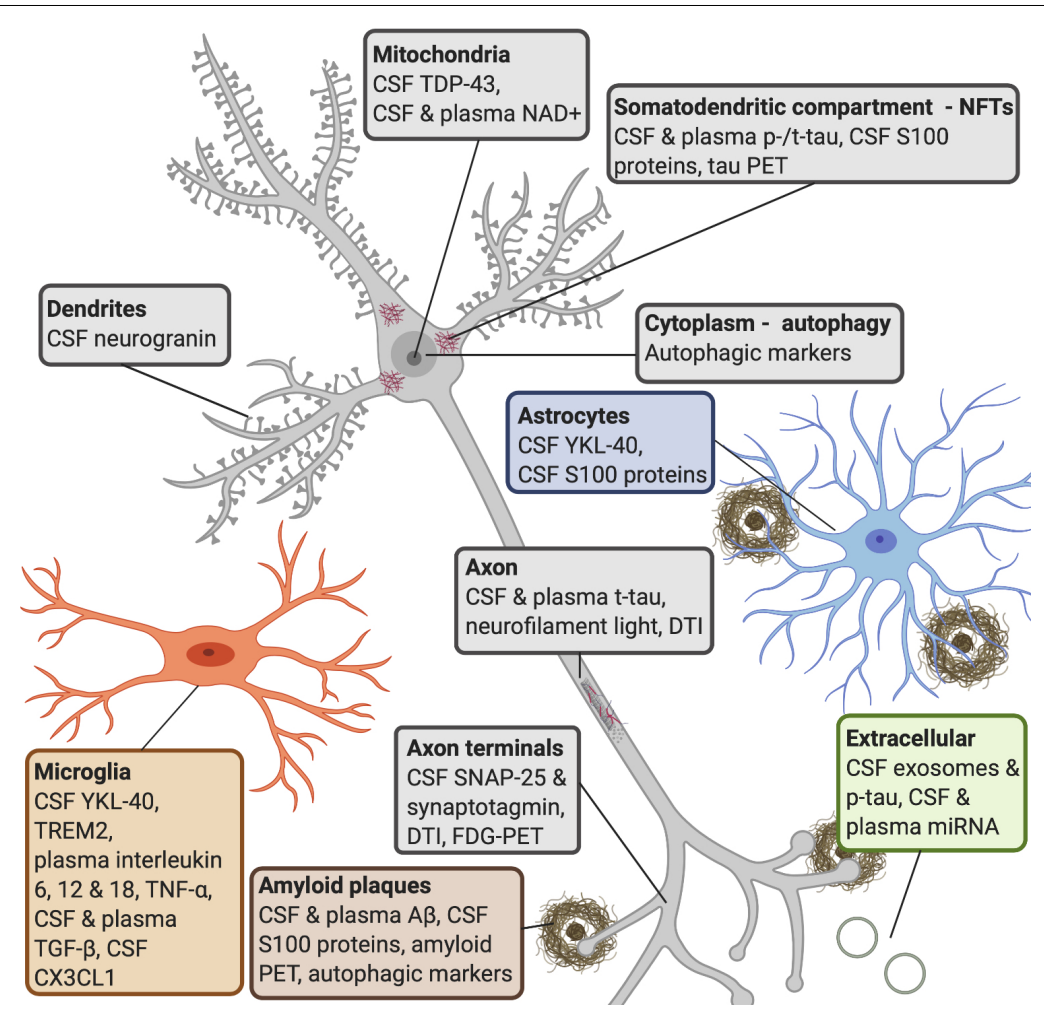

FIGURE 3 | AD molecular processes that can be detected by biomarkers. Amyloid plaques: a widely used biomarker for diagnosis in AD is the concentration of CSF A 442 and A 440 (Rogeberg et al., 2015). Studies have shown that CSF A 42 can detect amyloid pathology earlier than amyloid PET imaging (Palmqvist et al., 2016). Some research shows that serum A $\beta 42$ levels do not correlate with CSF levels (Liu et al., 2004), whereas others have found that plasma A $\beta$ can be measured with good sensitivity (Lee et al., 2019). Several S100 proteins (S100B, S100A1, S100A6, S100A8, S100A9, and S100A12) are found within amyloid plaques and in astrocytes and/or microglia near amyloid deposits (Boom et al., 2004; Shepherd et al., 2006; Walker et al., 2006; Ha et al., 2010; Afanador et al., 2014; Lodeiro et al., 2017). NFTs: increased CSF tau is a sensitive biomarker for neurodegeneration, but CSF p-tau is more specific to neurodegeneration linked to AD (Lewczuk et al., 2004; Blennow et al., 2015). P-tau is secreted via exosomal release, and reaches the CSF (Saman et al., 2012). Increased levels of CSF t-tau and p-tau can predict the progression of cognitive symptoms better than CSF A 42 (EI Kadmiri et al., 2018), but the diagnostic utility of CSF $\mathrm{t}$-tau and p-tau are improved when measured in combination with A 42 (Dubois et al., 2014). Increased plasma tau observed in AD patients compared to MCl patients and healthy controls (Mattsson et al., 2016; Pase et al., 2019). S100B and S100A9 are found within NFTs (Sheng et al., 1994, 1997; Shepherd et al., 2006). Autophagy: late stages of autophagy is disrupted in AD patients, as an accumulation of autophagic vesicles can be observed in dystrophic neurites (Komatsu et al., 2006), and are observed prior to extracellular A $\beta$ deposition (Mehrpour et al., 2010; Nixon and Yang, 2011). Microglia: YKL-40 is expressed by microglia. CSF TREM2 is associated with higher CSF $\mathrm{t}$-tau and p-tau levels, probably reflecting a corresponding change in microglia activation in response to neurodegeneration (Suarez-Calvet et al., 2016). It has been shown that AD patients have higher levels of interleukin-6, 12, and 18, TNF- $\alpha$ and TGF- $\beta$, in blood, and higher levels of TGF- $\beta$ in CSF, compared to healthy controls (Swardfager et al., 2010). Decreases in CSF neuronal CX3CL1 is found in AD patients (Perea et al., 2018). Astrocytes: YKL-40 is expressed in astrocytes near A $\beta$ plaques (Craig-Schapiro et al., 2010) and correlates positively with tau pathology (Querol-Vilaseca et al., 2017; Janelidze et al., 2018). Axon terminals: CSF levels of SNAP-25 (Brinkmalm et al., 2014; Sutphen et al., 2018) and synaptotagmin (Öhrfelt et al., 2016) have been found at elevated levels in patients with AD or MCl compared with control subjects. Synaptic neurodegeneration can be detected by DTI or FDG-PET (Shen et al., 2018). Dendrites: increased CSF neurogranin is found in $\mathrm{MCl}$ and $\mathrm{AD}$ patients as compared with healthy controls (Thorsell et al., 2010; De Vos et al., 2015). Axon: increased neurofilament light is observed in response to axonal damage, which occurs in AD. The core CSF biomarkers (Aß42, t-tau, and p-tau) and CSF neurofilament light levels strongly correlated with AD (Olsson et al., 2016). Blood levels of this protein strongly correlate with its CSF levels (Gisslen et al., 2016; Kuhle et al., 2016; Rojas et al., 2016). Mitochondria: studies have shown that TDP-43 contributes to neuroinflammation and may have a role in mitochondrial and neuronal dysfunction (James et al., 2016). NAD+ levels can be detected in CSF and plasma in early AD. Extracellular: miRNAs released from exosomes appear to be associated with neurodegenerative aspects in AD (Wang et al., 2008, 2012; Chen et al., 2017). Studies have reported that changes in levels of blood miRNA distinguished AD patients from healthy controls with 93\% accuracy (Leidinger et al., 2013; Swarbrick et al., 2019). AD, Alzheimer's disease; CSF, cerebrospinal fluid; A $\beta$, amyloid- $\beta$; PET, positron emission tomography; NFTs, neurofibrillary tangles; $p$-tau, phosphorylated tau; t-tau, total tau; MCl, mild cognitive impairment; TREM2, triggering receptor expressed on myeloid cells 2; TNF- $\alpha$, tumor necrosis factor- $\alpha$; TGF- $\beta$, transforming growth factor- $\beta$; CX3CL1, CX3 chemokine ligand 1; SNAP-25, synaptosomal-associated protein 25; TDP-43, transactive response element (TAR) deoxyribonucleic acid (DNA)-binding protein 43; NAD+, oxidized nicotinamide adenine dinucleotide; miRNA, microRNA.

no significant change (Andreasen et al., 1998, 1999a; Hoglund et al., 2005; Andersson et al., 2008; Brys et al., 2009; Stomrud et al., 2010) during the disease. The prevailing explanation for a reduced amount of $\mathrm{A} \beta$ in later stages of $\mathrm{AD}$ is that as the pathology progresses, more $A \beta$, especially $A \beta 42$, aggregates into plaques in the brain, which effectively means that less $A \beta$ can diffuse from the brain to the CSF. Another explanation may be that $A \beta$ first accumulates intracellularly, and neurodegeneration releases $A \beta$ in the extracellular compartment, increasing CSF $A \beta$ levels, and subsequently accumulates onto neuronal surfaces and 
in synapses as it clears away from the CSF. As neurodegeneration occurs, less $A \beta$ is produced and therefore smaller amounts will accumulate in the CSF and subsequently in the brain, where $\mathrm{A} \beta$ will reach plateau levels. Alternatively, reduced CSF A $\beta 42$ might follow neuronal dysfunction, which results in decreased metabolism of APP and A $\beta$. It is important to note that this is unlikely in transgenic mice, as A $\beta 42$ levels in the CSF decline, while its levels in the brain keep rising. Also, when above a certain level, parts of CSF A $\beta 42$ may aggregate into a large assembly that antibodies of currently used enzyme-linked immunosorbent assay (ELISA) kits cannot capture (Pitschke et al., 1998; Liu et al., 2004). These seemingly disparate findings regarding CSF $\mathrm{A} \beta$ concentrations may therefore reflect different timepoints of the disease progression.

With regard to studies using $\mathrm{A} \beta$ as a fluid biomarker for $\mathrm{AD}$, studies have shown that concentrations of CSF A $\beta 42$ increased between 5 and 7 months of age, but not between 8 and 13 months of age in an APP/PS1 mouse model (Liu et al., 2004). This was despite a rapid increase in brain levels of A $\beta 42$ (Liu et al., 2004). However, between 6 and 9 months of age in another APP/PS1 mouse model with a more aggressive $\mathrm{AD}$ phenotype a decline in CSF A $\beta 42$ levels was reported (Liu et al., 2004). Based on these findings, it appears that CSF A $\beta 42$ may initially reflect the rate of $A \beta 42$ production (most likely in the synaptic cleft), but after reaching a critical threshold, CSF A $\beta 42$ levels stay in equilibrium until plaque formation leads to their decrease (Liu et al., 2004). Consistent with this notion, CSF A $\beta 42$ levels have a strong link with the deposition of amyloid plaques, whereby an inverse correlation between $A \beta 42$ levels, plaques (Strozyk et al., 2003) and amyloid PET is observed (Toledo et al., 2015; Leuzy et al., 2016; Niemantsverdriet et al., 2017). This implies that as $\mathrm{A} \beta$ aggregates and forms plaques in the brain, lower levels of the protein diffuse into the CSF (Lee et al., 2019).

Compared to tau as a fluid biomarker, the drop in CSF $\mathrm{A} \beta 42$ should precede the increase in CSF tau proteins. This notion is supported by biomarker studies in sporadic AD patients demonstrating that a decrease in CSF A $\beta 42$ was the earliest change reported (Skoog et al., 2003; Gustafson et al., 2007), while in patients with familial AD reductions in CSF A 342 and elevations in tau occur around 10-15 years prior to symptom development (Bateman et al., 2012; Ringman et al., 2012). Similar to $A \beta$, tau can also change its conformation to prionlike oligomers and there is evidence for misfolded $A \beta$ initiating tau misfolding (Pulawski et al., 2012; Nussbaum et al., 2013). Therefore, $A \beta$ appears to be an initiator of tau pathology and subsequent neurodegeneration.

\section{Tau as a Biomarker for AD}

Tau is a microtubule-associated protein comprising six human isoforms and is located in neuronal axons (Barten et al., 2011; Khan and Bloom, 2016). A characteristic of many neurons in $\mathrm{AD}$ is that tau is hyperphosphorylated and translocated from axons to the somatodendritic compartment, where it becomes misfolded and aggregates. Tau aggregates develop intracellularly and may thus trap functional proteins adding to microtubule destabilization, cellular dysfunction and eventually neurodegeneration (Benilova et al., 2012). Intracellular trafficking is dependent on the phosphorylation of tau in order to separate tau from microtubules, allowing transport, followed by dephosphorylation in order to return tau into microtubules (Avila et al., 2004). It has been proposed that A $\beta$ pathology drives the abnormal phosphorylation of tau in AD (Bakota and Brandt, 2016; Khan and Bloom, 2016). However, transgenic mice modeling $A \beta$ pathology alone do not develop NFTs endogenously (Lee and Trojanowski, 2001), while intracerebral injections of human mutated and/or aggregated tau are necessary to observe this neuropathological hallmark (Clavaguera et al., 2013; Ahmed et al., 2014; Kaufman et al., 2017; Lewczuk et al., 2017; Mudher et al., 2017; Narasimhan et al., 2017; He et al., 2018). Tau aggregates and NFTs are produced in the cytoplasm under pathological conditions, when tau changes its conformation from a highly soluble state to one with a high $\beta$-sheet content and is hyperphosphorylated (Yamada et al., 2015). Studies have shown that the elevation in CSF tau in AD is due to axonal loss and neuronal death, leading to the release of the intracellular protein (Blennow and Hampel, 2003; Hampel et al., 2010). However, despite significant neurodegeneration and tau pathology, CSF tau is not elevated in other pure tauopathies (Grossman et al., 2005; Bian et al., 2008). This suggests that cell death may not be the only mechanism responsible for CSF tau elevations in AD (Jack et al., 2010).

When using tau as a fluid biomarker for $\mathrm{AD}$, increased CSF concentrations of the protein constitutes a sensitive marker for neurodegeneration, but an entirely unspecific one for $\mathrm{AD}$ (Figure 3). However, the increased concentration of p-tau molecules seems much more AD specific (Figure 3; Lewczuk et al., 2004; Blennow et al., 2015). P-tau is secreted via exosomal release, and reaches the CSF (Saman et al., 2012; Figure 3). CSF p-tau levels are usually stable in other dementias, whereas both CSF p-tau and t-tau levels can be used to distinguish $\mathrm{AD}$ patients from healthy controls, suggesting that CSF tau is an important biomarker for differential dementia diagnosis (Blennow et al., 2015). In addition, high CSF t-tau and p-tau can predict the progression of cognitive symptoms better than CSF A 42 (El Kadmiri et al., 2018; Figure 3). Researchers have found correlations between p-tau in CSF and NFTs in the brain (Clark et al., 2003; Buerger et al., 2006; Tapiola et al., 2009; de Souza et al., 2012), and CSF t-tau has been found to correlate with neurodegeneration (Lee et al., 2019). Importantly, the utility of CSF p-tau and t-tau for AD diagnosis is markedly improved when measured together with CSF A $\beta 42$ (Figure 3; Dubois et al., 2014).

To examine CSF tau levels in rodents, researchers have used P301S human tau transgenic mice and found that ISF tau was at fivefold higher levels compared to endogenous tau, in line with its elevated levels of expression (Yamada et al., 2011). It is important to keep this in mind when comparing CSF tau between rodents and patients, as the CSF tau from rodents might be contaminated by ISF tau levels, and the CSF levels may not reflect the actual tau levels expressed in the brain. Studies have found that tau in brain tissue is approximately 50,000-fold more abundant than its levels in the CSF (Barten et al., 2011). In humans, patients with sporadic $\mathrm{AD}$ display longitudinal increases in tau when low levels of tau were detectable early in the disease course, but no differences (or 
increases) have been observed in tau in patients with high levels of tau at baseline (Kanai et al., 1998; Sunderland et al., 1999).

Compared to $\mathrm{A} \beta$, which aggregates broadly in the brain parenchyma and the perivascular space, tau readily drains into CSF. In contrast to $A \beta$, tau levels increase in the CSF with the progression of AD (Olsson et al., 2016). Changes in CSF A $\beta 42$ precede changes in CSF tau, consistent with the proposition that $\mathrm{A} \beta$ affects and drives CSF tau levels (Jack et al., 2010). However, further research is needed to explain whether $A \beta$ and tau pathology represent early initiators of neurodegeneration and cognitive decline, or merely downstream effects of other early pathophysiological events in $\mathrm{AD}$.

\section{Neuroinflammatory Biomarkers}

Inflammation is now considered another core feature of $\mathrm{AD}$ as it relates to the pathogenesis of the disease and also serves as a link between amyloid plaques and NFTs (Akama and Van Eldik, 2000; Akiyama et al., 2000). Inflammatory response has now been reported in post-mortem tissues of $\mathrm{AD}$ patients (GomezNicola and Boche, 2015) and is routinely observed in preclinical models. The presence of inflammation in the brain of $\mathrm{AD}$ patients was initially thought to be a consequence of the accumulating neurodegeneration present at late stages of the disease. However, a substantial body of research now demonstrates that a persistent immune response in the brain not only is associated with neurodegeneration, but it also exacerbates $A \beta$ and tau pathology (Figure 1). Inflammatory markers may be able to give evidence to intracellular abnormalities early in the course of $\mathrm{AD}$, prior to extracellular $\mathrm{A} \beta$ deposition (marked by an increase in CSF $\mathrm{A} \beta 40 / \mathrm{A} \beta 42$ and amyloid PET) as evidence points to a dysfunction in autophagic processes in $\mathrm{AD}$ patients (Figure 1; Menzies et al., 2015). Moreover, there have been reports of immunerelated proteins and cells opposed to amyloid plaques (Figure 1; Griffin et al., 1989). In line with this, it has been suggested that inflammation may provide a link between the initial $A \beta$ pathology and subsequent development of NFTs (Kitazawa et al., 2004; Rhein et al., 2009; Garwood et al., 2011; Nisbet et al., 2015).

\section{Autophagic Markers}

One way for intracellular accumulation of $A \beta$ peptides to occur is through a disruption in the autophagic and lysosomal clearance systems. In this way, autophagic markers could ultimately serve as the earliest biomarker to diagnose $\mathrm{AD}$ patients, as this process may likely initiate the aggregation of monomeric $A \beta$ into oligomeric $A \beta$ intracellularly (Figure 1). Autophagy is a complex process, in which a vesicle known as the phagophore elongates around the cytoplasmic components selected for degradation. The recognition of these components are dependent on the lipidated form of the microtubule-associated protein light chain 3 (LC3) (Milisav et al., 2015). The late stage of autophagy depends on the successful fusion of the autophagosome with the lysosome, which then degrades and recycles the autophagosome cargo. There is evidence supporting that the late stage of autophagy is disrupted in $\mathrm{AD}$, as accumulation of autophagic vesicles can be observed in dystrophic neurites (components of dense plaques) (Komatsu et al., 2006), and these are observed prior to extracellular $A \beta$ deposition in model systems and patients (Figure 3; Mehrpour et al., 2010; Nixon and Yang, 2011).

The above findings suggest that autophagy dysfunction leads to the accumulation of intracellular $A \beta$ by avoiding proper degradation and/or recycling. In line with this, researchers have found that LC3-associated endocytosis is used to clear and recycle $A \beta$ surface receptors (Heckmann et al., 2019). In model systems with LC3-associated endocytosis disrupted, an increase in extracellular $A \beta$ deposition, NFTs, neurodegeneration and behavioral deficits was observed. Another line of research found that autophagic markers were significantly increased in AD patients compared with control subjects (Cho et al., 2019). Furthermore, other studies suggest that metabolism of $\mathrm{A} \beta$ and tau is crucially influenced by autophagy (Uddin et al., 2018). Recent evidence suggests that $\mathrm{A} \beta$ monomers and oligomers modulate autophagy differently in neurons. Monomers have been found to stimulate autophagy, increasing autophagosome rates and elevation of LC3 protein levels, while simultaneously impairing the lysosomal pathway affecting the autophagy efflux, leading to autophagosome accumulation (Menzies et al., 2015). By contrast, $\mathrm{A} \beta$ oligomers do not cause a significant increase in LC3 protein levels nor affect efflux of autophagic vacuoles (Menzies et al., 2015), which suggests that an increase in intracellular $\mathrm{A} \beta$ monomers may be the result of a defective autophagic system. This fits the proposition that autophagic disruption and accumulation of $\mathrm{A} \beta$ monomers constitute some of the earliest events in the $\mathrm{AD}$ cascade (Figure 1). The exact cascade by which autophagy can degrade amyloid plaques is still not known, however, microglial autophagy appears to play and important role.

\section{Glial Cells and Markers}

Neuroinflammation involving astrocytes, microglia, and secreted compounds like reactive oxygen species, cytokines, and chemokines are key pathophysiological processes assessed when diagnosing AD (Ramesh et al., 2018a). Microglia and astrocytes are the two types of glial cells primarily affected (McGeer et al., 1987; Rogers et al., 1988; Bronzuoli et al., 2016), which in turn affect the clearance and production of $\mathrm{A} \beta 42$ (Hickman et al., 2008; Liu et al., 2017). Glial cells also affect the development and propagation of tau pathology (Asai et al., 2015) and thus influence disease progression and severity (Block et al., 2007; Calsolaro and Edison, 2016). Importantly, if glial cells are activated for too long, they can become pro-inflammatory (Bronzuoli et al., 2016). Chitinase-3-like protein 1 (or YKL-40) is an inflammatory marker expressed by microglia and astrocytes (Figure 3). In $\mathrm{AD}, \mathrm{YKL}-40$ is expressed in astrocytes near $\mathrm{A} \beta$ plaques (Craig-Schapiro et al., 2010) and correlates positively with tau pathology (Figure 3; Querol-Vilaseca et al., 2017; Janelidze et al., 2018).

Another glial marker is triggering receptor expressed on myeloid cells 2 (TREM2), which is an inflammatory cell-surface receptor. Loss-of-function mutations of TREM2 are associated with an increased risk of developing AD (Suarez-Calvet et al., 2016). Researchers have found that TREM 2 phagocytose $A \beta$ in early AD stages (Jay et al., 2017). A rare mutation in the TREM2 gene affects the phagocytic activity of microglia and consequently 
contributes to accumulation of $\mathrm{A} \beta$ (Kleinberger et al., 2014; Ramesh et al., 2018b). With regard to TREM2 measured in CSF, studies have shown increased levels to be associated with higher CSF t-tau and p-tau levels, probably reflecting a corresponding change in microglia activation in response to neurodegeneration (Figure 3; Suarez-Calvet et al., 2016). Relevant research findings imply that neuroinflammation is a robust biomarker even at pre-symptomatic stages (Janelidze et al., 2018). In line with this, high levels of inflammatory biomarkers are associated with increased CSF levels of t-tau (Janelidze et al., 2018). Interestingly, PET studies have revealed increased microglial activation in the precuneus (Hamelin et al., 2016; Fan et al., 2017), a region in the default mode network that displays early $\mathrm{A} \beta$ deposits in $\mathrm{AD}$ (Palmqvist et al., 2017).

\section{Cytokines}

With regard to cytokines, it has been shown that $\mathrm{AD}$ patients have higher levels of interleukin-6, 12, and 18, tumor necrosis factor- $\alpha$ (TNF- $\alpha$ ), and transforming growth factor- $\beta$ (TGF- $\beta$ ), in blood, and higher levels of TGF- $\beta$ in CSF, compared to healthy controls (Figure 3; Swardfager et al., 2010). Endothelial growth factor receptor 1 (also known as Flt-1), has been found to be upregulated in entorhinal cortical sections from human $\mathrm{AD}$ brains and in human microglia following treatment of A $\beta 42$ (Ryu et al., 2009). Following neuroinflammation, oxidative stress in the intracellular environment occurs. Oxidative stress plays an important role in the early stages of AD (Oh et al., 2010) and its associated signaling cascades are being investigated and explored for biomarkers. For instance, higher reactive oxygen species levels lead to post-translational modification of proteins, toxic cell damage, fragmentation and aggregation of $\mathrm{A} \beta$ (Brinkmalm et al., 2014). One type of reactive oxygen species are sulfatides, which have been found to be depleted in both gray and white matter of $\mathrm{AD}$ patients, and results in decreased hippocampal volume and cognitive decline (Ramesh et al., 2018b).

Since neuroinflammation occurs in $\mathrm{AD}$ brains, the levels of several S100 proteins are increased and some of the proteins play roles related to the processing of APP, regulation of $A \beta$ levels and tau phosphorylation. S100A1, S100A6, and S100B have been found to be involved in the disassembly of microtubules and tau protein release (Zimmer et al., 2005; Roltsch et al., 2010; Wruck et al., 2016; Sidoryk-Wegrzynowicz et al., 2017), while S100B and S100A9 are found within NFTs (Figure 3; Sheng et al., 1994, 1997; Shepherd et al., 2006). Traumatic brain injury (TBI) has been found to predispose people to developing AD (Johnson et al., 2010). Interestingly, TBI results in an increase in S100A1 and S100B levels in plasma and CSF in patients (de Boussard et al., 2005). Research has shown that levels of $\mathrm{S} 100 \mathrm{~B}$ originating from necrotic tissue might enhance or amplify neurodegeneration by apoptosis (Sedaghat and Notopoulos, 2008). Thus, various S100 proteins could be a link between neurodegenerative diseases induced by brain damage. Comorbidities often accompany a diagnosis of $\mathrm{AD}$, thus the spectrum of pathological processes that can end in $\mathrm{AD}$ at different degrees of severity and symptomology needs to be kept in mind in order to accurately diagnose and treat patients. Additionally, S100 proteins may serve as an early biomarker for a later $\mathrm{AD}$ diagnosis in patients with $\mathrm{TBI}$ or other comorbidities that increase S100 levels.

Moreover, several S100 proteins are implicated in the amyloidogenic pathway of APP cleavage. S100A9 regulates $\gamma$-secretase and BACE1 expression and activity (Kummer et al., 2012; Li et al., 2014), and S100B and S100A1 regulate APP levels (Zimmer et al., 2005; Anderson et al., 2009; Mori et al., 2010). S100A7, S100A8, S100A9, and S100B have been found to influence $A \beta$ levels (Qin et al., 2009; Lee et al., 2013; Lodeiro et al., 2017; Cristovao et al., 2018). Moreover, S100B and S100A6 have been found to reduce zinc levels and senile plaque load in preclinical models (Roltsch et al., 2010; Hagmeyer et al., 2017; Tian et al., 2019). S100A1, S100A9, and S100B proteins can interact and alter the aggregated $A \beta$ and is found to co-aggregate with A $\beta$ peptides (Zimmer et al., 2005; Shepherd et al., 2006; Ha et al., 2010; Mori et al., 2010; Chang et al., 2012; Afanador et al., 2014; Cristovao et al., 2018). In line with this, several S100 proteins (S100B, S100A1, S100A6, S100A8, S100A9, and S100A12) are present in amyloid plaques and in astrocytes and/or microglia near amyloid deposits (Figure 3; Boom et al., 2004; Shepherd et al., 2006; Walker et al., 2006; Ha et al., 2010; Afanador et al., 2014; Lodeiro et al., 2017).

\section{Chemokines}

In order to maintain brain homeostasis, microglia establish continuous communication with neurons and astrocytes, through the expression and secretion of chemokines (Mennicken et al., 1999). The CX3 chemokine ligand 1 (CX3CL1; or fractalkine), is predominantly expressed in neurons (Bazan et al., 1997) and interacts with the CX3 chemokine receptor 1 (CX3CR1) exclusively present in microglia (Imai et al., 1997; Maciejewski-Lenoir et al., 1999). The CX3CL1/CX3CR1 tandem allows for direct communication between neurons and microglia (Harrison et al., 1998; Sheridan and Murphy, 2013), and it has been suggested that this axis becomes impaired in $\mathrm{AD}$ patients (Bolos et al., 2017). Consistent with this, neuronal CX3CL1 is found to be decreased in CSF from AD patients compared to MCI and control subjects (Figure 3; Perea et al., 2018). Furthermore, researchers have aimed to regulate neuroinflammation in tau depositing mouse lines by overexpressing CX3CL1 and found that it significantly reduced tau pathology, ameliorated neuronal loss, reduced microgliosis (Nash et al., 2013) as well as rescuing cognitive function (Finneran et al., 2019). In another line of research, it has been found that when microglia are transferred from tau depositing knock-out Cx3crl mice, hyperphosphorylation of endogenous murine tau is observed (Maphis et al., 2015). Disruption of CX3CL1 signaling in amyloid depositing mouse lines has shown reduced pathology due to increased microglial phagocytosis of amyloid plaques (Lee et al., 2010).

\section{Synaptic Neurodegeneration Markers}

There is of yet no established or reliable biomarker test for synaptic degeneration, which is considered a crucial feature for the development of AD-related cognitive decline. The ability to monitor neurodegeneration as a downstream effect of synaptic dysfunction would be an important advantage for 
early $\mathrm{AD}$ diagnosis and in clinical trials related to drug testing. Synaptotagmin, a pre-synaptic calcium sensor vesicle protein, facilitates neurotransmitter release from the synaptic vesicle by exocytosis and also functions as an essential vesicle cargo molecule in hippocampal neurons (Leinenbach et al., 2014). Various studies have shown a decrease in synaptotagmin-1 in AD patients (Mattsson et al., 2011).

Another marker for synaptic degeneration is synaptosomalassociated protein 25 (SNAP-25), which is an essential component of the soluble $\mathrm{N}$-ethylmaleimide-sensitive fusion protein attachment protein receptors (SNARE) complex that mediates synaptic communication by initiating fusion of synaptic vesicles (Olsson et al., 2016). A negative correlation has been found between SNAP-25 and cognitive decline, suggesting that this is a promising novel CSF biomarker for AD (Andreasen et al., 1999b). Overall, CSF levels of SNAP-25 (Brinkmalm et al., 2014; Sutphen et al., 2018) and synaptotagmin (Öhrfelt et al., 2016) have been assessed and found at elevated levels in patients with $\mathrm{AD}$ or MCI compared with control subjects (Figure 3). Another marker for synaptic neurodegeneration is neurogranin, which plays an important role in synaptic plasticity and long-term potentiation processes (Geppert et al., 1994; Sudhof and Rizo, 1996; Thorsell et al., 2010). Neurogranin has also been found at increased levels in CSF of patients with MCI and dementia due to developing $\mathrm{AD}$ as compared with healthy controls (Figure 3; Thorsell et al., 2010; De Vos et al., 2015). CSF neurogranin concentrations have been found at increased levels in patients that have reached the threshold for $\mathrm{A} \beta$ PET detection (Palmqvist et al., 2019), and also CSF neurogranin and tau levels have been found to correlate strongly (Thorsell et al., 2010; De Vos et al., 2015).

\section{Novel Biomarkers for AD}

Many biomarkers are now being investigated as complimentary to the core $\mathrm{AD}$ biomarkers. One such biomarker is neurofilament light, which is a marker of neuronal integrity reflecting axonal damage of the subcortical white matter (Petzold, 2005; Jahn and Fasshauer, 2012; Neselius et al., 2012; Kuhle et al., 2015; Zetterberg et al., 2016). Neurofilament light is released from axons into the extracellular space during healthy aging, which results in increased CSF level concentrations (Figure 3). The release of neurofilament light is accelerated during axonal damage, which occurs in $\mathrm{AD}$ (Figure 3). A recent meta-analysis showed that the core CSF biomarkers (A $\beta 42$, $t$-tau, and $\mathrm{p}$-tau) and CSF neurofilament light levels strongly correlated with AD (Figure 3; Olsson et al., 2016). Importantly, CSF neurofilament light levels have been shown to be higher in AD (Sjogren et al., 2001; Pijnenburg et al., 2007; Zetterberg et al., 2016; Alcolea et al., 2017; Lista et al., 2017). Blood neurofilament levels strongly correlate with CSF levels (Figure 3; Gisslen et al., 2016; Kuhle et al., 2016; Rojas et al., 2016), and blood neurofilament light concentrations have been found at increased levels in many forms of neurodegenerative disease (Gisslen et al., 2016; Kuhle et al., 2016; Rohrer et al., 2016; Rojas et al., 2016; Steinacker et al., 2016, 2017; Weydt et al., 2016; Mattsson et al., 2017a) and have proven almost as reliant as CSF analysis in monitoring treatment outcome in patients (Bacioglu et al., 2016; Disanto et al., 2017). Another novel biomarker is the transactive response element (TAR) deoxyribonucleic acid (DNA)-binding protein 43 (TDP-43) protein, which can become pathologic if triggered by A $\beta$ peptides. Studies have shown that TDP-43 contributes to neuroinflammation and may have a role in mitochondrial and neuronal dysfunction (Figure 3; James et al., 2016). In accordance with this, TDP-43 pathology has been observed in some AD cases (Amador-Ortiz et al., 2007; Chang et al., 2015; James et al., 2016). Another novel biomarker is oxidized nicotinamide adenine dinucleotide (NAD+; involved in mitochondrial homeostasis), which has been found to decrease during healthy aging, but even more rapidly in neurodegenerative diseases (Figure 3; Lautrup et al., 2019). This could be related to the observed decrease in neuronal metabolism that occurs during healthy aging, but this is accelerated in the $\mathrm{AD}$ brain. NAD+ levels can be detected in CSF and plasma early during the disease progression, and in combination with core biomarkers, it presents as a novel preclinical biomarker for AD (Figure 3).

Neuropathology is associated with a distinct subset of cells in specific regions in the brain and this makes the identification of relevant biomarker molecules a challenge. The transport of macromolecules from the brain to the CSF and blood, mediated by extracellular vesicles, presents a promising source of central nervous system (CNS)-specific biomarkers (Thompson et al., 2016). One such trafficking macromolecule is exosomes, which can be picked up in CSF. An increasing body of evidence suggests that exosomal proteins and microRNAs (miRNAs) may constitute novel biomarkers for clinical AD diagnosis (Van Giau and An, 2016). miRNAs released from exosomes appear to be associated with neurodegenerative aspects in AD (Figure 3; Wang et al., 2008, 2012; Chen et al., 2017). miRNAs are a class of small non-coding RNAs which regulate over $50 \%$ of protein-coding genes, and miRNA-107 has been found to be downregulated in AD brains (Van Giau and An, 2016; Fransquet and Ryan, 2018; Ramesh et al., 2018b). Accumulating evidence presents that miRNAs regulate $A \beta$ production, NFT formation, and neurodegeneration by targeting different genes (Wang et al., 2008; Van Giau and An, 2016). Research has also identified BACE1 as a target of miRNA-107, connecting the level of miRNA-107 to $A \beta$ formation and neuronal pathogenesis (Wang et al., 2008).

\section{CSF AND BLOOD-BASED BIOMARKERS}

Although protein content is lower in CSF compared to blood, CSF holds great value for developing consistent biomarkers for $\mathrm{AD}$ as it reflects biochemical changes in the brain by direct interaction with the extracellular space (Hampel et al., 2012). At present, there is no approved blood biomarker for $\mathrm{AD}$ (Stadtman and Levine, 2003). It is important to note, however, that blood biomarkers have lower sensitivity and specificity than CSF biomarkers, and this can be attributed to the fact that the blood-brain barrier (BBB) prevents diffusion of analytes into the blood via a filtering mechanism (Lee et al., 2019). Furthermore, one complication of measuring CNS biomarkers in blood is that many of the analytes are produced in the 
periphery as well as in the brain, and thus the source of detectable change may be difficult to determine (Barten et al., 2017). However, there is currently an urgent need within the field to develop blood-based biomarkers which are inexpensive and which can detect early neuropathological changes in $\mathrm{AD}$ (Hane et al., 2017). For instance, detection of autophagic markers in plasma could serve as an early biomarker for $\mathrm{AD}$ (Cho et al., 2019). Blood test sampling is routinely performed in the clinic, it is minimally invasive, cheap and suitable for recurrent measurements (Shen et al., 2018).

When comparing $\mathrm{A} \beta$ levels in blood and CSF, some researchers have found that serum $A \beta 42$ levels do not correlate with CSF levels (Figure 3; Liu et al., 2004). However, contrary to this, others have found that plasma $\mathrm{A} \beta$ can be measured with good sensitivity (Figure 3; Lee et al., 2019). A $\beta$ can easily penetrate the $\mathrm{BBB}$ and is therefore an attractive blood biomarker candidate (Lee et al., 2019). Indeed, studies have shown that cerebral amyloid deposits may be sourced in the periphery, while other studies suggest that amyloid deposits in cerebral vessels may originate from circulating $A \beta$ peptides (Yankner and Mesulam, 1991; Chen et al., 1995; DeMattos et al., 2002; Lee et al., 2019). Plasma $A \beta$ and $A \beta$-approximate peptide concentrations have been reported to be consistent with amyloid PET results (Kaneko et al., 2014). Moreover, levels of $A \beta 42$ and the ratio of $\mathrm{A} \beta 42: \mathrm{A} \beta 40$ in plasma have been shown to correlate with CSF concentrations and with amyloid PET (Janelidze et al., 2016; Verberk et al., 2018). However, it is important to note that some researchers have found that reduction of $A \beta$ in the periphery does not reduce brain A $\beta$ levels (Georgievska et al., 2015) [but see Jin et al. (2017)].

To date, neurofilament light is the only biomarker that is translatable from plasma to CSF, and therefore holds great promise as a clinical tool to predict cognitive decline and neurodegeneration in AD (Figure 3; Zetterberg et al., 2016; Mattsson et al., 2017a; Lewczuk et al., 2018). Furthermore, it has been shown that measurements in blood and CSF levels strongly correlate and that neurofilament light increases coincided with the onset and progression of corresponding amyloid pathology in the brain (Figure 3; Bacioglu et al., 2016). Studies have shown that plasma neurofilament light can be used as a non-invasive biomarker that strongly correlates with neurodegeneration in human AD patients (Mattsson et al., 2019). Moreover, plasma $\mathrm{t}$-tau levels can be used for screening and prognosis of cognitive decline in patients where CNS injury has been ruled out (Molinuevo et al., 2018). However, there are decreased amounts of tau in plasma compared to CSF (Barten et al., 2017; Mattsson et al., 2017b), but increases have been found in plasma of $\mathrm{AD}$ patients when compared to MCI patients and healthy controls (Figure 3; Mattsson et al., 2016; Pase et al., 2019). Studies looking at circulating RNA biomarkers for AD have reported that changes in levels of blood miRNA distinguished AD patients from healthy controls with 93\% accuracy (Figure 3; Leidinger et al., 2013; Swarbrick et al., 2019). Therefore, blood miRNAs could be an addition to the biomarker toolbox for diagnosing $\mathrm{AD}$ patients. For a more extensive review on comparisons between CSF and blood biomarkers in $\mathrm{AD}$, and developments in biochemical analyses of blood, see Ashton et al. (2020).

\section{METHODS FOR CSF SAMPLING}

\section{CSF Collection in Human Patients}

The most commonly used method for sampling CSF in human patients is by lumbar puncture. Clinically, lumbar punctures are routinely performed for diagnosing multiple brain disorders (e.g., meningitis, encephalitis, multiple sclerosis) and for the administration of spinal anesthesia and chemotherapy. However, there are several limitations associated with the use of lumbar punctures, such as associated pain during and after the sampling (including post-puncture headache) in patients (Blennow et al., 2015). Additionally, CSF sampling in patients who cannot cognitively consent to the procedure is ethically problematic. One also needs to keep in mind that $A \beta$ is higher in lumbar CSF (Brandner et al., 2014), and tau is higher in ventricular CSF (Tarnaris et al., 2011; Pyykkö et al., 2014; Herukka et al., 2015) when using this method for CSF collections. However, the timing of intraventricular CSF sampling will likely affect concentrations of $A \beta$ and tau, for example whether the sample is taken immediately after the insertion of a ventricular catheter. Research suggests that increased ventricular CSF tau concentrations may be caused by the sampling procedure itself, whereby neurons affected by the insertion of the needle for spinal tap increasingly release tau molecules (Brandner et al., 2014). In line with this, CSF samples taken shortly after surgery often have elevated tau and neurofilament light levels (Barten et al., 2017). CSF flow rate is slower in lumbar regions compared to cephalic regions (Sweetman and Linninger, 2011), and this may additionally cause the differences in concentrations of analytes. However, contradictory evidence suggests that $\mathrm{p}$ - and t-tau concentrations are 20-30\% lover in intraventricular CSF, compared to lumbar CSF, and that this initial upregulation postsurgery is stable in patients irrespective of brain $A \beta$ pathology (Leinonen et al., 2019).

\section{CSF Collection in Animal Models}

The most commonly used method for sampling CSF in rodents is collections from the cisterna magna, however, this sampling method usually constitutes a terminal procedure. Collections from the cisterna magna in preclinical models for in vivo sampling of CSF have proven a valuable technique for studying treatment outcomes after drug delivery to the CNS. This CSF sampling method offers the advantage of serial sampling without the cofound of anesthesia, with the added benefit of using animals as their intrinsic controls (Amen et al., 2017). Another technique involves inverting animals during CSF collection in order to drain spinal CSF into the cisterna magna (DeMattos et al., 2002). An alternative technique involves collecting CSF by puncturing the membrane by suction using a pipette (DeMattos et al., 2002; Barten et al., 2011). One major limitation of collections from the cisterna magna in preclinical models is the small volume of CSF that can be obtained. In transgenic mice, the average volume is approximately 5-15 $\mu \mathrm{l}$ for terminal sampling (Liu and Duff, 2008). For serial sampling, a maximum of 7-8 $\mu \mathrm{l}$ can be safely taken each time at an interval of 2-3 months (Liu and Duff, 2008). 
Microdialysis is an alternative CSF sampling technique, which allows continuous in vivo sampling of molecules within the extracellular space (Takeda et al., 2011), which may help circumvent some of the above limitations. Sampling using this method relies on diffusion of analytes across a semipermeable dialysis membrane (Takeda et al., 2011). This method is advantageous over other CSF sampling techniques as it enables serial sampling that follows the dynamic temporal alterations of a target molecule without necessitating the collection of biopsy samples or sacrifice (Meyding-Lamadé et al., 1996; Trickler and Miller, 2003; Liu et al., 2004; Liu and Duff, 2008). Importantly, each preclinical model can serve as their own intrinsic control in order to reduce inter-animal variability and the number of animals used in experiments. One limitation of this method, however, is detection of large molecules due to adsorption in tubing and the dialysis membrane, as well as low concentration of analytes in the target tissue (Ao and Stenken, 2006). Furthermore, histochemical techniques have revealed that severe gliosis around implanted devices such as microdialysis cannulas takes place at about 4 days after the surgery (Hamberger et al., 1985; Benveniste and Diemer, 1987; Benveniste et al., 1987). Reports suggest that a complete recovery of physiological functions occurs at the earliest at 5-7 days after the implantation surgery (Drijfhout et al., 1995).

\section{CSF AD BIOMARKERS AND TREATMENT}

Studies suggest that the neuropathological events that occur in $\mathrm{AD}$ may disturb physiological functions of the $\mathrm{BBB}$ and thereby distribution of drugs to the brain (Pahnke et al., 2014; Vellonen et al., 2017). Drug molecules in the peripheral circulation are controlled and limited from entry into the brain by the $\mathrm{BBB}$, while dysfunction of the $\mathrm{BBB}$ has been associated with neurodegeneration (Vellonen et al., 2017). Furthermore, AD drugs may not be transported to their site of action due to a dysfunctional BBB. This may lead to an increase of the drug in the brain leading to unwanted effects, or decreased drug circulation leading to an insufficient response (Vellonen et al., 2017). Many agents are better dosed directly into the CSF than peripherally because of limited permeability of the drug through the BBB (Barten et al., 2017). The presence of $A \beta$ plaques, brain atrophy and dilated ventricles in the $\mathrm{AD}$ brain may affect the distribution of drugs in brain tissue (Vellonen et al., 2017). CSF levels of autophagic markers, $\mathrm{A} \beta$ and tau may help select an appropriate $\mathrm{AD}$ treatment for the timepoint of diagnosis. The CSF pharmacokinetics of a treatment after administration may show how well the drug entered the CNS. Therefore, levels of CSF autophagic markers or $\mathrm{A} \beta$ could be a pharmacodynamic marker of inhibited $A \beta$ production (Dockens et al., 2012; Albright et al., 2013; Coric et al., 2015), and, in a longer term, CSF tau decreases could be a downstream functional marker of reduced neurodegeneration (Riekse et al., 2006).

\section{Assessing Autophagy in CSF Samples}

Inductors of autophagy could be used in order to halt or stop the development and progression of $A \beta$ pathology in model systems and patients with $\mathrm{AD}$. Trehalose, an inductor of autophagy, was found to significantly improve memory and learning tasks in APP/PS1 mice (Rami, 2009). Importantly, $A \beta$ deposits were found to be significantly reduced in the hippocampus of these mice (Rami, 2009). Furthermore, the induction of autophagy by rapamycin in another model system was found to improve cognitive performance through the degradation of extracellular $\mathrm{A} \beta$ depositions (Rami, 2009), and has been found by others to inhibit tau pathology (Caccamo et al., 2010). In AD, changes in early endocytosis and autophagy can be detected in CSF (Armstrong et al., 2014). Moreover, some work within the $\mathrm{AD}$ field has focused on lysosomal proteins, as they can be found in and around amyloid plaques and is present in CSF (Cataldo and Nixon, 1990; Schwagerl et al., 1995). It is now widely believed that the deposition of $A \beta$ is an early initiator of neurodegeneration in $\mathrm{AD}$, thus finding methods that can reduce $\mathrm{A} \beta$ or enhance its clearance could be a strong therapeutic target. In this sense, autophagy appears to be the first line of defense against accumulation of $\mathrm{A} \beta$.

\section{Assessing A $\beta$ Pathology in CSF Samples}

Cerebrospinal fluid $A \beta 40$ and $A \beta 42$ may be useful (in addition to other biomarkers) in assessing efficacy of drugs such as BACE1 inhibitors, which selectively decrease toxic forms of $A \beta$ (Kennedy et al., 2016). For instance, when CSF levels of $A \beta 42$ are still rising during early stages of amyloid pathology, decreased levels of CSF A $\beta 42$ measured after treatment would show a successful outcome, but at a later stage in amyloid pathology the same finding may indicate accelerated plaque formation (Liu et al., 2004). Anti-amyloid agents are most likely more effective during early $\mathrm{AD}$ since deposition of the protein begins many years before diagnosis (Musiek and Holtzman, 2015). Promoting the elimination of $\mathrm{A} \beta$ by enzymatic degradation or by clearance enhancement may halt both the aggregation and the accumulation of the peptide (Menendez-Gonzalez et al., 2018). The choroid plexus is known to produce A $\beta$ (Krzyzanowska and Carro, 2012), thus the effect of $A \beta$ synthesis inhibitors on CSF $\mathrm{A} \beta$ is bound to reflect changes both sourced in the brain and in the choroid plexus. In addition, evidence suggests that the choroid plexus can remove substances, such as $A \beta$, from the CSF (Matsumoto et al., 2015).

\section{BACE1 Inhibitors}

A potent BACE1 inhibitor known as Verubecestat has been shown to reduce plasma, CSF and brain levels of $\mathrm{A} \beta 40, \mathrm{~A} \beta 42$, and soluble APP $\beta$ (a direct product of BACE1 enzymatic activity) after short- and long-term administration in rats and monkeys (Kennedy et al., 2016). Recently, a study in healthy elderly $\mathrm{AD}$ subjects who received treatment with a BACE1 inhibitor showed no alterations in CSF BACE1 levels following treatment, but revealed a strong link between levels of CSF BACE1 and downstream markers such as CSF A $\beta 42$ (Timmers et al., 2017). Genetic deletion of BACE1 eliminated $\mathrm{A} \beta$ production and resolved the amyloid plaques and cognitive deficits observed in transgenic mice over-expressing human APP with familial AD mutations (Dominguez et al., 2005; McConlogue et al., 2007; Ohno et al., 2007). Researchers have demonstrated that longterm BACE1 inhibition diminishes CSF tau levels both in early 
depositing APP transgenic mice and APP transgenic mice with moderate A $\beta$ pathology (Schelle et al., 2017). Overall, BACE1 inhibition appears to not only reduce $A \beta$ generation, but also downstream AD neuropathology (Schelle et al., 2017).

\section{$\gamma$-Secretase Inhibitors}

$\gamma$-secretase inhibitors have also proven promising as a therapeutic approach; APP/PS1 mice treated with this compound displayed that a modest decrease $(\sim 30 \%)$ of $\mathrm{A} \beta$ in ISF was enough to halt amyloid plaque development (Yan et al., 2009). Also, NGP 555 (a $\gamma$-secretase inhibitor) has been shown to shift amyloid peptide production to the smaller, non-aggregating forms of amyloid (Olsson et al., 2014; Kounnas et al., 2017). Inhibition of $\gamma$-secretase has initially been unsuccessful as a therapeutic target (Cummings, 2010), but more recent compounds have been shown to avoid notch-related toxicity and side effects (Basi et al., 2010; Imbimbo et al., 2010). One failure of slowing A $\beta$ production in patients may be that non-homogenous groups of patients have been included in the trials, and that the treatment has been administered too late in the disease course or has been too short (Bjerke and Engelborghs, 2018). In line with this, some clinical trials have reported changes in CSF $\mathrm{A} \beta 42$, but no improvement in clinical endpoints (Ritter and Cummings, 2015).

\section{COMPARATIVE BIOMARKING}

Studies aiming to translate findings between $\mathrm{AD}$ system models and patients found that tau derived from $\mathrm{AD}$ brains injected into susceptible mouse models induced prion-like tau aggregation (Skachokova et al., 2019). CSF from AD or MCI patients injected into the hippocampus of young P301S tau transgenic mice increased tau phosphorylation and NFT formation 4 months following injection. Post-seeding, the injections accentuated tau pathology in the contralateral hippocampus of the mice, indicative of spreading (Skachokova et al., 2019). Other researchers found that peritoneal dialysis reduced plasma $A \beta$ levels in both chronic kidney disease patients and APP/PS1 mice. ISF A $\beta$ levels in APP/PS1 mice immediately decreased after reducing blood $\mathrm{A} \beta$ by peritoneal dialysis. The treatment also attenuated other AD-type pathologies, including inflammation, tau hyperphosphorylation, neurodegeneration, synaptic dysfunction, and rescued the behavioral deficits of the mice. Importantly, the $A \beta$ phagocytic function of microglia was enhanced in APP/PS1 mice after peritoneal dialysis (Jin et al., 2017). Current strategies for clearing $A \beta$ focus on introducing agents into the brain (Jin et al., 2017), but this likely causes adverse effects such as neuroinflammation and tissue scarring (Iijima-Ando et al., 2008; Liu et al., 2012), in addition to increased endogenous tau levels.

\section{The ABC Scoring System}

Well-characterized mouse models hold great translational value given that identifying patients at preclinical $\mathrm{AD}$ stages has proven difficult (Bacioglu et al., 2016). However, there are important differences between species, which should be kept in mind while interpreting results (Barten et al., 2017). The ideal
TABLE 2 | The ABC scoring system developed by NIA-AA.

\begin{tabular}{lc}
\hline Assessment & NIA-AA scoring \\
\hline A $\beta$ plaques & AO (not) \\
& A1 (low) \\
NFTs, including pretangles and threads & A3 (high) \\
& B0 (not) \\
Neuritic and diffuse plaque density & B2 (intermediate) \\
B3 (high) \\
C0 (not) \\
C1 (sparse) \\
C2 (moderate) \\
C3 (frequent)
\end{tabular}

The scoring system can be used to help assess and validate the neuropathological features of $A D$ in mouse lines that are potential preclinical models for $A D$ research. Reproduced with permission from Keene et al. (2016). NIA-AA, Alzheimer's Association; $A \beta$, amyloid- $\beta$; NFT, neurofibrillary tangle.

translational model for $\mathrm{AD}$ would require $\mathrm{A} \beta$ and tau deposition in a pathological manner and disease-relevant accumulation of amyloid plaques and tangles similar to that seen in $\mathrm{AD}$ patients (Keene et al., 2016). The ABC scoring system (Table 2) can be used to determine the level of $\mathrm{AD}$ neuropathological change in both system models and patients. The ABC score is generated by a summary of measures of amyloid plaque distribution A0 to A3 (Thal stages), NFT distribution B0 to B3 (Braak stages), and cortical neuritic plaque density C0 to $\mathrm{C} 3$ [Consortium to Establish a Registry for Alzheimer's Disease (CERAD) score] (Keene et al., 2016). The ideal translational model system of human AD would display amyloid plaques and NFTs in a spatial and temporal manner correlating with "no" or "low" AD pathology at early ages, progressing to "intermediate" and "high" $\mathrm{AD}$ pathology at older ages or in the presence of gene mutations related to neuropathological development (Keene et al., 2016).

In terms of the specifics of the ABC scoring system (Table 2), scoring of diffuse $A \beta$ plaques is based on assessment in the cerebral cortex, hippocampus, striatum, midbrain, brainstem, and cerebellum (Box 1) according to staging established by Thal et al. (2002) resulting in a Thal phase $0-5$, which is translated into the NIA-AA score of A0-A3. Meanwhile, scores for NFTs are determined in the trans-entorhinal cortex, corpora ammonis, fronto-parietal cortex, and primary visual cortex (Box 1) to generate a Braak stage (Braak and Braak, 1991), which is translated into the NIA-AA score of B0-B3. Since most existing mouse models do not generate NFTs, the NIH have developed a modified B score for p-tau pathology, including distribution of pre-tangles and threads. In addition, most existing mouse models do not form neuritic plaques (contains fibrillar $A \beta$ ), so a $C$ score for CERAD (Sperling et al., 2011) neuritic plaque density (none, sparse, moderate, or frequent) and a modified C score for diffuse plaque (does not contain fibrillar $A \beta$ ) density are generated from frontal and parietal cortex. Considering that behavioral data from mice have replication issues and are challenging to translate to patients, memory testing per se should not constitute a validation criterion or a drug testing endpoint (Keene et al., 2016). 


\section{CSF Collection Methods}

When translating CSF biomarkers between system models and patients, an advantage with subcutaneous access systems is that drugs can be dosed and also samples can be obtained from unanesthetized animals, as is typical with humans, and without the confound of anesthesia on CSF production or flow. It has been shown that anesthesia can cause disturbances in neurotransmitter density and cell metabolism, and therefore most times, it is desirable to perform experiments on non-anesthetized animals (Kehr, 1999). It is important to note that in most rodent studies, CSF is collected from the cisterna magna above the spinal column, whereas in humans most CSF is collected from the lumbar spinal vertebrae, and therefore drainage from this latter area in preclinical models has a translational advantage (Barten et al., 2017).

Due to the difficulties in collecting CSF samples from preclinical models the quality of the sample may be comprised, and therefore should be tested. The quality of the sample is most often affected by blood and brain-derived protein contamination (Barten et al., 2017). It is critical to minimize blood-contamination when analytes of interest are found in much higher concentration in the blood compared to the CSF, such as the 1:50,000-fold gradient of tau. Another major contamination source of CSF is proteins released in the brain during the collection procedure; this has a higher impact on tau levels compared to $\mathrm{A} \beta$ (Barten et al., 2005).

Furthermore, biomarker development for clinical utility is currently being hampered as comparisons of measurements and techniques between laboratories tend to be unreliable. Factors that may induce variability include storage in different tube types, different aliquot volumes, and the number of freeze-thaw cycles performed, which significantly influences CSF biomarker concentrations (Clough, 2005; Bjerke and Engelborghs, 2018). For instance, CSF A $\beta 42$ measures have been found to be greatly influenced by pre-analytical factors such as the type of collection tube used and the number of freeze-thaw cycles of the sample (Perret-Liaudet et al., 2012b; Toombs et al., 2013; Leitão et al., 2015). Various studies have determined the importance of tube types when collecting CSF samples, highlighting that it is crucial to use polypropylene vials (Perret-Liaudet et al., 2012a), and that the tubes are filled to enhance the volume to surface ratio (Perret-Liaudet et al., 2012a). Ultimately there is poor standardization of biobanking protocols and assay consistency, a fact that hampers novel biomarker discoveries and replication of important findings (Teunissen et al., 2018).

One of the reasons why non-human primates are being preferred over canine or rodent species in CSF studies is that they share an upright orientation of the spinal column akin to humans (Spector et al., 2015). Moreover, the difference in brain size (and thereby CSF volume) between mice and humans is over 3000 times, whereas macaque brains are 10 - to 20 -fold smaller than human brains. Therefore, the distance from the CSF compartments to deeper regions of the brain significantly varies across species and likely influences the exchange analytes (Spector et al., 2015). Nevertheless, most differences across species are otherwise minor, including the volume ratio of CSF to the brain, ranging from 9 to $18 \%$ across species
(Barten et al., 2017). CSF turnover per day is also similar between humans and macaques, but is approximately 2-fold higher for rats and 3-fold higher for mice (Barten et al., 2017). The higher turnover rate for rodents can be explained by movement of CSF initiated by the ventricles and arterial pressure as a result of a fast heartbeat, which creates an increase in back- and-forth movement of the CSF (Feinberg and Mark, 1987; Sweetman and Linninger, 2011).

\section{The Physiology of CSF}

The exchange of CSF analytes (including therapeutics) may be highly different between patients and rodents as the latter have a much faster heart rate. However, this factor has not been studied. Non-human primates are most likely better preclinical in vivo models for biomarker translation because body weight-based allometric scaling is comparable (Karelina et al., 2017). Moreover, ventricular CSF from AD patients has been found to contain a rare high-molecular-weight tau species that was found to exert high seeding activity (Takeda et al., 2016). This needs to be kept in mind when comparing CSF samples gathered from different regions. Moreover, the sleep-wake cycle regulates ISF and CSF levels of $\mathrm{A} \beta$ in $\mathrm{AD}$ (Holth et al., 2019), and it has been shown that chronic sleep deprivation increases $A \beta$ plaques. Mouse ISF tau was found to increase $\sim 90 \%$ during normal wakefulness versus sleep and $\sim 100 \%$ during sleep deprivation. The relevant study found that sleep deprivation significantly increased CSF $\mathrm{A} \beta$ by $30 \%$ (Lucey et al., 2018). This means that the time of day is bound to influence $A \beta$ levels in CSF, which suggests that the timing of sampling needs to be chosen with care and kept consistent between clinical sampling and experiments for correct comparisons.

\section{The Efficacy of Drugs}

One major drawback of comparative biomarking is the translatability of AD drugs from animal models to human clinical trials. Compared to preclinical models, AD pathology in patients develops over decades rather than over months. Longitudinal studies in AD system models may determine the initiation and progression of biomarkers that allow for evaluation of diseasemodifying drugs. For example, research shows that BACE1 inhibitors can decrease both plasma and CSF A $\beta 40$ and A $\beta 42$ concentrations in mice, guinea pigs (Tagawa et al., 1991), and non-human primates (Sankaranarayanan et al., 2009; Gravenfors et al., 2012; Jeppsson et al., 2012; Wu et al., 2012). A separate study found that a $\gamma$-secretase inhibitor reduced CSF A $\beta$ production in rhesus monkeys without a subsequent rise in $\mathrm{A} \beta$ production (Cook et al., 2010). Candidates for therapeutics could be further addressed by extending these findings to translational transgenic AD models and may ultimately offer insights into mechanisms of the disease. Furthermore, increased plasma levels of interleukin10 has been shown following A $\beta$ immunotherapy in Tg2576 mice (Town et al., 2002; Kim et al., 2007). In a separate study, researchers found that peripheral structures play important roles in clearing $A \beta$ sourced from the brain, suggesting that removing $\mathrm{A} \beta$ from the blood may also be effective as an $\mathrm{AD}$ therapy (Jin et al., 2017). 

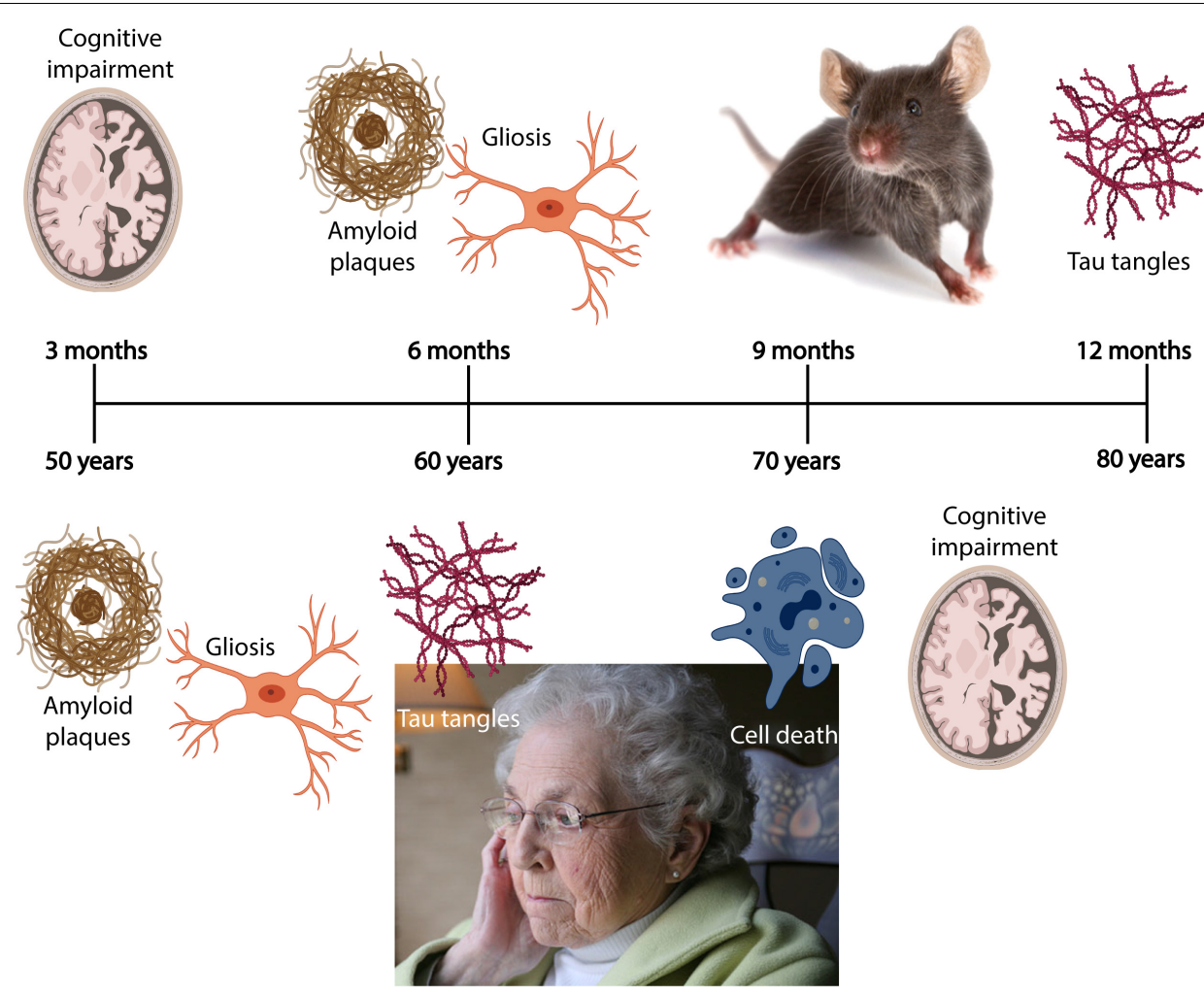

FIGURE 4 | A comparison of pathology and subsequent symptoms along the AD disease cascade between a preclinical model and patients. In the 3xTg AD mouse model (Oddo et al., 2003), cognitive impairment is observed at 3 months of age, whereas amyloid plaques and gliosis are present at 6 months of age. Tau pathology is first present at 12 months of age. In the typical sporadic AD patient, amyloid plaques and associated gliosis may be abundant at 50 years of age, and this pathology is followed by NFTs at approximately 60 years of age. Between 70 and 80 years of age, neurodegeneration occurs, and cognitive impairment becomes prominent in patients. AD, Alzheimer's disease; NFTs, neurofibrillary tangles. Images were generated using BioRender or taken from a public database.

$\gamma$-secretase modulators have proven especially useful as therapeutic candidates because they do not alter the total amount of $\mathrm{A} \beta$ peptides produced by $\gamma$-secretase activity, instead, they spare the products of other $\gamma$-secretase processing, such as notch (Toyn et al., 2016). Importantly, these compounds do not accelerate the production of the potentially toxic product BACE1-C-terminal fragment (C99) (Toyn et al., 2016). In all species, research suggests that $\gamma$-secretase modulator treatment decrease $A \beta 42$ and $A \beta 40$ levels while increasing $A \beta 38$ and $\mathrm{A} \beta 37$ by a corresponding amount. Therefore, the mechanism of action of $\gamma$-secretase modulators may translate well across species, validating its therapeutic strategy for utility in $\mathrm{AD}$ (Toyn et al., 2016).

Other translational research across species has shown increased levels of plasma interleukin-10 following $A \beta$ immunotherapy in Tg2576 mice (Town et al., 2002; Kim et al., 2007). Thereby, translation of inflammatory mechanisms and their peripheral markers may benefit from investigation of changes in microglial markers. However, when interpreting and comparing immune markers from mice caution is warranted, as recent evidence suggests that these markers do not translate well to human inflammatory diseases (Seok et al., 2013). Moreover, increased levels of isoprostanes have been shown in Tg2576 mice prior to plaque formation (Pratico et al., 2001), suggesting isoprostane levels may be useful as a predictive biomarker. Neurofilament light in bodily fluid constitutes a biomarker of neurodegeneration reflecting its translational value in system models and in clinical settings (Bacioglu et al., 2016).

\section{Comparative AD Neuropathology}

The earliest (current) detectable $A \beta$ deposition in humans is the formation of diffuse plaques, whereas in the brain of $\operatorname{Tg} 2576$ mice diffuse plaques are not observed until 12 months of age, which is 4 months after biochemically detectable alterations of A $\beta$ (Kawarabayashi et al., 2001). The most common observation in $\mathrm{AD}$ patients is minor amounts of $\mathrm{A} \beta 40$ deposited in the brain, whereas in $33 \%$ of patients great amounts of this $A \beta$ variant are detected. Intriguingly, this latter group of patients also display substantial amyloid angiopathy (amyloid build up on the walls of the arteries in the brain) (Gravina et al., 1995). Similarly, the Tg2576 mouse model displays marked angiopathy and the deposition of a large amount of $A \beta 40$ (Gravina et al., 1995). Generally CSF A $\beta 40$ levels are much higher in patients compared to mice, while brain concentrations are similar (Karelina et al., 2017). In terms of plasma concentrations of $A \beta 40$, this is highly similar between patients and mice, and therefore the greater A $\beta 40$ concentrations observed in human CSF may likely reflect a higher brain production of the peptide (Karelina et al., 2017). 
In terms of the similarity between system models and patients, and specifically transgenic mice and human patients, mice and humans share virtually the same set of genes. Almost every gene found in mice or humans has been observed in a closely related form in the other. To look directly at differences along the $\mathrm{AD}$ disease cascade, we compare pathological events between the 3xTg AD mouse model and sporadic AD patients (Figure 4). The 3xTg AD mouse model develops amyloid and tau pathology, including amyloid plaques and NFTs (Oddo et al., 2003). At 3 months of age these mice have developed cognitive impairment (Oddo et al., 2003), whereas at approximately 50 years of age an $\mathrm{AD}$ patient has developed amyloid plaques and gliosis (Braak and Del Trecidi, 2015). At 6 months of age, the mice develop amyloid plaques and gliosis (Oddo et al., 2003), while patients develop tau tangles at approximately 60 years of age (Braak and Del Trecidi, 2015). At 70 years of age, patients usually suffer from neurodegeneration because of the presence of tau tangles and exhibit cognitive impairment (Braak and Del Trecidi, 2015). First at 12 months of age will the mice develop tau tangles (Oddo et al., 2003).

There are two important differences observed along the $\mathrm{AD}$ disease cascade between the species: first, mice exhibit cognitive impairment prior to tau tangles, whereas cognitive impairment is most likely a result from neurodegeneration caused by NFTs in human patients. Second, one does not observe neuronal death in this mouse model, while neuronal death is thought to be the sole causative pathology for symptom development in $\mathrm{AD}$ patients. In line with this, by comparing CSF, plasma and in vivo amyloid imaging, cross-sectional data obtained at baseline in individuals from $\mathrm{AD}$ families enrolled in the Dominantly Inherited Alzheimer Network (DIAN) show lower concentrations of CSF A $\beta 42$ when amyloid plaques accumulate, and elevated concentrations of CSF t-tau and p-tau in mutation carriers $10-20$ years prior to symptom onset and detection of cognitive deficits (Fagan et al., 2014). This highlights the need for longitudinal CSF sampling in animals modeling $\mathrm{AD}$, in order to compare biochemical, imaging and behavioral tests against each other, and eventually to patients. However, given the difficulty of identifying patients at preclinical $\mathrm{AD}$ stages, it is important to remember that wellcharacterized preclinical disease models hold great translational value (Mattsson et al., 2017a).

\section{CONCLUSION AND FUTURE DIRECTIONS}

Clearly, there is a pressing need for better quality data from model systems investigating biomarkers that can be directly translated to human biomarkers. The core biomarkers (A 342 , $\mathrm{t}$-tau, and $\mathrm{p}$-tau) have been found to translate well across species, whereas biomarkers of inflammation translate to a lesser extent between mouse models and patients. Researchers should use autophagic and synaptic degeneration markers when analyzing samples from preclinical models because these markers appear promising in predicting development of AD. Changes in levels of autophagic markers and neurofilament light correlate strongly with the core biomarkers of $\mathrm{AD}$, and other novel biomarkers should be tested in combination in preclinical models to validate findings observed in patients. Currently, non-invasive structural and functional imaging can detect $\mathrm{AD}$ onset and longitudinally monitor disease progression in $\mathrm{AD}$ patients. By the combination of early predictive CSF biomarkers, imaging modalities can be strengthened in their ability to characterize patients along the disease cascade. Additional non-invasive methods for detecting $\mathrm{AD}$ biomarkers need to be established, such as blood sampling, which could be used in combination with CSF sampling. CSF sampling is invasive but reflects changes in protein levels in the brain to a greater extent compared to blood-based markers. Another advantage of CSF sampling compared to blood testing is that $A \beta$ is found in the periphery, so it is difficult to differentiate between brain- and peripherybased $A \beta$ levels. Additionally, there are greater levels of tau in ISF compared to CSF, so this needs to be controlled for when analyzing CSF samples. Neurofilament light is transferable between CSF and plasma in humans, but this needs to be verified in system models.

Furthermore, large inter- and intra-laboratory variations in biomarker sampling may have great consequences in terms of comparisons of results, while within individual laboratories such variations may affect planning and interpretations of longitudinal studies (Blennow et al., 2015). One also needs to consider differences in the CSF sampling methods used, given that protein levels differ between ventricular and lumbar CSF. Studies have shown that changes in the levels of core biomarkers as measured in CSF may be useful for assessing the efficacy of drugs. When translating findings across species, it is important to use the same scoring or grouping system when assessing changes in biomarkers and observed neuropathology. Ultimately, an early diagnosis by utilizing biomarkers detectable at this stage of disease will be the cornerstone for early identification of patients that are regressing away from the prodromal stage of AD (Teunissen et al., 2018). There is a need for continued progress within the $\mathrm{AD}$ biomarker field so that markers can be translated across animal models and clinical populations to serve as a translational bridge between model systems and clinical populations (Sabbagh et al., 2013). We still cannot translate all pathological hallmarks seen in AD patients to preclinical models, and we therefore need to be aware of pertinent differences when comparing $\mathrm{AD}$ research across species and bringing findings into the clinic.

\section{AUTHOR CONTRIBUTIONS}

All authors contributed to the content of the article, and critically reviewed and edited the manuscript.

\section{FUNDING}

This work was supported by the Liaison Committee for Education, Research and Innovation in Central Norway (Samarbeidsorganet HMN- NTNU) grant number 2018/42794. 


\section{ACKNOWLEDGMENTS}

The authors would like to acknowledge support by the Liaison Committee for Education, Research and

\section{REFERENCES}

Afanador, L., Roltsch, E. A., Holcomb, L., Campbell, K. S., Keeling, D. A., Zhang, Y., et al. (2014). The Ca2+ sensor S100A1 modulates neuroinflammation, histopathology and Akt activity in the PSAPP Alzheimer's disease mouse model. Cell Calcium. 56, 68-80. doi: 10.1016/j.ceca.2014.05.002

Ahmed, Z., Cooper, J., Murray, T. K., Garn, K., McNaughton, E., Clarke, H., et al. (2014). A novel in vivo model of tau propagation with rapid and progressive neurofibrillary tangle pathology: the pattern of spread is determined by connectivity, not proximity. Acta Neuropathol. 127, 667-683. doi: 10.1007/ s00401-014-1254-6

Akama, K., and Van Eldik, L. (2000). $\beta$-Amyloid stimulation of Inducible nitricoxide synthase in astrocytes Is interleukin-1 $\beta$ - and tumor necrosis factor- $\alpha$ $(\mathrm{TNF} \alpha)$-dependent, and involves a TNF $\alpha$ receptor-associated factor- and nfkbinducing kinase-dependent signaling mechanism. J. Biol. Chem. 275, 79187924. doi: 10.1074/jbc.275.11.7918

Akiyama, H., Barger, S., Barnum, S., Bradt, B., Bauer, J., Cole, G. M., et al. (2000). Inflammation and Alzheimer's disease. Neurobiol. Aging 21, 383-421. doi: 10. 1016/s0197-4580(00)00124-x

Albright, C. F., Dockens, R. C., Meredith, J. E., Olson, R. E., Slemmon, R., Lentz, K. A., et al. (2013). Pharmacodynamics of selective inhibition of $\gamma$-secretase by avagacestat. J. Pharmacol. Exp. Ther. 344, 686-695. doi: 10.1124/jpet.112. 199356

Alcolea, D., Vilaplana, E., Suarez-Calvet, M., Illan-Gala, I., Blesa, R., Clarimon, J., et al. (2017). CSF sAPPbeta, YKL-40, and neurofilament light in frontotemporal lobar degeneration. Neurology 89, 178-188. doi: 10.1212/wnl. 0000000000004088

Alzheimer, A., Stelzmann, R. A., Schnitzlein, H. N., and Murtagh, F. R. (1995). An English translation of Alzheimer's 1907 paper, "Uber eine eigenartige Erkankung der Hirnrinde. Clin. Anat. 8, 429-431. doi: 10.1002/ca.980080612

Amador-Ortiz, C., Lin, W. L., Ahmed, Z., Personett, D., Davies, P., Duara, R., et al. (2007). TDP-43 immunoreactivity in hippocampal sclerosis and Alzheimer's disease. Ann. Neurol. 61, 435-445. doi: 10.1002/ana.21154

Amen, E. M., Brecheisen, M., Sach-Peltason, L., and Bergadano, A. (2017). Refinement of a model of repeated cerebrospinal fluid collection in conscious rats. Lab. Anim. 51, 44-53. doi: 10.1177/0023677216646069

Anderson, P. J., Watts, H. R., Jen, S., Gentleman, S. M., Moncaster, J. A., Walsh, D. T., et al. (2009). Differential effects of interleukin-1beta and S100B on amyloid precursor protein in rat retinal neurons. Clin. Ophthalmol. 3, 235-242. doi: $10.2147 /$ opth.s2684

Andersson, C., Blennow, K., Almkvist, O., Andreasen, N., Engfeldt, P., Johansson, S. E., et al. (2008). Increasing CSF phospho-tau levels during cognitive decline and progression to dementia. Neurobiol. Aging 29, 1466-1473. doi: 10.1016/j. neurobiolaging.2007.03.027

Andreasen, N., Hesse, C., Davidsson, P., Minthon, L., Wallin, A., Winblad, B., et al. (1999a). Cerebrospinal fluid beta-amyloid(1-42) in Alzheimer disease: differences between early- and late-onset Alzheimer disease and stability during the course of disease. Arch. Neurol. 56, 673-680. doi: 10.1001/archneur.56.6.673

Andreasen, N., Minthon, L., Clarberg, A., Davidsson, P., Gottfries, J., Vanmechelen, E., et al. (1999b). Sensitivity, specificity, and stability of CSF-tau in AD in a community-based patient sample. Neurology 53, 1488-1494. doi: 10.1212/wnl. 53.7.1488

Andreasen, N., Vanmechelen, E., Van de Voorde, A., Davidsson, P., Hesse, C., Tarvonen, S., et al. (1998). Cerebrospinal fluid tau protein as a biochemical marker for Alzheimer's disease: a community based follow up study. J. Neurol. Neurosurg. Psychiatry 64, 298-305. doi: 10.1136/jnnp.64.3.298

Ao, X., and Stenken, J. A. (2006). Microdialysis sampling of cytokines. Methods 38, 331-341. doi: 10.1016/j.ymeth.2005.11.012

Armstrong, A., Mattsson, N., Appelqvist, H., Janefjord, C., Sandin, L., Agholme, L., et al. (2014). Lysosomal network proteins as potential novel CSF biomarkers
Innovation in Central Norway (Samarbeidsorganet HMNNTNU), and the Joint Research Committee between St. Olavs Hospital and the Faculty of Medicine and Health Sciences, NTNU.

for Alzheimer's disease. Neuromol. Med. 16, 150-160. doi: 10.1007/s12017-0138269-3

Arriagada, P. V., Growdon, J. H., Hedley-Whyte, E. T., and Hyman, B. T. (1992). Neurofibrillary tangles but not senile plaques parallel duration and severity of Alzheimer's disease. Neurology 42, 631-639. doi: 10.1212/wnl.42.3.631

Asai, H., Ikezu, S., Tsunoda, S., Medalla, M., Luebke, J., Haydar, T., et al. (2015). Depletion of microglia and inhibition of exosome synthesis halt tau propagation. Nat. Neurosci. 18, 1584-1593. doi: 10.1038/nn.4132

Ashton, N. J., Hye, A., Rajkumar, A. P., Leuzy, A., Snowden, S., Suárez-Calvet, M., et al. (2020). An update on blood-based biomarkers for non-Alzheimer neurodegenerative disorders. Nat. Rev. Neurol. 16, 265-284. doi: 10.1038/ s41582-020-0348-0

Avila, J., Lucas, J. J., Perez, M., and Hernandez, F. (2004). Role of tau protein in both physiological and pathological conditions. Physiol. Rev. 84, 361-384. doi: $10.1152 /$ physrev.00024.2003

Bacioglu, M., Maia, L. F., Preische, O., Schelle, J., Apel, A., Kaeser, S. A., et al. (2016). Neurofilament light chain in blood and csf as marker of disease progression in mouse models and in neurodegenerative diseases. Neuron 91, 56-66. doi: 10.1016/j.neuron.2016.05.018

Bakota, L., and Brandt, R. (2016). Tau biology and Tau-Directed therapies for Alzheimer's disease. Drugs 76, 301-313. doi: 10.1007/s40265-015-0529-0

Barten, D. M., Cadelina, G. W., and Weed, M. R. (2017). Dosing, collection, and quality control issues in cerebrospinal fluid research using animal models. Handb. Clin. Neurol. 146, 47-64. doi: 10.1016/B978-0-12-804279-3.00004-6

Barten, D. M., Cadelina, G. W., Hoque, N., DeCarr, L. B., Guss, V. L., Yang, L., et al. (2011). Tau transgenic mice as models for cerebrospinal fluid tau biomarkers. J. Alzheimers Dis. 24(Suppl. 2), 127-141. doi: 10.3233/JAD-2011-110161

Barten, D. M., Guss, V. L., Corsa, J. A., Loo, A., Hansel, S. B., Zheng, M., et al. (2005). Dynamics of \{beta $\}$-amyloid reductions in brain, cerebrospinal fluid, and plasma of \{beta\}-amyloid precursor protein transgenic mice treated with a \{gamma\}-secretase inhibitor. J. Pharmacol. Exp. Ther. 312, 635-643. doi: 10.1124/jpet.104.075408

Basi, G. S., Hemphill, S., Brigham, E. F., Liao, A., Aubele, D. L., Baker, J., et al. (2010). Amyloid precursor protein selective gamma-secretase inhibitors for treatment of Alzheimer's disease. Alzheimers Res. Ther. 2:36. doi: 10.1186/ alzrt60

Bateman, R. J., Xiong, C., Benzinger, T. L. S., Fagan, A. M., Goate, A., Fox, N. C., et al. (2012). Clinical and biomarker changes in dominantly inherited Alzheimer's disease. N. Engl J. Med. 367, 795-804. doi: 10.1056/ NEJMoa1202753

Bazan, J. F., Bacon, K. B., Hardiman, G., Wang, W., Soo, K., Rossi, D., et al. (1997). A new class of membrane-bound chemokine with a CX3C motif. Nature 385, 640-644. doi: 10.1038/385640a0

Beckett, L. A., Harvey, D. J., Gamst, A., Donohue, M., Kornak, J., Zhang, H., et al. (2010). The Alzheimer's Disease Neuroimaging Initiative: annual change in biomarkers and clinical outcomes. Alzheimers Dement. 6, 257-264. doi: 10. 1016/j.jalz.2010.03.002

Benilova, I., Karran, E., and De Strooper, B. (2012). The toxic abeta oligomer and Alzheimer's disease: an emperor in need of clothes. Nat. Neurosci. 15, 349-357. doi: $10.1038 / \mathrm{nn} .3028$

Benveniste, H., and Diemer, N. H. (1987). Cellular reactions to implantation of a microdialysis tube in the rat hippocampus. Acta Neuropathol. 74, 234-238. doi: $10.1007 /$ bf00688186

Benveniste, H., Drejer, J., Schousboe, A., and Diemer, N. H. (1987). Regional cerebral glucose phosphorylation and blood flow after insertion of a microdialysis fiber through the dorsal hippocampus in the rat. J. Neurochem. 49, 729-734. doi: 10.1111/j.1471-4159.1987.tb00954.x

Bian, H., Van Swieten, J. C., Leight, S., Massimo, L., Wood, E., Forman, M., et al. (2008). CSF biomarkers in frontotemporal lobar degeneration with known pathology. Neurology 70, 1827-1835. doi: 10.1212/01.wnl.0000311445.21321.fc 
Billings, L. M., Oddo, S., Green, K. N., McGaugh, J. L., and LaFerla, F. M. (2005). Intraneuronal Abeta causes the onset of early Alzheimer's diseaserelated cognitive deficits in transgenic mice. Neuron 45, 675-688. doi: 10.1016/ j.neuron.2005.01.040

Biswal, B., Zerrin Yetkin, F., Haughton, V. M., and Hyde, J. S. (1995). Functional connectivity in the motor cortex of resting human brain using echo-planar mri. Magn. Reson. Med. 34, 537-541. doi: 10.1002/mrm.1910340409

Bjerke, M., and Engelborghs, S. (2018). Cerebrospinal fluid biomarkers for early and differential Alzheimer's disease diagnosis. J. Alzheimers Dis. 62, 1199-1209. doi: 10.3233/JAD- 170680

Blennow, K., and Hampel, H. (2003). CSF markers for incipient Alzheimer's disease. Lancet Neurol. 2, 605-613. doi: 10.1016/s1474-4422(03)00530-1

Blennow, K., Dubois, B., Fagan, A. M., Lewczuk, P., de Leon, M. J., and Hampel, H. (2015). Clinical utility of cerebrospinal fluid biomarkers in the diagnosis of early Alzheimer's disease. Alzheimers Dement. 11, 58-69. doi: 10.1016/j.jalz.2014.02. 004

Block, M. L., Zecca, L., and Hong, J. S. (2007). Microglia-mediated neurotoxicity: uncovering the molecular mechanisms. Nat. Rev. Neurosci. 8, 57-69. doi: 10. 1038/nrn2038

Bolos, M., Llorens-Martin, M., Perea, J. R., Jurado-Arjona, J., Rabano, A., Hernandez, F., et al. (2017). Absence of CX3CR1 impairs the internalization of Tau by microglia. Mol. Neurodegener. 12:59. doi: 10.1186/s13024-017-0200- 1

Boom, A., Pochet, R., Authelet, M., Pradier, L., Borghgraef, P., Van Leuven, F., et al. (2004). Astrocytic calcium/zinc binding protein S100A6 over expression in Alzheimer's disease and in PS1/APP transgenic mice models. Biochim. Biophys. Acta 1742. doi: 10.1016/j.bbamcr.2004.09.011

Bouwman, F. H., van der Flier, W. M., Schoonenboom, N. S., van Elk, E. J., Kok, A., Rijmen, F., et al. (2007). Longitudinal changes of CSF biomarkers in memory clinic patients. Neurology 69, 1006-1011. doi: 10.1212/01.wnl. 0000271375.37131.04

Bozzali, M., Falini, A., Franceschi, M., Cercignani, M., Zuffi, M., Scotti, G., et al. (2002). White matter damage in Alzheimer's disease assessed in vivo using diffusion tensor magnetic resonance imaging. J. Neurol. Neurosurg. Psychiatry 72, 742-746. doi: 10.1136/jnnp.72.6.742

Braak, H., and Braak, E. (1991). Neuropathological stageing of Alzheimer-related changes. Acta Neuropathol. 82, 239-259. doi: 10.1007/bf00308809

Braak, H., and Braak, E. (1997). Frequency of stages of Alzheimer-related lesions in different age categories. Neurobiol. Aging 18, 351-357. doi: 10.1016/s01974580(97)00056-0

Braak, H., and Del Trecidi, K. (2015). Neuroanatomy and pathology of sporadic Alzheimer's disease. Adv. Anat. Embryol. Cell Biol. 215, 1-162.

Brandner, S., Thaler, C., Lelental, N., Buchfelder, M., Kleindienst, A., Maler, J. M., et al. (2014). Ventricular and lumbar cerebrospinal fluid concentrations of Alzheimer's disease biomarkers in patients with normal pressure hydrocephalus and posttraumatic hydrocephalus. J. Alzheimers Dis. 41, 1057-1062. doi: 10. 3233/JAD- 132708

Brinker, T., Stopa, E., Morrison, J., and Klinge, P. (2014). A new look at cerebrospinal fluid circulation. Fluids Barriers CNS 11:10. doi: 10.1186/20458118-11-10

Brinkmalm, A., Brinkmalm, G., Honer, W. G., Frolich, L., Hausner, L., Minthon, L., et al. (2014). SNAP-25 is a promising novel cerebrospinal fluid biomarker for synapse degeneration in Alzheimer's disease. Mol. Neurodegener. 9:53. doi: 10.1186/1750-1326-9-53

Bronzuoli, M. R., Iacomino, A., Steardo, L., and Scuderi, C. (2016). Targeting neuroinflammation in Alzheimer's disease. J. Inflamm. Res. 9, 199-208. doi: $10.2147 /$ jir.S86958

Brys, M., Pirraglia, E., Rich, K., Rolstad, S., Mosconi, L., Switalski, R., et al. (2009). Prediction and longitudinal study of CSF biomarkers in mild cognitive impairment. Neurobiol. Aging 30, 682-690. doi: 10.1016/j.neurobiolaging.2007. 08.010

Buchhave, P., Minthon, L., Zetterberg, H., Wallin, A. K., Blennow, K., and Hansson, O. (2012). Cerebrospinal fluid levels of beta-amyloid 1-42, but not of tau, are fully changed already 5 to 10 years before the onset of Alzheimer dementia. Arch. Gen. Psychiatry 69, 98-106. doi: 10.1001/archgenpsychiatry.2011.155

Buckner, R. L., Andrews-Hanna, J. R., and Schacter, D. L. (2008). The brain's default network: anatomy, function, and relevance to disease. Ann. N.Y. Acad. Sci. 1124, 1-38. doi: 10.1196/annals.1440.011
Buerger, K., Ewers, M., Pirttila, T., Zinkowski, R., Alafuzoff, I., Teipel, S. J., et al. (2006). CSF phosphorylated tau protein correlates with neocortical neurofibrillary pathology in Alzheimer's disease. Brain 129, 3035-3041. doi: 10.1093/brain/awl269

Caccamo, A., Majumder, S., Richardson, A., Strong, R., and Oddo, S. (2010). Molecular interplay between mammalian target of rapamycin (mTOR), amyloid-beta, and Tau: effects on cognitive impairments. J. Biol. Chem. 285, 13107-13120. doi: 10.1074/jbc.M110.100420

Calsolaro, V., and Edison, P. (2016). Neuroinflammation in Alzheimer's disease: current evidence and future directions. Alzheimers Dement. 12, 719-732. doi: 10.1016/j.jalz.2016.02.010

Campioni, S., Mannini, B., Zampagni, M., Pensalfini, A., Parrini, C., Evangelisti, E., et al. (2010). A causative link between the structure of aberrant protein oligomers and their toxicity. Nat. Chem. Biol. 6, 140-147. doi: 10.1038/ nchembio. 283

Cataldo, A. M., and Nixon, R. A. (1990). Enzymatically active lysosomal proteases are associated with amyloid deposits in Alzheimer brain. Proc. Natl. Acad. Sci. U.S.A. 87, 3861-3865. doi: 10.1073/pnas.87.10.3861

Chang, K. A., Kim, H. J., and Suh, Y. H. (2012). The role of S100a9 in the pathogenesis of Alzheimer's disease: the therapeutic effects of S100a9 knockdown or knockout. Neurodegener. Dis. 10, 27-29. doi: 10.1159/000333781

Chang, X.-L., Tan, M.-S., Tan, L., and Yu, J.-T. (2015). The role of TDP-43 in Alzheimer's disease. Mol. Neurobiol. 53, 3349-3359.

Chen, J. J., Zhao, B., Zhao, J., and Li, S. (2017). Potential roles of exosomal MicroRNAs as diagnostic biomarkers and therapeutic application in Alzheimer's disease. Neural Plast. 2017:7027380. doi: 10.1155/2017/7027380

Chen, M., Inestrosa, N. C., Ross, G. S., and Fernandez, H. L. (1995). Platelets are the primary source of amyloid beta-peptide in human blood. Biochem. Biophys. Res. Commun. 213, 96-103. doi: 10.1006/bbrc.1995.2103

Cho, H., Choi, J. Y., Hwang, M. S., Kim, Y. J., Lee, H. M., Lee, H. S., et al. (2016). In vivo cortical spreading pattern of tau and amyloid in the Alzheimer disease spectrum. Ann. Neurol. 80, 247-258. doi: 10.1002/ana.24711

Cho, S.-J., Lim, H. J., Jo, C., Park, M. H., Han, C., and Koh, Y. H. (2019). Plasma ATG5 is increased in Alzheimer's disease. Sci. Rep. 9:4741. doi: 10.1038/s41598019-41347-2

Chua, T. C., Wen, W., Slavin, M. J., and Sachdev, P. S. (2008). Diffusion tensor imaging in mild cognitive impairment and Alzheimer's disease: a review. Curr. Opin. Neurol. 21, 83-92. doi: 10.1097/WCO.0b013e3282f4594b

Cirrito, J. R., May, P. C., O’Dell, M. A., Taylor, J. W., Parsadanian, M., Cramer, J. W., et al. (2003). In vivo assessment of brain interstitial fluid with microdialysis reveals plaque-associated changes in amyloid-beta metabolism and half-life. $J$ Neurosci. 23, 8844-8853.

Clark, C. M., Xie, S., Chittams, J., Ewbank, D., Peskind, E., Galasko, D., et al. (2003). Cerebrospinal fluid tau and beta-amyloid: how well do these biomarkers reflect autopsy-confirmed dementia diagnoses? Arch. Neurol. 60, 1696-1702. doi: 10.1001/archneur.60.12.1696

Clavaguera, F., Akatsu, H., Fraser, G., Crowther, R. A., Frank, S., Hench, J., et al. (2013). Brain homogenates from human tauopathies induce tau inclusions in mouse brain. Proc. Natl. Acad. Sci. U.S.A. 110, 9535-9540. doi: 10.1073/pnas. 1301175110

Clough, G. F. (2005). Microdialysis of large molecules. AAPS J. 7, E686-E692. doi: $10.1208 /$ aapsj070369

Cook, J. J., Wildsmith, K. R., Gilberto, D. B., Holahan, M. A., Kinney, G. G., Mathers, P. D., et al. (2010). Acute gamma-secretase inhibition of nonhuman primate CNS shifts amyloid precursor protein (APP) metabolism from amyloid-beta production to alternative APP fragments without amyloid-beta rebound. J. Neurosci. 30, 6743-6750. doi: 10.1523/jneurosci.1381-10.2010

Coric, V., Salloway, S., van Dyck, C. H., Dubois, B., Andreasen, N., Brody, M., et al. (2015). Targeting prodromal Alzheimer Disease with avagacestat: a randomized clinical trial. JAMA Neurol. 72, 1324-1333. doi: 10.1001/jamaneurol.2015.0607

Craig-Schapiro, R., Perrin, R. J., Roe, C. M., Xiong, C., Carter, D., Cairns, N. J., et al. (2010). YKL-40: a novel prognostic fluid biomarker for preclinical Alzheimer's disease. Biol. Psychiatry 68, 903-912. doi: 10.1016/j.biopsych.2010. 08.025

Cristovao, J. S., Morris, V. K., Cardoso, I., Leal, S. S., Martinez, J., Botelho, H. M., et al. (2018). The neuronal S100B protein is a calcium-tuned suppressor of amyloid-beta aggregation. Sci. Adv. 4, eaaq1702. doi: 10.1126/sciadv.aaq1702 
Cummings, J. (2010). What can be inferred from the interruption of the semagacestat trial for treatment of Alzheimer's disease? Biol. Psychiatry 68, 876-878. doi: 10.1016/j.biopsych.2010.09.020

Davies, P., Resnick, J., Resnick, B., Gilman, S., Growdon, J. H., Khachaturian, Z. S., et al. (1998). Consensus report of the working group on: "molecular and biochemical markers of Alzheimer's disease. Neurobiol. Aging 19, 109-116. doi: 10.1016/S0197-4580(98)00022-0

de Boussard, C. N., Lundin, A., Karlstedt, D., Edman, G., Bartfai, A., and Borg, J. (2005). S100 and cognitive impairment after mild traumatic brain injury. J. Rehabil. Med. 37, 53-57. doi: 10.1080/16501970410015587

de Leon, M. J., DeSanti, S., Zinkowski, R., Mehta, P. D., Pratico, D., Segal, S., et al. (2006). Longitudinal CSF and MRI biomarkers improve the diagnosis of mild cognitive impairment. Neurobiol. Aging 27, 394-401. doi: 10.1016/j. neurobiolaging.2005.07.003

de Leon, M. J., Ferris, S. H., George, A. E., Christman, D. R., Fowler, J. S., Gentes, C., et al. (1983). Positron emission tomographic studies of aging and Alzheimer disease. AJNR Am. J. Neuroradiol. 4, 568-571.

de Souza, L. C., Chupin, M., Lamari, F., Jardel, C., Leclercq, D., Colliot, O., et al. (2012). CSF tau markers are correlated with hippocampal volume in Alzheimer's disease. Neurobiol. Aging 33, 1253-1257. doi: 10.1016/j. neurobiolaging.2011.02.022

De Vos, A., Jacobs, D., Struyfs, H., Fransen, E., Andersson, K., Portelius, E., et al. (2015). C-terminal neurogranin is increased in cerebrospinal fluid but unchanged in plasma in Alzheimer's disease. Alzheimers Dement. 11, 14611469. doi: 10.1016/j.jalz.2015.05.012

DeMattos, R. B., Bales, K. R., Parsadanian, M., O’Dell, M. A., Foss, E. M., Paul, S. M., et al. (2002). Plaque-associated disruption of CSF and plasma amyloid-beta (Abeta) equilibrium in a mouse model of Alzheimer's disease. J. Neurochem. 81, 229-236. doi: 10.1046/j.1471-4159.2002.00889.x

Desikan, R. S., McEvoy, L. K., Thompson, W. K., Holland, D., Brewer, J. B., Aisen, P. S., et al. (2012). Amyloid-beta-associated clinical decline occurs only in the presence of elevated P-tau. Arch. Neurol. 69, 709-713. doi: 10.1001/archneurol. 2011.3354

Desikan, R. S., McEvoy, L. K., Thompson, W. K., Holland, D., Roddey, J. C., Blennow, K., et al. (2011). Amyloid-beta associated volume loss occurs only in the presence of phospho-tau. Ann. Neurol. 70, 657-661. doi: 10.1002/ana.22509

Desikan, R. S., Sabuncu, M. R., Schmansky, N. J., Reuter, M., Cabral, H. J., Hess, C. P., et al. (2010). Selective disruption of the cerebral neocortex in Alzheimer's disease. PLoS One 5:e12853. doi: 10.1371/journal.pone.0012853

Dickerson, B. C., Bakkour, A., Salat, D. H., Feczko, E., Pacheco, J., Greve, D. N., et al. (2009). The cortical signature of Alzheimer's disease: regionally specific cortical thinning relates to symptom severity in very mild to mild $\mathrm{AD}$ dementia and is detectable in asymptomatic amyloid-positive individuals. Cereb. Cortex 19, 497-510. doi: 10.1093/cercor/bhn113

Disanto, G., Barro, C., Benkert, P., Naegelin, Y., Schadelin, S., Giardiello, A., et al. (2017). Serum Neurofilament light: a biomarker of neuronal damage in multiple sclerosis. Ann. Neurol. 81, 857-870. doi: 10.1002/ana.24954

Dockens, R., Wang, J.-S., Castaneda, L., Sverdlov, O., Huang, S.-P., Slemmon, R., et al. (2012). A placebo-controlled, multiple ascending dose study to evaluate the safety, pharmacokinetics and pharmacodynamics of avagacestat (BMS-708163) in healthy young and elderly subjects. Clin. Pharmacokinet. 51, 681-693. doi: 10.1007/s40262-012-0005-x

Dominguez, D., Tournoy, J., Hartmann, D., Huth, T., Cryns, K., Deforce, S., et al. (2005). Phenotypic and biochemical analyses of BACE1- and BACE2-deficient mice. J. Biol. Chem. 280, 30797-30806. doi: 10.1074/jbc.M505249200

Drijfhout, W. J., Kemper, R. H., Meerlo, P., Koolhaas, J. M., Grol, C. J., and Westerink, B. H. (1995). A telemetry study on the chronic effects of microdialysis probe implantation on the activity pattern and temperature rhythm of the rat. J. Neurosci. Methods 61, 191-196. doi: 10.1016/0165-0270(94) 00041-e

Dubois, B., Feldman, H. H., Jacova, C., Hampel, H., Molinuevo, J. L., Blennow, K., et al. (2014). Advancing research diagnostic criteria for Alzheimer's disease: the IWG-2 criteria. Lancet Neurol. 13, 614-629. doi: 10.1016/s1474-4422(14) 70090-0

Duyckaerts, C., Brion, J. P., Hauw, J. J., and Flament-Durand, J. (1987). Quantitative assessment of the density of neurofibrillary tangles and senile plaques in senile dementia of the Alzheimer type. Comparison of immunocytochemistry with a specific antibody and Bodian's protargol method. Acta Neuropathol. 73, 167-170. doi: 10.1007/BF00693783

El Kadmiri, N., Said, N., Slassi, I., El Moutawakil, B., and Nadifi, S. (2018). Biomarkers for Alzheimer disease: classical and novel candidates' review. Neuroscience 370, 181-190. doi: 10.1016/j.neuroscience.2017.07.017

Engelborghs, S., De Vreese, K., Van de Casteele, T., Vanderstichele, H., Van Everbroeck, B., Cras, P., et al. (2008). Diagnostic performance of a CSFbiomarker panel in autopsy-confirmed dementia. Neurobiol. Aging 29, 11431159. doi: 10.1016/j.neurobiolaging.2007.02.016

Engler, H., Forsberg, A., Almkvist, O., Blomquist, G., Larsson, E., Savitcheva, I., et al. (2006). Two-year follow-up of amyloid deposition in patients with Alzheimer's disease. Brain 129, 2856-2866. doi: 10.1093/brain/awl178

Eskildsen, S. F., Coupe, P., Garcia-Lorenzo, D., Fonov, V., Pruessner, J. C., and Collins, D. L. (2013). Prediction of Alzheimer's disease in subjects with mild cognitive impairment from the ADNI cohort using patterns of cortical thinning. Neuroimage 65, 511-521. doi: 10.1016/j.neuroimage.2012.09.058

Fagan, A. M., Xiong, C., Jasielec, M. S., Bateman, R. J., Goate, A. M., Benzinger, T. L., et al. (2014). Longitudinal change in CSF biomarkers in autosomaldominant Alzheimer's disease. Sci. Transl. Med. 6:226ra230. doi: 10.1126/ scitranslmed.3007901

Fan, Z., Brooks, D. J., Okello, A., and Edison, P. (2017). An early and late peak in microglial activation in Alzheimer's disease trajectory. Brain 140, 792-803. doi: 10.1093/brain/aww349

Feinberg, D. A., and Mark, A. S. (1987). Human brain motion and cerebrospinal fluid circulation demonstrated with MR velocity imaging. Radiology 163, 793799. doi: 10.1148/radiology.163.3.3575734

Finneran, D. J., Morgan, D., Gordon, M. N., and Nash, K. R. (2019). CNS-wide over expression of fractalkine improves cognitive functioning in a tauopathy model. J. Neuroimmune. Pharmacol. 14, 312-325. doi: 10.1007/s11481-018-9822-5

Fox, M. D., and Raichle, M. E. (2007). Spontaneous fluctuations in brain activity observed with functional magnetic resonance imaging. Nat. Rev. Neurosci. 8, 700-711. doi: 10.1038/nrn2201

Fransquet, P. D., and Ryan, J. (2018). Micro RNA as a potential blood-based epigenetic biomarker for Alzheimer's disease. Clin. Biochem .58, 5-14. doi: 10.1016/j.clinbiochem.2018.05.020

Freudenberg-Hua, Y., Li, W., and Davies, P. (2018). The role of genetics in advancing precision medicine for Alzheimer's disease-a narrative review. Front. Med. 5:108. doi: 10.3389/fmed.2018.00108

Frölich, L., Peters, O., Lewczuk, P., Gruber, O., Teipel, S. J., Gertz, H. J., et al. (2017). Incremental value of biomarker combinations to predict progression of mild cognitive impairment to Alzheimer's dementia. Alzheimers Res. Ther. 9:84. doi: 10.1186/s13195-017-0301-7

Gaffan, D. (1992). Amnesia for complex naturalistic scenes and for objects following fornix transection in the rhesus monkey. Eur. J. Neurosci. 4, 381-388. doi: $10.1111 / j .1460-9568.1992 . t b 00886 . x$

Gaffan, D. (1994). Scene-specific memory for objects: a model of episodic memory impairment in monkeys with fornix transection. J. Cogn. Neurosci. 6, 305-320. doi: 10.1162/jocn.1994.6.4.305

Gaffan, D., Saunders, R. C., Gaffan, E. A., Harrison, S., Shields, C., and Owen, M. J. (1984). Effects of fornix transection upon associative memory in monkeys: role of the hippocampus in learned action. Q. J. Exp. Psychol. Sec. B 36, 173-221. doi: 10.1080/14640748408402203

Garwood, C. J., Pooler, A. M., Atherton, J., Hanger, D. P., and Noble, W. (2011). Astrocytes are important mediators of $\mathrm{A} \beta$-induced neurotoxicity and tau phosphorylation in primary culture. Cell Death Dis. 2, e167-e167. doi: 10.1038/ cddis. 2011.50

Geinisman, Y., deToledo-Morrell, L., Morrell, F., Persina, I. S., and Rossi, M. (1992). Age-related loss of axospinous synapses formed by two afferent systems in the rat dentate gyrus as revealed by the unbiased stereological dissector technique. Hippocampus 2, 437-444. doi: 10.1002/hipo.450020411

Georgievska, B., Gustavsson, S., Lundkvist, J., Neelissen, J., Eketjall, S., Ramberg, V., et al. (2015). Revisiting the peripheral sink hypothesis: inhibiting BACE1 activity in the periphery does not alter beta-amyloid levels in the CNS. J. Neurochem. 132, 477-486. doi: 10.1111/jnc.12937

Geppert, M., Goda, Y., Hammer, R. E., Li, C., Rosahl, T. W., Stevens, C. F., et al. (1994). Synaptotagmin I: a major Ca2+ sensor for transmitter release at a central synapse. Cell 79, 717-727. doi: 10.1016/0092-8674(94)90556-8 
Gisslen, M., Price, R. W., Andreasson, U., Norgren, N., Nilsson, S., Hagberg, L., et al. (2016). Plasma Concentration of the neurofilament light protein (NFL) is a biomarker of CNS Injury in HIV infection: a cross-sectional study. EBioMedicine 3, 135-140. doi: 10.1016/j.ebiom.2015.11.036

Gomez-Isla, T., Price, J. L., McKeel, D. W. Jr., Morris, J. C., Growdon, J. H., and Hyman, B. T. (1996). Profound loss of layer II entorhinal cortex neurons occurs in very mild Alzheimer's disease. J. Neurosci. 16, 4491-4500.

Gomez-Nicola, D., and Boche, D. (2015). Post-mortem analysis of neuroinflammatory changes in human Alzheimer's disease. Alzheimers Res. Ther. 7:42. doi: 10.1186/s13195-015-0126-1

Gravenfors, Y., Viklund, J., Blid, J., Ginman, T., Karlstrom, S., Kihlstrom, J., et al. (2012). New aminoimidazoles as beta-secretase (BACE-1) inhibitors showing amyloid-beta (Abeta) lowering in brain. J. Med. Chem. 55, 9297-9311. doi: 10.1021/jm300991n

Gravina, S. A., Ho, L., Eckman, C. B., Long, K. E., Otvos, L. Jr., Younkin, L. H., et al. (1995). Amyloid beta protein (A beta) in Alzheimer's disease brain. Biochemical and immunocytochemical analysis with antibodies specific for forms ending at A beta 40 or A beta 42(43). J. Biol. Chem. 270, 7013-7016. doi: 10.1074/jbc.270. 13.7013

Greicius, M. D., and Menon, V. (2004). Default-mode activity during a passive sensory task: uncoupled from deactivation but impacting activation. J. Cogn. Neurosci. 16, 1484-1492. doi: 10.1162/0898929042568532

Griffin, W. S., Stanley, L. C., Ling, C., White, L., MacLeod, V., Perrot, L. J., et al. (1989). Brain interleukin 1 and S-100 immunoreactivity are elevated in down syndrome and Alzheimer disease. Proc. Natl. Acad. Sci. U.S.A. 86, 7611-7615. doi: $10.1073 /$ pnas.86.19.7611

Grossman, M., Farmer, J., Leight, S., Work, M., Moore, P., Van Deerlin, V., et al. (2005). Cerebrospinal fluid profile in frontotemporal dementia and Alzheimer's disease. Ann. Neurol. 57, 721-729. doi: 10.1002/ana.20477

Gusnard, D. A., Raichle, M. E., and Raichle, M. E. (2001). Searching for a baseline: functional imaging and the resting human brain. Nat. Rev. Neurosci. 2, 685-694. doi: $10.1038 / 35094500$

Gustafson, D. R., Skoog, I., Rosengren, L., Zetterberg, H., and Blennow, K. (2007). Cerebrospinal fluid $\beta$-amyloid 1-42 concentration may predict cognitive decline in older women. J. Neurol. Neurosurg. Psychiatry 78, 461-464. doi: 10.1136/ jnnp.2006.100529

Ha, T. Y., Chang, K. A., Kim, J., Kim, H. S., Kim, S., Chong, Y. H., et al. (2010). S100a9 knockdown decreases the memory impairment and the neuropathology in Tg2576 mice, AD animal model. PLoS One 5:e8840. doi: 10.1371/journal. pone. 0008840

Haass, C., and De Strooper, B. (1999). The presenilins in Alzheimer's diseaseproteolysis holds the key. Science 286, 916-919. doi: 10.1126/science.286.5441. 916

Haass, C., and Selkoe, D. J. (2007). Soluble protein oligomers in neurodegeneration: lessons from the Alzheimer's amyloid beta-peptide. Nat. Rev. Mol. Cell Biol. 8, 101-112. doi: 10.1038/nrm2101

Hagmeyer, S., Cristovao, J. S., Mulvihill, J. J. E., Boeckers, T. M., Gomes, C. M., and Grabrucker, A. M. (2017). Zinc binding to S100B affords regulation of trace metal homeostasis and excitotoxicity in the brain. Front. Mol. Neurosci. 10:456. doi: 10.3389/fnmol.2017.00456

Hamberger, A., Berthold, C.-H., Jacobson, I., Karlsson, B., Lehmann, A., Nyström, B. et al. (1985). "In vivo brain dialysis of extracellular nontransmitter and putative transmitter amino acids" in Vivo Perfusion and Release of Neuroactive Substances, eds A. Bayon, and R. Drucker-Colin, (New York, NY: Academic Press Inc), 473-492.

Hamelin, L., Lagarde, J., Dorothee, G., Leroy, C., Labit, M., Comley, R. A., et al. (2016). Early and protective microglial activation in Alzheimer's disease: a prospective study using 18F-DPA-714 PET imaging. Brain 139, 1252-1264. doi: 10.1093/brain/aww017

Hampel, H., Blennow, K., Shaw, L. M., Hoessler, Y. C., Zetterberg, H., and Trojanowski, J. Q. (2010). Total and phosphorylated tau protein as biological markers of Alzheimer's disease. Exp. Gerontol. 45, 30-40. doi: 10.1016/j.exger. 2009.10.010

Hampel, H., Lista, S., and Khachaturian, Z. S. (2012). Development of biomarkers to chart all Alzheimer's disease stages: the royal road to cutting the therapeutic Gordian Knot. Alzheimers Dement. 8, 312-336. doi: 10.1016/j.jalz.2012.05.2116
Hane, F. T., Robinson, M., Lee, B. Y., Bai, O., Leonenko, Z., and Albert, M. S. (2017). Recent progress in alzheimer's disease research, part 3: diagnosis and treatment. J. Alzheimers Dis. 57, 645-665. doi: 10.3233/JAD-160907

Hansson, O., Zetterberg, H., Buchhave, P., Andreasson, U., Londos, E., Minthon, L., et al. (2007). Prediction of Alzheimer's disease using the CSF Abeta42/Abeta40 ratio in patients with mild cognitive impairment. Dement. Geriatr. Cogn. Disord. 23, 316-320. doi: 10.1159/000100926

Hardy, J. A., and Higgins, G. A. (1992). Alzheimer's disease: the amyloid cascade hypothesis. Science 256, 184-185. doi: 10.1126/science. 1566067

Harper, J. D., and Lansbury, P. T. Jr. (1997). Models of amyloid seeding in Alzheimer's disease and scrapie: mechanistic truths and physiological consequences of the time-dependent solubility of amyloid proteins. Annu. Rev. Biochem. 66, 385-407. doi: 10.1146/annurev.biochem.66.1.385

Harrison, J. K., Jiang, Y., Chen, S., Xia, Y., Maciejewski, D., McNamara, R. K., et al. (1998). Role for neuronally derived fractalkine in mediating interactions between neurons and CX3CR1-expressing microglia. Proc. Natl. Acad. Sci. U.S.A. 95, 10896-10901. doi: 10.1073/pnas.95.18.10896

He, Z., Guo, J. L., McBride, J. D., Narasimhan, S., Kim, H., Changolkar, L., et al. (2018). Amyloid-beta plaques enhance Alzheimer's brain tau-seeded pathologies by facilitating neuritic plaque tau aggregation. Nat. Med. 24, 29-38. doi: $10.1038 / \mathrm{nm} .4443$

Heckmann, B. L., Teubner, B. J. W., Tummers, B., Boada-Romero, E., Harris, L., Yang, M., et al. (2019). LC3-Associated endocytosis facilitates beta-amyloid clearance and mitigates neurodegeneration in murine Alzheimer's disease. Cell 178, 536.e14-551.e14. doi: 10.1016/j.cell.2019.05.056

Hellstrand, E., Boland, B., Walsh, D. M., and Linse, S. (2010). Amyloid betaprotein aggregation produces highly reproducible kinetic data and occurs by a two-phase process. ACS Chem. Neurosci. 1, 13-18. doi: 10.1021/cn900015v

Herukka, S. K., Rummukainen, J., Ihalainen, J., Von Und Zu Fraunberg, M., Koivisto, A. M., Nerg, O., et al. (2015). Amyloid- $\beta$ and tau dynamics in human brain interstitial fluid in patients with suspected normal pressure hydrocephalus. J. Alzheimers Dis. 46, 261-269. doi: 10.3233/JAD- 142862

Heyman, A., Peterson, B., Fillenbaum, G., and Pieper, C. (1996). The consortium to establish a registry for Alzheimer's disease (CERAD). Part XIV: demographic and clinical predictors of survival in patients with Alzheimer's disease. Neurology 46, 656-660. doi: 10.1212/wnl.46.3.656

Hickman, S. E., Allison, E. K., and El Khoury, J. (2008). Microglial dysfunction and defective beta-amyloid clearance pathways in aging Alzheimer's disease mice. J. Neurosci. 28, 8354-8360. doi: 10.1523/jneurosci.0616-08.2008

Hoglund, K., Thelen, K. M., Syversen, S., Sjogren, M., von Bergmann, K., Wallin, A., et al. (2005). The effect of simvastatin treatment on the amyloid precursor protein and brain cholesterol metabolism in patients with Alzheimer's disease. Dement. Geriatr. Cogn. Disord. 19, 256-265. doi: 10.1159/000084550

Holland, D., McEvoy, L. K., and Dale, A. M. (2012a). Unbiased comparison of sample size estimates from longitudinal structural measures in ADNI. Hum. Brain. Mapp. 33, 2586-2602. doi: 10.1002/hbm.21386

Holland, D., McEvoy, L. K., Desikan, R. S., and Dale, A. M. (2012b). Enrichment and stratification for predementia Alzheimer disease clinical trials. PLoS One 7:e47739. doi: 10.1371/journal.pone.0047739

Holth, J., Fritschi, S., Wang, C., Pedersen, N., Cirrito, J., Mahan, T., et al. (2019). The sleep-wake cycle regulates brain interstitial fluid tau in mice and CSF tau in humans. Science 363, eaav2546. doi: 10.1126/science.aav2546

Hong, S., Quintero-Monzon, O., Ostaszewski, B. L., Podlisny, D. R., Cavanaugh, W. T., Yang, T., et al. (2011). Dynamic analysis of amyloid beta-protein in behaving mice reveals opposing changes in ISF versus parenchymal Abeta during age-related plaque formation. J. Neurosci. 31, 15861-15869. doi: 10. 1523/jneurosci.3272-11.2011

Huang, J., Friedland, R. P., and Auchus, A. P. (2007). Diffusion tensor imaging of normal-appearing white matter in mild cognitive impairment and early Alzheimer disease: preliminary evidence of axonal degeneration in the temporal lobe. AJNR Am. J. Neuroradiol. 28, 1943-1948. doi: 10.3174/ajnr. A0700

Hyman, B. T., Van Hoesen, G. W., Kromer, L. J., and Damasio, A. R. (1986). Perforant pathway changes and the memory impairment of Alzheimer's disease. Ann. Neurol. 20, 472-481. doi: 10.1002/ana.41020 0406 
Iijima-Ando, K., Hearn, S. A., Granger, L., Shenton, C., Gatt, A., Chiang, H. C., et al. (2008). Overexpression of neprilysin reduces alzheimer amyloidbeta42 (Abeta42)-induced neuron loss and intraneuronal Abeta42 deposits but causes a reduction in cAMP-responsive element-binding protein-mediated transcription, age-dependent axon pathology, and premature death in Drosophila. J. Biol. Chem. 283. doi: 10.1074/jbc.M710509200

Imai, T., Hieshima, K., Haskell, C., Baba, M., Nagira, M., Nishimura, M., et al. (1997). Identification and molecular characterization of fractalkine receptor CX3CR1, which mediates both leukocyte migration and adhesion. Cell 91, 521-530. doi: 10.1016/s0092-8674(00)80438-9

Imbimbo, B. P., Giardino, L., Sivilia, S., Giuliani, A., Gusciglio, M., Pietrini, V., et al. (2010). CHF5074, a novel gamma-secretase modulator, restores hippocampal neurogenesis potential and reverses contextual memory deficit in a transgenic mouse model of Alzheimer's disease. J. Alzheimers Dis. 20, 159-173. doi: 10. 3233/jad-2010-1366

Jack, C. R. Jr., Bennett, D. A., Blennow, K., Carrillo, M. C., Feldman, H. H., Frisoni, G. B., et al. (2016). A/T/N: an unbiased descriptive classification scheme for Alzheimer disease biomarkers. Neurology 87, 539-547. doi: 10.1212/wnl. 0000000000002923

Jack, C. R. Jr., Knopman, D. S., Jagust, W. J., Shaw, L. M., Aisen, P. S., Weiner, M. W., et al. (2010). Hypothetical model of dynamic biomarkers of the Alzheimer's pathological cascade. Lancet Neurol. 9, 119-128. doi: 10.1016/ s1474-4422(09)70299-6

Jack, C. R. Jr., Petersen, R. C., Xu, Y., O’Brien, P. C., Smith, G. E., Ivnik, R. J., et al. (2000). Rates of hippocampal atrophy correlate with change in clinical status in aging and AD. Neurology 55, 484-489. doi: 10.1212/wnl.55.4.484

Jack, C. R. Jr., Wiste, H. J., Lesnick, T. G., Weigand, S. D., Knopman, D. S., Vemuri, P., et al. (2013). Brain beta-amyloid load approaches a plateau. Neurology 80, 890-896. doi: 10.1212/WNL.0b013e3182840bbe

Jagust, W. J., Landau, S. M., Koeppe, R. A., Reiman, E. M., Chen, K., Mathis, C. A., et al. (2015). The Alzheimer's disease neuroimaging initiative 2 PET core: 2015. Alzheimers Dement. 11, 757-771. doi: 10.1016/j.jalz.2015.05.001

Jahn, R., and Fasshauer, D. (2012). Molecular machines governing exocytosis of synaptic vesicles. Nature 490, 201-207. doi: 10.1038/nature11320

James, B. D., Wilson, R. S., Boyle, P. A., Trojanowski, J. Q., Bennett, D. A., and Schneider, J. A. (2016). TDP-43 stage, mixed pathologies, and clinical Alzheimer's-type dementia. Brain 139, 2983-2993. doi: 10.1093/brain/aww224

Janelidze, S., Mattsson, N., Stomrud, E., Lindberg, O., Palmqvist, S., Zetterberg, H., et al. (2018). CSF biomarkers of neuroinflammation and cerebrovascular dysfunction in early Alzheimer disease. Neurology 91, e867-e877. doi: 10.1212/ WNL.0000000000006082

Janelidze, S., Stomrud, E., Palmqvist, S., Zetterberg, H., van Westen, D., Jeromin, A., et al. (2016). Plasma beta-amyloid in Alzheimer's disease and vascular disease. Sci. Rep. 6:26801. doi: 10.1038/srep26801

Jay, T. R., von Saucken, V. E., and Landreth, G. E. (2017). TREM2 in neurodegenerative diseases. Mol. Neurodegener. 12:56. doi: 10.1186/s13024017-0197-5

Jeppsson, F., Eketjall, S., Janson, J., Karlstrom, S., Gustavsson, S., Olsson, L. L., et al. (2012). Discovery of AZD3839, a potent and selective BACE1 inhibitor clinical candidate for the treatment of Alzheimer disease. J. Biol. Chem. 287, 41245-41257. doi: 10.1074/jbc.M112.409110

Jin, W. S., Shen, L. L., Bu, X. L., Zhang, W. W., Chen, S. H., Huang, Z. L., et al. (2017). Peritoneal dialysis reduces amyloid-beta plasma levels in humans and attenuates Alzheimer-associated phenotypes in an APP/PS1 mouse model. Acta Neuropathol. 134, 207-220. doi: 10.1007/s00401-017-1721-y

Johnson, A. E., Jeppsson, F., Sandell, J., Wensbo, D., Neelissen, J. A., Jureus, A., et al. (2009). AZD2184: a radioligand for sensitive detection of beta-amyloid deposits. J. Neurochem. 108, 1177-1186. doi: 10.1111/j.1471-4159.2008.05861.x

Johnson, K. A., Fox, N. C., Sperling, R. A., and Klunk, W. E. (2012). Brain imaging in Alzheimer disease. Cold Spring Harb. Perspect. Med. 2, a006213. doi: 10.1101/cshperspect.a006213

Johnson, V. E., Stewart, W., and Smith, D. H. (2010). Traumatic brain injury and amyloid- $\beta$ pathology: a link to Alzheimer's disease? Nat. Rev. Neurosci. 11, 361-370. doi: 10.1038/nrn2808

Jürgen, M. K., Milan, M., and George, P. (2016). Atlas of the Human Brain, 4th Edn. Cambridge, MA: Academic Press.

Kanai, M., Matsubara, E., Isoe, K., Urakami, K., Nakashima, K., Arai, H., et al. (1998). Longitudinal study of cerebrospinal fluid levels of tau, A beta1-40, and
A beta1-42(43) in Alzheimer's disease: a study in Japan. Ann. Neurol. 44, 17-26. doi: 10.1002/ana.410440108

Kaneko, N., Nakamura, A., Washimi, Y., Kato, T., Sakurai, T., Arahata, Y., et al. (2014). Novel plasma biomarker surrogating cerebral amyloid deposition. Proc. JPN Acad. Ser. B Phys. Biol. Sci. 90, 353-364. doi: 10.2183/pjab.90.353

Karelina, T., Demin, O., Nicholas, T., Lu, Y., Duvvuri, S., and Barton, H. A. (2017). A translational systems pharmacology model for abeta kinetics in mouse, monkey, and human. CPT Pharmacometrics Syst. Pharmacol. 6, 666-675. doi: 10.1002/psp4.12211

Karimy, J. K., Kahle, K. T., Kurland, D. B., Yu, E., Gerzanich, V., and Simard, J. M. (2015). A novel method to study cerebrospinal fluid dynamics in rats. J. Neurosci. Methods 241, 78-84. doi: 10.1016/j.jneumeth.2014.12.015

Kaufman, S. K., Thomas, T. L., Del Tredici, K., Braak, H., and Diamond, M. I. (2017). Characterization of tau prion seeding activity and strains from formaldehyde-fixed tissue. Acta Neuropathol. Commun. 5:41. doi: 10.1186/ s40478-017-0442-8

Kawarabayashi, T., Younkin, L. H., Saido, T. C., Shoji, M., Ashe, K. H., and Younkin, S. G. (2001). Age-dependent changes in brain, CSF, and plasma amyloid (beta) protein in the Tg2576 transgenic mouse model of Alzheimer's disease. J. Neurosci. 21, 372-381.

Keene, C. D., Darvas, M., Kraemer, B., Liggitt, D., Sigurdson, C., and Ladiges, W. (2016). Neuropathological assessment and validation of mouse models for Alzheimer's disease: applying NIA-AA guidelines. Pathobiol. Aging Age Relat. Dis. 6:32397. doi: 10.3402/pba.v6.32397

Kehr, J. (1999). "Monitoring chemistry of brain microenvironment: biosensors, microdialysis and related techniques," in Modern Techniques in Neuroscience Research, U. Windhorst, and H. Johansson, (Heidelberg: Springer-Verlag) 41, 1149-1198.

Kennedy, M. E., Stamford, A. W., Chen, X., Cox, K., Cumming, J. N., Dockendorf, M. F., et al. (2016). The BACE1 inhibitor verubecestat (MK-8931) reduces CNS beta-amyloid in animal models and in Alzheimer's disease patients. Sci. Transl. Med. 8:363ra150. doi: 10.1126/scitranslmed.aad9704

Khan, S. S., and Bloom, G. S. (2016). Tau: the center of a signaling nexus in Alzheimer's disease. Front. Neurosci. 10:31. doi: 10.3389/fnins.2016.00031

Kim, H. D., Tahara, K., Maxwell, J. A., Lalonde, R., Fukuiwa, T., Fujihashi, K., et al. (2007). Nasal inoculation of an adenovirus vector encoding 11 tandem repeats of Abeta1-6 upregulates IL-10 expression and reduces amyloid load in a Mo/Hu APPswe PS1dE9 mouse model of Alzheimer's disease. J. Gene Med. 9, 88-98. doi: $10.1002 /$ jgm. 993

Kitazawa, M., Yamasaki, T. R., and LaFerla, F. M. (2004). Microglia as a potential bridge between the amyloid beta-peptide and tau. Ann. N. Y. Acad. Sci. 1035, 85-103. doi: 10.1196/annals.1332.006

Kleinberger, G., Yamanishi, Y., Suarez-Calvet, M., Czirr, E., Lohmann, E., Cuyvers, E., et al. (2014). TREM2 mutations implicated in neurodegeneration impair cell surface transport and phagocytosis. Sci. Transl. Med. 6:243ra286. doi: 10.1126/ scitranslmed.3009093

Klunk, W. E., Engler, H., Nordberg, A., Wang, Y., Blomqvist, G., Holt, D. P., et al. (2004). Imaging brain amyloid in Alzheimer's disease with pittsburgh compound-B. Ann. Neurol. 55, 306-319. doi: 10.1002/ana. 20009

Komatsu, M., Waguri, S., Chiba, T., Murata, S., Iwata, J., Tanida, I., et al. (2006). Loss of autophagy in the central nervous system causes neurodegeneration in mice. Nature 441, 880-884. doi: 10.1038/nature04723

Kounnas, M. Z., Lane-Donovan, C., Nowakowski, D. W., Herz, J., and Comer, W. T. (2017). NGP 555, a gamma-secretase modulator, lowers the amyloid biomarker, Abeta42, in cerebrospinal fluid while preventing alzheimer's disease cognitive decline in rodents. Alzheimers Dement. 3, 65-73. doi: 10.1016/j.trci. 2016.09.003

Krzyzanowska, A., and Carro, E. (2012). Pathological alteration in the choroid plexus of alzheimer's disease: implication for new therapy approaches. Front. Pharmacol. 3:75. doi: 10.3389/fphar.2012.00075

Kuhl, D. E., Metter, E. J., Riege, W. H., and Phelps, M. E. (1982). Effects of human aging on patterns of local cerebral glucose utilization determined by the [18F]fluorodeoxyglucose method. J. Cereb. Blood Flow Metab. 2, 163-171. doi: $10.1038 / \mathrm{jcbfm} .1982 .15$

Kuhle, J., Barro, C., Andreasson, U., Derfuss, T., Lindberg, R., Sandelius, A., et al. (2016). Comparison of three analytical platforms for quantification of the neurofilament light chain in blood samples: eLISA, electrochemiluminescence 
immunoassay and Simoa. Clin. Chem. Lab. Med. 54, 1655-1661. doi: 10.1515/ cclm-2015-1195

Kuhle, J., Gaiottino, J., Leppert, D., Petzold, A., Bestwick, J. P., Malaspina, A., et al. (2015). Serum neurofilament light chain is a biomarker of human spinal cord injury severity and outcome. J. Neurol. Neurosurg. 86:273. doi: 10.1136/jnnp2013-307454

Kummer, M. P., Vogl, T., Axt, D., Griep, A., Vieira-Saecker, A., Jessen, F., et al. (2012). Mrp14 deficiency ameliorates amyloid beta burden by increasing microglial phagocytosis and modulation of amyloid precursor protein processing. J. Neurosci. 32, 17824-17829. doi: 10.1523/jneurosci.150412.2012

LaFerla, F. M., Green, K. N., and Oddo, S. (2007). Intracellular amyloid-beta in Alzheimer's disease. Nat. Rev. Neurosci. 8, 499-509. doi: 10.1038/nrn2168

Landau, S. M., Mintun, M. A., Joshi, A. D., Koeppe, R. A., Petersen, R. C., Aisen, P. S., et al. (2012). Amyloid deposition, hypometabolism, and longitudinal cognitive decline. Ann. Neurol. 72, 578-586. doi: 10.1002/ana.23650

Lautrup, S., Sinclair, D. A., Mattson, M. P., and Fang, E. F. (2019). NAD(+) in brain aging and neurodegenerative disorders. Cell Metab. 30, 630-655. doi: 10.1016/j.cmet.2019.09.001

Leclerc, B., and Abulrob, A. (2013). Perspectives in molecular imaging using staging biomarkers and immunotherapies in Alzheimer's disease. Sci. World J. 2013:589308.

Lee, E. O., Yang, J. H., Chang, K. A., Suh, Y. H., and Chong, Y. H. (2013). Amyloid-beta peptide-induced extracellular S100A9 depletion is associated with decrease of antimicrobial peptide activity in human THP-1 monocytes. J. Neuroinflammation 10:68. doi: 10.1186/1742-2094-10-68

Lee, J. C., Kim, S. J., Hong, S., and Kim, Y. (2019). Diagnosis of Alzheimer's disease utilizing amyloid and tau as fluid biomarkers. Exp. Mol. Med. 51, 1-10. doi: 10.1038/s12276-019-0250-2

Lee, S., Varvel, N. H., Konerth, M. E., Xu, G., Cardona, A. E., Ransohoff, R. M., et al. (2010). CX3CR1 deficiency alters microglial activation and reduces betaamyloid deposition in two Alzheimer's disease mouse models. Am. J. Pathol. 177, 2549-2562. doi: 10.2353/ajpath.2010.100265

Lee, V. M., and Trojanowski, J. Q. (2001). Transgenic mouse models of tauopathies: prospects for animal models of Pick's disease. Neurology 56, S26-S30. doi: 10.1212/wnl.56.suppl_4.s26

Leidinger, P., Backes, C., Deutscher, S., Schmitt, K., Mueller, S. C., Frese, K., et al. (2013). A blood based 12-miRNA signature of Alzheimer disease patients. Genome. Biol. 14, R78. doi: 10.1186/gb-2013-14-7-r78

Leinenbach, A., Pannee, J., Dulffer, T., Huber, A., Bittner, T., Andreasson, U., et al. (2014). Mass spectrometry-based candidate reference measurement procedure for quantification of amyloid-beta in cerebrospinal fluid. Clin. Chem. 60, 987-994. doi: 10.1373/clinchem.2013.220392

Leinonen, V., Pemberton, D., Van Der Ark, P., Timmers, M., Slemmon, J. R., Janssens, L., et al. (2019). P1-257: longitudinal comparison of Csf biomarkers of neurodegeneration in patients with probable idiopathic normal pressure hydrocephalus (INPH). Alzheimers Dement. 15, 337-338. doi: 10.1016/j.jalz. 2019.06.812

Leitão, M. J., Baldeiras, I., Herukka, S.-K., Pikkarainen, M., Leinonen, V., Simonsen, A. H., et al. (2015). Chasing the effects of pre-analytical confounders - a multicenter study on CSF-AD biomarkers. Front. Neurol. 6:153. doi: 10.3389/fneur.2015.00153

Leuzy, A., Chiotis, K., Hasselbalch, S. G., Rinne, J. O., de Mendonca, A., Otto, M., et al. (2016). Pittsburgh compound B imaging and cerebrospinal fluid amyloidbeta in a multicentre European memory clinic study. Brain 139, 2540-2553. doi: 10.1093/brain/aww160

Leuzy, A., Chiotis, K., Lemoine, L., Gillberg, P. G., Almkvist, O., RodriguezVieitez, E., et al. (2019). Tau PET imaging in neurodegenerative tauopathiesstill a challenge. Mol. Psychiatry 24, 1112-1134. doi: 10.1038/s41380-0180342-8

Lewczuk, P., Ermann, N., Andreasson, U., Schultheis, C., Podhorna, J., Spitzer, P., et al. (2018). Plasma neurofilament light as a potential biomarker of neurodegeneration in Alzheimer's disease. Alzheimers Res. Ther. 10:71. doi: 10.1186/s13195-018-0404-9

Lewczuk, P., Esselmann, H., Bibl, M., Beck, G., Maler, J. M., Otto, M., et al. (2004). Tau protein phosphorylated at threonine 181 in CSF as a neurochemical biomarker in Alzheimer's disease: original data and review of the literature. J. Mol. Neurosci. 23, 115-122. doi: 10.1385/jmn:23:1-2:115
Lewczuk, P., Lelental, N., Lachmann, I., Holzer, M., Flach, K., Brandner, S., et al. (2017). Non-phosphorylated tau as a potential biomarker of Alzheimer's disease: analytical and diagnostic characterization. J. Alzheimers Dis. 55, 159170. doi: 10.3233/JAD-160448

Li, G., Chen, H., Cheng, L., Zhao, R., Zhao, J., and Xu, Y. (2014). Amyloid precursor-like protein 2 C-terminal fragments upregulate S100A9 gene and protein expression in BV2 cells. Neural Regen. Res. 9, 1923-1928. doi: 10.4103/ 1673-5374.145362

Lista, S., Toschi, N., Baldacci, F., Zetterberg, H., Blennow, K., Kilimann, I., et al. (2017). Diagnostic accuracy of CSF neurofilament light chain protein in the biomarker-guided classification system for Alzheimer's disease. Neurochem. Int. 108, 355-360. doi: 10.1016/j.neuint.2017.05.010

Liu, C. C., Hu, J., Zhao, N., Wang, J., Wang, N., Cirrito, J. R., et al. (2017). Astrocytic LRP1 mediates brain abeta clearance and impacts amyloid deposition. J. Neurosci. 37, 4023-4031. doi: 10.1523/jneurosci.3442-16.2017

Liu, L., and Duff, K. (2008). A technique for serial collection of cerebrospinal fluid from the cisterna magna in mouse. J. Vis. Exp. 960. doi: 10.3791/960

Liu, L., Herukka, S. K., Minkeviciene, R., van Groen, T., and Tanila, H. (2004). Longitudinal observation on CSF Abeta42 levels in young to middle-aged amyloid precursor protein/presenilin-1 doubly transgenic mice. Neurobiol. Dis. 17, 516-523. doi: 10.1016/j.nbd.2004.08.005

Liu, Y. H., Giunta, B., Zhou, H. D., Tan, J., and Wang, Y. J. (2012). Immunotherapy for Alzheimer disease: the challenge of adverse effects. Nat. Rev. Neurol. 8, 465-469. doi: 10.1038/nrneurol.2012.118

Lodeiro, M., Puerta, E., Ismail, M. A., Rodriguez-Rodriguez, P., Ronnback, A., Codita, A., et al. (2017). Aggregation of the inflammatory S100A8 precedes abeta plaque formation in transgenic APP mice: positive feedback for S100A8 and abeta productions. J. Gerontol. A Biol. Sci. Med. Sci. 72, 319-328. doi: 10.1093/gerona/glw073

Lucey, B. P., Hicks, T. J., McLeland, J. S., Toedebusch, C. D., Boyd, J., Elbert, D. L., et al. (2018). Effect of sleep on overnight cerebrospinal fluid amyloid beta kinetics. Ann. Neurol. 83, 197-204. doi: 10.1002/ana.25117

Lue, L. F., Kuo, Y. M., Roher, A. E., Brachova, L., Shen, Y., Sue, L., et al. (1999). Soluble amyloid beta peptide concentration as a predictor of synaptic change in Alzheimer's disease. Am. J. Pathol. 155, 853-862. doi: 10.1016/s0002-9440(10) 65184- $\mathrm{x}$

Maass, A., Landau, S., Baker, S. L., Horng, A., Lockhart, S. N., La Joie, R., et al. (2017). Comparison of multiple tau-PET measures as biomarkers in aging and Alzheimer's disease. Neuroimage 157, 448-463. doi: 10.1016/j.neuroimage.2017. 05.058

Maciejewski-Lenoir, D., Chen, S., Feng, L., Maki, R., and Bacon, K. B. (1999). Characterization of fractalkine in rat brain cells: migratory and activation signals for CX3CR-1-expressing microglia. J. Immunol. 163, 1628-1635.

Maphis, N., Xu, G., Kokiko-Cochran, O. N., Jiang, S., Cardona, A., Ransohoff, R. M., et al. (2015). Reactive microglia drive tau pathology and contribute to the spreading of pathological tau in the brain. Brain 138, 1738-1755. doi: 10.1093/brain/awv081

Márquez, F., and Yassa, M. A. (2019). Neuroimaging biomarkers for Alzheimer's disease. Mol. Neurodegener. 14:21. doi: 10.1186/s13024-019-0325-5

Matsumoto, K., Chiba, Y., Fujihara, R., Kubo, H., Sakamoto, H., and Ueno, M. (2015). Immunohistochemical analysis of transporters related to clearance of amyloid- $\beta$ peptides through blood-cerebrospinal fluid barrier in human brain. Histochem. Cell Biol. 144, 597-611. doi: 10.1007/s00418-015-1366-7

Mattsson, N., Andreasson, U., Persson, S., Arai, H., Batish, S. D., Bernardini, S., et al. (2011). The Alzheimer's Association external quality control program for cerebrospinal fluid biomarkers. Alzheimers Dement. 7, 386.e6-395.e6. doi: 10.1016/j.jalz.2011.05.2243

Mattsson, N., Andreasson, U., Zetterberg, H., and Blennow, K. (2017a). Association of plasma neurofilament light with neurodegeneration in patients with Alzheimer disease. JAMA Neurol. 74, 557-566. doi: 10.1001/jamaneurol.2016. 6117

Mattsson, N., Cullen, N. C., Andreasson, U., Zetterberg, H., and Blennow, K. (2019). Association between longitudinal plasma neurofilament light and neurodegeneration in patients with Alzheimer disease. JAMA Neurol. 76, 791799. doi: 10.1001/jamaneurol.2019.0765

Mattsson, N., Scholl, M., Strandberg, O., Smith, R., Palmqvist, S., Insel, P. S., et al. (2017b). (18)F-AV-1451 and CSF T-tau and P-tau as biomarkers in Alzheimer's disease. EMBO Mol. Med. 9, 1212-1223. doi: 10.15252/emmm.201707809 
Mattsson, N., Zetterberg, H., Janelidze, S., Insel, P. S., Andreasson, U., Stomrud, E., et al. (2016). Plasma tau in Alzheimer disease. Neurology 87, 1827-1835. doi: $10.1212 / \mathrm{wnl} .0000000000003246$

McConlogue, L., Buttini, M., Anderson, J. P., Brigham, E. F., Chen, K. S., Freedman, S. B., et al. (2007). Partial reduction of BACE1 has dramatic effects on Alzheimer plaque and synaptic pathology in APP Transgenic Mice. J. Biol. Chem. 282, 26326-26334. doi: 10.1074/jbc.M611687200

McDonald, R. J., and White, N. M. (1993). A triple dissociation of memory systems: hippocampus, amygdala, and dorsal striatum. Behav. Neurosci. 107, 3-22. doi: 10.1037//0735-7044.107.1.3

McGeer, P. L., Itagaki, S., Tago, H., and McGeer, E. G. (1987). Reactive microglia in patients with senile dementia of the Alzheimer type are positive for the histocompatibility glycoprotein HLA-DR. Neurosci. Lett. 79, 195-200. doi: 10. 1016/0304-3940(87)90696-3

McLean, C. A., Cherny, R. A., Fraser, F. W., Fuller, S. J., Smith, M. J., Beyreuther, K., et al. (1999). Soluble pool of Abeta amyloid as a determinant of severity of neurodegeneration in Alzheimer's disease. Ann. Neurol. 46, 860-866. doi: 10.1002/1531-8249(199912)46:6<860::aid-ana8<3.0.co;2-m

Mehrpour, M., Esclatine, A., Beau, I., and Codogno, P. (2010). Overview of macroautophagy regulation in mammalian cells. Cell Res. 20, 748-762. doi: $10.1038 / \mathrm{cr} .2010 .82$

Mehta, P. D., Pirttila, T., Patrick, B. A., Barshatzky, M., and Mehta, S. P. (2001). Amyloid beta protein 1-40 and 1-42 levels in matched cerebrospinal fluid and plasma from patients with Alzheimer disease. Neurosci. Lett. 304, 102-106. doi: 10.1016/s0304-3940(01)01754-2

Menendez-Gonzalez, M., Padilla-Zambrano, H. S., Alvarez, G., Capetillo-Zarate, E., Tomas-Zapico, C., and Costa, A. (2018). Targeting beta-amyloid at the CSF: a new therapeutic strategy in Alzheimer's disease. Front. Aging Neurosci. 10:100. doi: 10.3389/fnagi.2018.00100

Mennicken, F., Maki, R., de Souza, E. B., and Quirion, R. (1999). Chemokines and chemokine receptors in the CNS: a possible role in neuroinflammation and patterning. Trends Pharmacol. Sci. 20, 73-78. doi: 10.1016/s0165-6147(99) 01308-5

Menzies, F. M., Fleming, A., and Rubinsztein, D. C. (2015). Compromised autophagy and neurodegenerative diseases. Nat. Rev. Neurosci. 16, 345-357. doi: 10.1038/nrn3961

Meyding-Lamadé, U., Ehrhart, K., de Ruiz, H. L., Kehm, R., and Lamadé, W. A. (1996). new technique: serial puncture of the cisterna magna for obtaining cerebrospinal fluid in the mouse-application in a model of herpes simplex virus encephalitis. J. Exp. Anim. Sci. 38, 77-81.

Milisav, I., Šuput, D., and Ribariè, S. (2015). Unfolded protein response and macroautophagy in Alzheimer's, Parkinson's and Prion diseases. Molecules 20, 22718-22756.

Molinuevo, J. L., Ayton, S., Batrla, R., Bednar, M. M., Bittner, T., Cummings, J., et al. (2018). Current state of Alzheimer's fluid biomarkers. Acta Neuropathol. 136, 821-853. doi: 10.1007/s00401-0181932-x

Mollenhauer, B., Bibl, M., Trenkwalder, C., Stiens, G., Cepek, L., Steinacker, P., et al. (2005). Follow-up investigations in cerebrospinal fluid of patients with dementia with Lewy bodies and Alzheimer's disease. J. Neural. Transm. 112, 933-948. doi: 10.1007/s00702-004-0235-7

Mori, T., Koyama, N., Arendash, G. W., Horikoshi-Sakuraba, Y., Tan, J., and Town, T. (2010). Overexpression of human S100B exacerbates cerebral amyloidosis and gliosis in the Tg2576 mouse model of Alzheimer's disease. Glia 58, 300-314. doi: 10.1002/glia.20924

Mosconi, L., Tsui, W. H., De Santi, S., Li, J., Rusinek, H., Convit, A., et al. (2005). Reduced hippocampal metabolism in MCI and AD: automated FDG-PET image analysis. Neurology 64, 1860-1867. doi: 10.1212/01.Wnl.0000163856. 13524.08

Mosconi, L., Tsui, W. H., Herholz, K., Pupi, A., Drzezga, A., Lucignani, G., et al. (2008). Multicenter standardized 18F-FDG PET diagnosis of mild cognitive impairment, Alzheimer's disease, and other dementias. J. Nucl. Med. 49, 390398. doi: 10.2967/jnumed.107.045385

Mucke, L., and Selkoe, D. J. (2012). Neurotoxicity of amyloid beta-protein: synaptic and network dysfunction. Cold Spring Harb. Perspect. Med. 2:a006338. doi: $10.1101 /$ cshperspect.a006338
Mudher, A., Colin, M., Dujardin, S., Medina, M., Dewachter, I., Alavi Naini, S. M., et al. (2017). What is the evidence that tau pathology spreads through prionlike propagation? Acta Neuropathol. Commun. 5:99. doi: 10.1186/s40478-0170488-7

Murphy, M. P., and LeVine, H. III (2010). Alzheimer's disease and the amyloid-beta peptide. J. Alzheimers Dis. 19, 311-323. doi: 10.3233/JAD-2010-1221

Musiek, E. S., and Holtzman, D. M. (2015). Three dimensions of the amyloid hypothesis: time, space and 'wingmen'. Nat. Neurosci. 18, 800-806. doi: 10.1038/ nn.4018

Naggara, O., Oppenheim, C., Rieu, D., Raoux, N., Rodrigo, S., Dalla Barba, G., et al. (2006). Diffusion tensor imaging in early Alzheimer's disease. Psychiatry Res. 146, 243-249. doi: 10.1016/j.pscychresns.2006.01.005

Nakamura, T., Shoji, M., Harigaya, Y., Watanabe, M., Hosoda, K., Cheung, T. T., et al. (1994). Amyloid beta protein levels in cerebrospinal fluid are elevated in early-onset Alzheimer's disease. Ann. Neurol. 36, 903-911. doi: 10.1002/ana. 410360616

Narasimhan, S., Guo, J. L., Changolkar, L., Stieber, A., McBride, J. D., Silva, L. V., et al. (2017). Pathological Tau strains from human brains recapitulate the diversity of tauopathies in nontransgenic mouse brain. J. Neurosci. 37, 11406-11423. doi: 10.1523/jneurosci.1230-17.2017

Nash, K. R., Lee, D. C., Hunt, J. B. Jr., Morganti, J. M., Selenica, M. L., Moran, P., et al. (2013). Fractalkine overexpression suppresses tau pathology in a mouse model of tauopathy. Neurobiol. Aging 34, 1540-1548. doi: 10.1016/j. neurobiolaging.2012.12.011

Naslund, J., Haroutunian, V., Mohs, R., Davis, K. L., Davies, P., Greengard, P., et al. (2000). Correlation between elevated levels of amyloid beta-peptide in the brain and cognitive decline. Jama 283, 1571-1577. doi: 10.1001/jama.283.12.1571

Neselius, S., Brisby, H., Theodorsson, A., Blennow, K., Zetterberg, H., and Marcusson, J. (2012). CSF-Biomarkers in olympic boxing: diagnosis and effects of repetitive head trauma. PLoS One 7:e33606. doi: 10.1371/journal.pone. 0033606

Niemantsverdriet, E., Ottoy, J., Somers, C., De Roeck, E., Struyfs, H., Soetewey, F., et al. (2017). The Cerebrospinal fluid abeta1-42/Abetal-40 ratio improves concordance with amyloid-PET for diagnosing Alzheimer's disease in a clinical setting. J. Alzheimers Dis. 60, 561-576. doi: 10.3233/jad-170327

Nisbet, R. M., Polanco, J. C., Ittner, L. M., and Gotz, J. (2015). Tau aggregation and its interplay with amyloid-beta. Acta Neuropathol. 129, 207-220. doi: 10.1007/ s00401-014-1371-2

Nixon, R. A., and Yang, D. S. (2011). Autophagy failure in Alzheimer's diseaselocating the primary defect. Neurobiol. Dis. 43, 38-45. doi: 10.1016/j.nbd.2011. 01.021

Nussbaum, J. M., Seward, M. E., and Bloom, G. S. (2013). Alzheimer disease: a tale of two prions. Prion 7, 14-19. doi: 10.4161/pri.22118

Oddo, S., Caccamo, A., Shepherd, J. D., Murphy, M. P., Golde, T. E., Kayed, R., et al. (2003). Triple-transgenic model of Alzheimer's disease with plaques and tangles. Neuron 39, 409-421. doi: 10.1016/s0896-6273(03)00434-3

Oh, E. S., Mielke, M. M., Rosenberg, P. B., Jain, A., Fedarko, N. S., Lyketsos, C. G., et al. (2010). Comparison of conventional ELISA with electrochemiluminescence technology for detection of amyloid-beta in plasma. J Alzheimers Dis. 21, 769-773. doi: 10.3233/jad-2010-100456

Ohno, M., Cole, S. L., Yasvoina, M., Zhao, J., Citron, M., Berry, R., et al. (2007). BACE1 gene deletion prevents neuron loss and memory deficits in 5XFAD APP/PS1 transgenic mice. Neurobiol. Dis. 26, 134-145. doi: 10.1016/j.nbd.2006. 12.008

Öhrfelt, A., Brinkmalm, A., Dumurgier, J., Brinkmalm, G., Hansson, O., Zetterberg, H., et al. (2016). The pre-synaptic vesicle protein synaptotagmin is a novel biomarker for Alzheimer's disease. Alzheimers Res. Ther. 8:41. doi: 10.1186/ s13195-016-0208-8

Olsson, B., Lautner, R., Andreasson, U., Öhrfelt, A., Portelius, E., Bjerke, M., et al. (2016). CSF and blood biomarkers for the diagnosis of Alzheimer's disease: a systematic review and meta-analysis. Lancet Neurol. 15, 673-684. doi: 10.1016/ s1474-4422(16)00070-3

Olsson, F., Schmidt, S., Althoff, V., Munter, L. M., Jin, S., Rosqvist, S., et al. (2014). Characterization of intermediate steps in amyloid beta (Abeta) production under near-native conditions. J. Biol. Chem. 289, 1540-1550. doi: 10.1074/jbc. M113.498246 
Pahnke, J., Langer, O., and Krohn, M. (2014). Alzheimer's and ABC transporters new opportunities for diagnostics and treatment. Neurobiol. Dis. 72, 54-60. doi: 10.1016/j.nbd.2014.04.001

Palmqvist, S., Insel, P. S., Stomrud, E., Janelidze, S., Zetterberg, H., Brix, B., et al. (2019). Cerebrospinal fluid and plasma biomarker trajectories with increasing amyloid deposition in Alzheimer's disease. EMBO Mol. Med. 11:e11170. doi: 10.15252/emmm.201911170

Palmqvist, S., Mattsson, N., and Hansson, O. (2016). Cerebrospinal fluid analysis detects cerebral amyloid-beta accumulation earlier than positron emission tomography. Brain 139, 1226-1236. doi: 10.1093/brain/aww015

Palmqvist, S., Schöll, M., Strandberg, O., Mattsson, N., Stomrud, E., Zetterberg, H., et al. (2017). Earliest accumulation of $\beta$-amyloid occurs within the default-mode network and concurrently affects brain connectivity. Nat. Commun. 8:1214. doi: 10.1038/s41467-017-01150-x

Pase, M. P., Beiser, A. S., Himali, J. J., Satizabal, C. L., Aparicio, H. J., DeCarli, C., et al. (2019). Assessment of plasma total tau level as a predictive biomarker for dementia and related endophenotypes. JAMA Neurol. 76, 598-606. doi: 10.1001/jamaneurol.2018.4666

Perea, J. R., Lleó, A., Alcolea, D., Fortea, J., Ávila, J., and Bolós, M. (2018). Decreased CX3CL1 levels in the cerebrospinal fluid of patients with Alzheimer's disease. Front. Neurosci. 12:609. doi: 10.3389/fnins.2018.00609

Perret-Liaudet, A., Pelpel, M., Tholance, Y., Dumont, B., Vanderstichele, H., Zorzi, W., et al. (2012a). Cerebrospinal fluid collection tubes: a critical issue for Alzheimer disease diagnosis. Clin. Chem. 58, 787-789. doi: 10.1373/clinchem. 2011.178368

Perret-Liaudet, A., Pelpel, M., Tholance, Y., Dumont, B., Vanderstichele, H., Zorzi, W., et al. (2012b). Risk of Alzheimer's disease biological misdiagnosis linked to cerebrospinal collection tubes. J. Alzheimers Dis. 31, 13-20. doi: 10.3233/jad2012-120361

Peters, A., Leahu, D., Moss, M. B., and McNally, K. J. (1994). The effects of aging on area 46 of the frontal cortex of the rhesus monkey. Cereb. Cortex 4, 621-635. doi: $10.1093 /$ cercor/4.6.621

Peterson, D. A., Lucidi-Phillipi, C. A., Eagle, K. L., and Gage, F. H. (1994). Perforant path damage results in progressive neuronal death and somal atrophy in layer II of entorhinal cortex and functional impairment with increasing postdamage age. J. Neurosci. 14, 6872-6885. doi: 10.1523/JNEUROSCI.14-11-06872.1994

Petzold, A. (2005). Neurofilament phosphoforms: surrogate markers for axonal injury, degeneration and loss. J. Neurol. Sci. 233, 183-198. doi: 10.1016/j.jns. 2005.03.015

Pijnenburg, Y. A., Janssen, J. C., Schoonenboom, N. S., Petzold, A., Mulder, C., Stigbrand, T., et al. (2007). CSF neurofilaments in frontotemporal dementia compared with early onset Alzheimer's disease and controls. Dement. Geriatr. Cogn. Disord. 23, 225-230. doi: 10.1159/000099473

Pitschke, M., Prior, R., Haupt, M., and Riesner, D. (1998). Detection of single amyloid $\beta$-protein aggregates in the cerebrospinal fluid of Alzheimer's patients by fluorescence correlation spectroscopy. Nat. Med. 4, 832-834. doi: 10.1038/ nm0798-832

Pratico, D., Uryu, K., Leight, S., Trojanoswki, J. Q., and Lee, V. M. (2001). Increased lipid peroxidation precedes amyloid plaque formation in an animal model of Alzheimer amyloidosis. J. Neurosci. 21, 4183-4187.

Pulawski, W., Ghoshdastider, U., Andrisano, V., and Filipek, S. (2012). Ubiquitous amyloids. Appl. Biochem. Biotechnol. 166, 1626-1643. doi: 10.1007/s12010-0129549-3

Pyykkö, O. T., Lumela, M., Rummukainen, J., Nerg, O., Seppälä, T. T., Herukka, S.-K., et al. (2014). Cerebrospinal fluid biomarker and brain biopsy findings in idiopathic normal pressure hydrocephalus. PLoS One 9:e91974. doi: 10.1371/ journal.pone.0091974

Qin, W., Ho, L., Wang, J., Peskind, E., and Pasinetti, G. M. (2009). S100A7, a novel Alzheimer's disease biomarker with non-amyloidogenic alpha-secretase activity acts via selective promotion of ADAM-10. PLoS One 4:e4183. doi: 10.1371/journal.pone.0004183

Querol-Vilaseca, M., Colom-Cadena, M., Pegueroles, J., San Martin-Paniello, C., Clarimon, J., Belbin, O., et al. (2017). YKL-40 (Chitinase 3-like I) is expressed in a subset of astrocytes in Alzheimer's disease and other tauopathies. J. Neuroinflammation 14:118. doi: 10.1186/s12974-017-0893-7

Raichle, M. E., MacLeod, A. M., Snyder, A. Z., Powers, W. J., Gusnard, D. A., and Shulman, G. L. (2001). A default mode of brain function. Proc. Natl. Acad. Sci. U.S.A. 98, 676-682. doi: 10.1073/pnas.98.2.676
Ramesh, S., Govindarajulu, M., Jones, E., Knowlton, S., Weeks, L., Suppiramaniam, V., et al. (2018a). Alzheimer's Disease and Treatment, Reno, NV: MedDocs Publishers.

Ramesh, S., Govindarajulu, M., Jones, E., Knowlton, S., Weeks, L., Suppiramaniam, V., et al. (2018b). Current and Novel Biomarkers for Alzheimer's Disease. Reno, NV: MedDocs Publishers LLC.

Rami, A. (2009). Review: autophagy in neurodegeneration: firefighter and/or incendiarist? Neuropathol. Appl. Neurobiol. 35, 449-461. doi: 10.1111/j.13652990.2009.01034.x

Ranganath, C., and Ritchey, M. (2012). Two cortical systems for memory-guided behaviour. Nat. Rev. Neurosci. 13, 713-726. doi: 10.1038/nrn3338

Rapp, P. R., and Gallagher, M. (1996). Preserved neuron number in the hippocampus of aged rats with spatial learning deficits. Proc. Natl. Acad. Sci. U.S.A. 93, 9926-9930. doi: 10.1073/pnas.93.18.9926

Rapp, P. R., Deroche, P. S., Mao, Y., and Burwell, R. D. (2002). Neuron number in the parahippocampal region is preserved in aged rats with spatial learning deficits. Cereb. Cortex 12, 1171-1179. doi: 10.1093/cercor/12.11.1171

Rasmussen, T., Schliemann, T., Sorensen, J. C., Zimmer, J., and West, M. J. (1996). Memory impaired aged rats: no loss of principal hippocampal and subicular neurons. Neurobiol. Aging 17, 143-147. doi: 10.1016/0197-4580(95)02032-2

Raz, N., Lindenberger, U., Rodrigue, K. M., Kennedy, K. M., Head, D., Williamson, A., et al. (2005). Regional brain changes in aging healthy adults: general trends, individual differences and modifiers. Cereb. Cortex 15, 1676-1689. doi: 10.1093/ cercor/bhi044

Rhein, V., Song, X., Wiesner, A., Ittner, L. M., Baysang, G., Meier, F., et al. (2009). Amyloid-beta and tau synergistically impair the oxidative phosphorylation system in triple transgenic Alzheimer's disease mice. Proc. Natl. Acad. Sci. U.S.A. 106, 20057-20062. doi: 10.1073/pnas.0905529106

Riekse, R. G., Li, G., Petrie, E. C., Leverenz, J. B., Vavrek, D., Vuletic, S., et al. (2006). Effect of statins on Alzheimer's disease biomarkers in cerebrospinal fluid. J. Alzheimers Dis. 10, 399-406. doi: 10.3233/JAD-2006-10408

Ringman, J. M., Coppola, G., Elashoff, D., Rodriguez-Agudelo, Y., Medina, L. D., Gylys, K., et al. (2012). Cerebrospinal fluid biomarkers and proximity to diagnosis in preclinical familial Alzheimer's disease. Dement. Geriatr. Cogn. Disord. 33, 1-5. doi: 10.1159/000335729

Ritter, A., and Cummings, J. (2015). Fluid biomarkers in clinical trials of alzheimer's disease therapeutics. Front. Neurol. 6:186. doi: 10.3389/fneur.2015.00186

Roe, C. M., Fagan, A. M., Grant, E. A., Hassenstab, J., Moulder, K. L., Maue Dreyfus, D., et al. (2013). Amyloid imaging and CSF biomarkers in predicting cognitive impairment up to 7.5 years later. Neurology 80, 1784-1791. doi: 10.1212/WNL. 0b013e3182918ca6

Rogeberg, M., Wettergreen, M., Nilsson, L. N., and Fladby, T. (2015). Identification of amyloid beta mid-domain fragments in human cerebrospinal fluid. Biochimie 113, 86-92. doi: 10.1016/j.biochi.2015.03.022

Rogers, J., Luber-Narod, J., Styren, S. D., and Civin, W. H. (1988). Expression of immune system-associated antigens by cells of the human central nervous system: relationship to the pathology of Alzheimer's disease. Neurobiol. Aging 9, 339-349. doi: 10.1016/s0197-4580(88)80079-4

Rohrer, J. D., Woollacott, I. O., Dick, K. M., Brotherhood, E., Gordon, E., Fellows, A., et al. (2016). Serum neurofilament light chain protein is a measure of disease intensity in frontotemporal dementia. Neurology 87, 1329-1336. doi: 10.1212/wnl.0000000000003154

Rojas, J. C., Karydas, A., Bang, J., Tsai, R. M., Blennow, K., Liman, V., et al. (2016). Plasma neurofilament light chain predicts progression in progressive supranuclear palsy. Ann. Clin. Transl. Neurol. 3, 216-225. doi: 10.1002/acn 3.290

Roltsch, E., Holcomb, L., Young, K. A., Marks, A., and Zimmer, D. B. (2010). PSAPP mice exhibit regionally selective reductions in gliosis and plaque deposition in response to S100B ablation. J. Neuroinflammation 7:78. doi: 10. 1186/1742-2094-7-78

Ryu, J. K., Cho, T., Choi, H. B., Wang, Y. T., and McLarnon, J. G. (2009). Microglial VEGF receptor response is an integral chemotactic component in Alzheimer's disease pathology. J. Neurosci. 29, 3-13. doi: 10.1523/jneurosci.2888-08.2009

Sabbagh, J. J., Kinney, J. W., and Cummings, J. L. (2013). Alzheimer's disease biomarkers in animal models: closing the translational gap. Am. J. Neurodegener. Dis. 2, 108-120.

Saman, S., Kim, W., Raya, M., Visnick, Y., Miro, S., Saman, S., et al. (2012). Exosome-associated tau is secreted in tauopathy models and is selectively 
phosphorylated in cerebrospinal fluid in early Alzheimer disease. J. Biol. Chem. 287, 3842-3849. doi: 10.1074/jbc.M111.277061

Sankaranarayanan, S., Holahan, M. A., Colussi, D., Crouthamel, M. C., Devanarayan, V., Ellis, J., et al. (2009). First demonstration of cerebrospinal fluid and plasma A beta lowering with oral administration of a beta-site amyloid precursor protein-cleaving enzyme 1 inhibitor in nonhuman primates. J. Pharmacol. Exp. Ther. 328, 131-140. doi: 10.1124/jpet.108.143628

Savage, M. J., Kalinina, J., Wolfe, A., Tugusheva, K., Korn, R., Cash-Mason, T., et al. (2014). A sensitive abeta oligomer assay discriminates Alzheimer's and aged control cerebrospinal fluid. J. Neurosci. 34, 2884-2897. doi: 10.1523/jneurosci. $1675-13.2014$

Schelle, J., Hasler, L. M., Gopfert, J. C., Joos, T. O., Vanderstichele, H., Stoops, E., et al. (2017). Prevention of tau increase in cerebrospinal fluid of APP transgenic mice suggests downstream effect of BACE1 inhibition. Alzheimers Dement. 13, 701-709. doi: 10.1016/j.jalz.2016.09.005

Scholl, M., Maass, A., Mattsson, N., Ashton, N. J., Blennow, K., Zetterberg, H., et al. (2019). Biomarkers for tau pathology. Mol. Cell Neurosci. 97, 18-33. doi: $10.1016 / j . m c n .2018 .12 .001$

Schöll, M., Schonhaut, D., Lockhart, S., Vogel, J. W., Baker, S., Schwimmer, H., et al. (2015). IC-01-05: in vivo braak staging using 18F-AV1451 Tau PET imaging. Alzheimers Dement. 11:P4. doi: 10.1016/j.jalz.2015.06.006

Schwagerl, A. L., Mohan, P. S., Cataldo, A. M., Vonsattel, J. P., Kowall, N. W., and Nixon, R. A. (1995). Elevated levels of the endosomal-lysosomal proteinase cathepsin D in cerebrospinal fluid in Alzheimer disease. J. Neurochem. 64, 443-446. doi: 10.1046/j.1471-4159.1995.64010443.x

Sedaghat, F., and Notopoulos, A. (2008). S100 protein family and its application in clinical practice. Hippokratia 12, 198-204.

Selkoe, D. J. (2001). Alzheimer's disease: genes, proteins, and therapy. Physiol. Rev. 81, 741-766. doi: 10.1152/physrev.2001.81.2.741

Seok, J., Warren, H. S., Cuenca, A. G., Mindrinos, M. N., Baker, H. V., Xu, W., et al. (2013). Genomic responses in mouse models poorly mimic human inflammatory diseases. Proc. Natl. Acad. Sci. U.S.A. 110, 3507-3512. doi: 10. 1073/pnas.1222878110

Serrano-Pozo, A., Frosch, M. P., Masliah, E., and Hyman, B. T. (2011). Neuropathological alterations in Alzheimer disease. Cold Spring Harb. Perspect. Med. 1:a006189. doi: 10.1101/cshperspect.a006189

Sheline, Y. I., and Raichle, M. E. (2013). Resting state functional connectivity in preclinical Alzheimer's disease. Biol. Psychiatry 74, 340-347. doi: 10.1016/j. biopsych.2012.11.028

Shen, L., Xia, S., Zhang, H., Yao, F., Liu, X., Zhao, Y., et al. (2018). Precision Medicine: Role of Biomarkers in Early Prediction and Diagnosis of Alzheimer's Disease.London: IntechOpen.

Sheng, J. G., Mrak, R. E., and Griffin, W. S. (1994). S100 beta protein expression in Alzheimer disease: potential role in the pathogenesis of neuritic plaques. J. Neurosci. Res. 39, 398-404. doi: 10.1002/jnr.490390406

Sheng, J. G., Mrak, R. E., and Griffin, W. S. (1997). Glial-neuronal interactions in Alzheimer disease: progressive association of IL-1alpha+ microglia and S100beta+ astrocytes with neurofibrillary tangle stages. J. Neuropathol. Exp. Neurol. 56, 285-290.

Shepherd, C. E., Goyette, J., Utter, V., Rahimi, F., Yang, Z., Geczy, C. L., et al. (2006). Inflammatory S100A9 and S100A12 proteins in Alzheimer's disease. Neurobiol. Aging 27, 1554-1563. doi: 10.1016/j.neurobiolaging.2005.09.033

Sheridan, G. K., and Murphy, K. J. (2013). Neuron-glia crosstalk in health and disease: fractalkine and CX3CR1 take centre stage. Open Biol. 3:130181. doi: 10.1098/rsob.130181

Sidoryk-Wegrzynowicz, M., Gerber, Y. N., Ries, M., Sastre, M., Tolkovsky, A. M., and Spillantini, M. G. (2017). Astrocytes in mouse models of tauopathies acquire early deficits and lose neurosupportive functions. Acta Neuropathol. Commun. 5:89. doi: 10.1186/s40478-017$0478-9$

Sjogren, M., Blomberg, M., Jonsson, M., Wahlund, L. O., Edman, A., Lind, K., et al. (2001). Neurofilament protein in cerebrospinal fluid: a marker of white matter changes. J. Neurosci. Res. 66, 510-516. doi: 10.1002/jnr. 1242

Skachokova, Z., Martinisi, A., Flach, M., Sprenger, F., Naegelin, Y., Steiner-Monard, V., et al. (2019). Cerebrospinal fluid from Alzheimer's disease patients promotes tau aggregation in transgenic mice. Acta Neuropathol. Commun. 7:72. doi: $10.1186 /$ s40478-019-0725-3
Skoog, I., Davidsson, P., Aevarsson, Ó, Vanderstichele, H., Vanmechelen, E., and Blennow, K. (2003). Cerebrospinal fluid beta-amyloid 42 is reduced before the onset of sporadic dementia: a population-based study in 85 -year-olds. Dement. Geriatr. Cogn. Disord. 15, 169-176. doi: 10.1159/000068478

Smith, D. E., Rapp, P. R., McKay, H. M., Roberts, J. A., and Tuszynski, M. H. (2004). Memory impairment in aged primates is associated with focal death of cortical neurons and atrophy of subcortical neurons. J. Neurosci. 24, 4373-4381. doi: 10.1523/jneurosci.4289-03.2004

Smith, T. D., Adams, M. M., Gallagher, M., Morrison, J. H., and Rapp, P. R. (2000). Circuit-specific alterations in hippocampal synaptophysin immunoreactivity predict spatial learning impairment in aged rats. J. Neurosci. 20, 6587-6593. doi: 10.1523/JNEUROSCI.20-17-06587.2000

Speake, T., Whitwell, C., Kajita, H., Majid, A., and Brown, P. D. (2001). Mechanisms of CSF secretion by the choroid plexus. Microsc. Res. Tech. 52, 49-59. doi: 10.1002/1097-0029(20010101)52:1<49::AID-JEMT7<3.0.CO;2-C

Spector, R., Robert Snodgrass, S., and Johanson, C. E. (2015). A balanced view of the cerebrospinal fluid composition and functions: focus on adult humans. Exp. Neurol. 273, 57-68. doi: 10.1016/j.expneurol.2015.07.027

Sperling, R. A., Aisen, P. S., Beckett, L. A., Bennett, D. A., Craft, S., Fagan, A. M., et al. (2011). Toward defining the preclinical stages of Alzheimer's disease: recommendations from the National Institute on Aging-Alzheimer's Association workgroups on diagnostic guidelines for Alzheimer's disease. Alzheimers Dement. 7, 280-292. doi: 10.1016/j.jalz.2011.03.003

Stadtman, E. R., and Levine, R. L. (2003). Free radical-mediated oxidation of free amino acids and amino acid residues in proteins. Amino. Acids 25, 207-218. doi: 10.1007/s00726-003-0011-2

Steinacker, P., Blennow, K., Halbgebauer, S., Shi, S., Ruf, V., Oeckl, P., et al. (2016). Neurofilaments in blood and CSF for diagnosis and prediction of onset in Creutzfeldt-Jakob disease. Sci. Rep. 6:38737. doi: 10.1038/srep38737

Steinacker, P., Semler, E., Anderl-Straub, S., Diehl-Schmid, J., Schroeter, M. L., Uttner, I., et al. (2017). Neurofilament as a blood marker for diagnosis and monitoring of primary progressive aphasias. Neurology 88, 961-969. doi: 10. 1212/wnl.0000000000003688

Stomrud, E., Hansson, O., Zetterberg, H., Blennow, K., Minthon, L., and Londos, E. (2010). Correlation of longitudinal cerebrospinal fluid biomarkers with cognitive decline in healthy older adults. Arch. Neurol. 67, 217-223. doi: 10. 1001/archneurol.2009.316

Stranahan, A. M., Jiam, N. T., Spiegel, A. M., and Gallagher, M. (2012). Aging reduces total neuron number in the dorsal component of the rodent prefrontal cortex. J. Comp. Neurol. 520, 1318-1326. doi: 10.1002/cne.22790

Strozyk, D., Blennow, K., White, L. R., and Launer, L. J. (2003). CSF Abeta 42 levels correlate with amyloid-neuropathology in a population-based autopsy study. Neurology 60, 652-656. doi: 10.1212/01.wnl.0000046581.81650.d0

Suarez-Calvet, M., Kleinberger, G., Araque Caballero, M. A., Brendel, M., Rominger, A., Alcolea, D., et al. (2016). sTREM2 cerebrospinal fluid levels are a potential biomarker for microglia activity in early-stage Alzheimer's disease and associate with neuronal injury markers. EMBO Mol. Med. 8, 466-476. doi: 10.15252/emmm.201506123

Sudhof, T. C., and Rizo, J. (1996). Synaptotagmins: c2-domain proteins that regulate membrane traffic. Neuron 17, 379-388. doi: 10.1016/s0896-6273(00) 80171-3

Sunderland, T., Wolozin, B., Galasko, D., Levy, J., Dukoff, R., Bahro, M., et al. (1999). Longitudinal stability of CSF tau levels in Alzheimer patients. Biol. Psychiatry 46, 750-755. doi: 10.1016/s0006-3223(99)00143-2

Sunkin, S. M., Ng, L., Lau, C., Dolbeare, T., Gilbert, T. L., Thompson, C. L., et al. (2013). Allen Brain Atlas: an integrated spatio-temporal portal for exploring the central nervous system. Nucleic Acids Res. 41, D996-D1008. doi: 10.1093/nar/ gks1042

Sutherland, R. J., Kolb, B., and Whishaw, I. Q. (1982). Spatial mapping: definitive disruption by hippocampal or medial frontal cortical damage in the rat. Neurosci. Lett. 31, 271-276. doi: 10.1016/0304-3940(82)90032-5

Sutphen, C. L., McCue, L., Herries, E. M., Xiong, C., Ladenson, J. H., Holtzman, D. M., et al. (2018). Longitudinal decreases in multiple cerebrospinal fluid biomarkers of neuronal injury in symptomatic late onset Alzheimer's disease. Alzheimers Dement. 14, 869-879. doi: 10.1016/j.jalz.2018.01.012

Swarbrick, S., Wragg, N., Ghosh, S., and Stolzing, A. (2019). Systematic review of miRNA as biomarkers in Alzheimer's disease. Mol. Neurobiol. 56, 6156-6167. doi: 10.1007/s12035-019-1500-y 
Swardfager, W., Lanctot, K., Rothenburg, L., Wong, A., Cappell, J., and Herrmann, N. (2010). A meta-analysis of cytokines in Alzheimer's disease. Biol. Psychiatry 68, 930-941. doi: 10.1016/j.biopsych.2010.06.012

Sweetman, B., and Linninger, A. A. (2011). Cerebrospinal fluid flow dynamics in the central nervous system. Ann. Biomed. Eng. 39, 484-496. doi: 10.1007/ s10439-010-0141-0

Tagawa, K., Kunishita, T., Maruyama, K., Yoshikawa, K., Kominami, E., Tsuchiya, T., et al. (1991). Alzheimer's disease amyloid beta-clipping enzyme (APP secretase): identification, purification, and characterization of the enzyme. Biochem. Biophys. Res. Commun. 177, 377-387. doi: 10.1016/0006-291x(91) 91994- $\mathrm{n}$

Takeda, S., Commins, C., DeVos, S. L., Nobuhara, C. K., Wegmann, S., Roe, A. D., et al. (2016). Seed-competent high-molecular-weight tau species accumulates in the cerebrospinal fluid of Alzheimer's disease mouse model and human patients. Ann. Neurol. 80, 355-367. doi: 10.1002/ana.24716

Takeda, S., Sato, N., Ikimura, K., Nishino, H., Rakugi, H., and Morishita, R. (2011). Novel microdialysis method to assess neuropeptides and large molecules in free-moving mouse. Neuroscience 186, 110-119. doi: 10.1016/j.neuroscience. 2011.04.035

Tapiola, T., Alafuzoff, I., Herukka, S. K., Parkkinen, L., Hartikainen, P., Soininen, H., et al. (2009). Cerebrospinal fluid \{beta\}-amyloid 42 and tau proteins as biomarkers of Alzheimer-type pathologic changes in the brain. Arch. Neurol. 66, 382-389. doi: 10.1001/archneurol.2008.596

Tapiola, T., Pirttilä, T., Mikkonen, M., Mehta, P. D., Alafuzoff, I., Koivisto, K., et al. (2000). Three-year follow-up of cerebrospinal fluid tau, beta-amyloid 42 and 40 concentrations in Alzheimer's disease. Neurosci. Lett. 280, 119-122. doi: 10.1016/s0304-3940(00)00767-9

Tarnaris, A., Toma, A. K., Chapman, M. D., Petzold, A., Keir, G., Kitchen, N. D., et al. (2011). Rostrocaudal dynamics of CSF biomarkers. Neurochem. Res. 36, 528-532. doi: 10.1007/s11064-010-0374-1

Terry, R. D., Masliah, E., Salmon, D. P., Butters, N., DeTeresa, R., Hill, R., et al. (1991). Physical basis of cognitive alterations in Alzheimer's disease: synapse loss is the major correlate of cognitive impairment. Ann. Neurol. 30, 572-580. doi: 10.1002/ana.410300410

Teunissen, C. E., Otto, M., Engelborghs, S., Herukka, S. K., Lehmann, S., Lewczuk, P., et al. (2018). White paper by the society for CSF analysis and clinical neurochemistry: overcoming barriers in biomarker development and clinical translation. Alzheimers Res. Ther. 10:30. doi: 10.1186/s13195-018-0359-x

Thal, D. R., Rub, U., Orantes, M., and Braak, H. (2002). Phases of a beta-deposition in the human brain and its relevance for the development of AD. Neurology 58, 1791-1800. doi: 10.1212/wnl.58.12.1791

Thompson, A. G., Gray, E., Heman-Ackah, S. M., Mager, I., Talbot, K., Andaloussi, S. E., et al. (2016). Extracellular vesicles in neurodegenerative disease pathogenesis to biomarkers. Nat. Rev. Neurol. 12, 346-357. doi: 10.1038/ nrneurol.2016.68

Thorsell, A., Bjerke, M., Gobom, J., Brunhage, E., Vanmechelen, E., Andreasen, N., et al. (2010). Neurogranin in cerebrospinal fluid as a marker of synaptic degeneration in Alzheimer's disease. Brain Res. 1362, 13-22. doi: 10.1016/j. brainres.2010.09.073

Tian, Z.-Y., Wang, C.-Y., Wang, T., Li, Y.-C., and Wang, Z.-Y. (2019). Glial S100A6 degrades $\beta$-amyloid aggregation through targeting competition with Zinc ions. Aging Dis. 10, 756-769. doi: 10.14336/AD.2018.0912

Timmers, M., Barao, S., Van Broeck, B., Tesseur, I., Slemmon, J., De Waepenaert, K., et al. (2017). BACE1 dynamics upon inhibition with a BACE inhibitor and correlation to downstream Alzheimer's disease markers in elderly healthy participants. J. Alzheimers Dis. 56, 1437-1449. doi: 10.3233/jad- 160829

Toledo, J. B., Bjerke, M., Da, X., Landau, S. M., Foster, N. L., Jagust, W., et al. (2015). Nonlinear association between cerebrospinal fluid and florbetapir F-18 betaamyloid measures across the spectrum of Alzheimer disease. JAMA Neurol. 72, 571-581. doi: 10.1001/jamaneurol.2014.4829

Toombs, J., Paterson, R. W., Lunn, M. P., Nicholas, J. M., Fox, N. C., Chapman, M. D., et al. (2013). Identification of an important potential confound in CSF AD studies: aliquot volume. Clin. Chem. Lab. Med. 51, 2311-2317. doi: 10.1515/ cclm-2013-0293

Town, T., Vendrame, M., Patel, A., Poetter, D., DelleDonne, A., Mori, T., et al. (2002). Reduced Th1 and enhanced Th2 immunity after immunization with Alzheimer's beta-amyloid(1-42). J. Neuroimmunol. 132, 49-59. doi: 10.1016/ s0165-5728(02)00307-7
Toyn, J. H., Boy, K. M., Raybon, J., Meredith, J. E. Jr., Robertson, A. S., Guss, V., et al. (2016). Robust translation of gamma-secretase modulator pharmacology across preclinical species and human subjects. J. Pharmacol. Exp. Ther. 358, 125-137. doi: 10.1124/jpet.116.232249

Trickler, W. J., and Miller, D. W. (2003). Use of osmotic agents in microdialysis studies to improve the recovery of macromolecules. J. Pharm. Sci. 92, 14191427. doi: $10.1002 /$ jps. 10410

Uddin, M. S., Stachowiak, A., Mamun, A. A., Tzvetkov, N. T., Takeda, S., Atanasov, A. G., et al. (2018). Autophagy and Alzheimer's disease: from molecular mechanisms to therapeutic implications. Front. Aging Neurosci. 10:4. doi: 10. 3389/fnagi.2018.00004

Uylings, H. B., and de Brabander, J. M. (2002). Neuronal changes in normal human aging and Alzheimer's disease. Brain Cogn. 49, 268-276. doi: 10.1006/brcg.2001. 1500

Van Giau, V., and An, S. S. (2016). Emergence of exosomal miRNAs as a diagnostic biomarker for Alzheimer's disease. J. Neurol. Sci. 360, 141-152. doi: 10.1016/j. jns.2015.12.005

Vellonen, K.-S., Ihalainen, J., Boucau, M.-C., Gosselet, F., Picardat, T., Gynther, M., et al. (2017). Disease-induced alterations in brain drug transporters in animal models of Alzheimer's disease. Pharm. Res. 34, 2652-2662. doi: 10.1007/s11095017-2263-7

Verberk, I. M. W., Slot, R. E., Verfaillie, S. C. J., Heijst, H., Prins, N. D., van Berckel, B. N. M., et al. (2018). Plasma amyloid as prescreener for the earliest Alzheimer pathological changes. Ann. Neurol. 84, 648-658. doi: 10.1002/ana.25334

Wahlund, L. O., and Blennow, K. (2003). Cerebrospinal fluid biomarkers for disease stage and intensity in cognitively impaired patients. Neurosci. Lett. 339, 99-102. doi: 10.1016/s0304-3940(02)01483-0

Walker, D. G., Link, J., Lue, L. F., Dalsing-Hernandez, J. E., and Boyes, B. E. (2006). Gene expression changes by amyloid beta peptide-stimulated human postmortem brain microglia identify activation of multiple inflammatory processes. J. Leukoc. Biol. 79, 596-610. doi: 10.1189/jlb.0705377

Wang, L. L., Huang, Y., Wang, G., and Chen, S. D. (2012). The potential role of microRNA-146 in Alzheimer's disease: biomarker or therapeutic target? Med. Hypotheses 78, 398-401. doi: 10.1016/j.mehy.2011.11.019

Wang, W. X., Rajeev, B. W., Stromberg, A. J., Ren, N., Tang, G., Huang, Q., et al. (2008). The expression of microRNA miR-107 decreases early in Alzheimer's disease and may accelerate disease progression through regulation of betasite amyloid precursor protein-cleaving enzyme 1. J. Neurosci. 28, 1213-1223. doi: 10.1523/jneurosci.5065-07.2008

Weiner, M. W., Aisen, P. S., Jack, C. R. Jr., Jagust, W. J., Trojanowski, J. Q., Shaw, L., et al. (2010). The Alzheimer's disease neuroimaging initiative: progress report and future plans. Alzheimers Dement. 6, 202.e7-211.e7. doi: 10.1016/j.jalz.2010. 03.007

Weydt, P., Oeckl, P., Huss, A., Muller, K., Volk, A. E., Kuhle, J., et al. (2016). Neurofilament levels as biomarkers in asymptomatic and symptomatic familial amyotrophic lateral sclerosis. Ann. Neurol. 79, 152-158. doi: 10.1002/ana.24552

Wildsmith, K. R., Holley, M., Savage, J. C., Skerrett, R., and Landreth, G. E. (2013). Evidence for impaired amyloid beta clearance in Alzheimer's disease. Alzheimers Res. Ther. 5:33. doi: 10.1186/alzrt187

Witter, M. P. (2007). The perforant path: projections from the entorhinal cortex to the dentate gyrus. Progress Brain Res. 163 43-61.

Wruck, W., Schroter, F., and Adjaye, J. (2016). Meta-analysis of transcriptome data related to hippocampus biopsies and iPSC-Derived neuronal cells from alzheimer's disease patients reveals an association with FOXA1 and FOXA2 gene regulatory networks. J. Alzheimers Dis. 50, 1065-1082. doi: 10.3233/jad150733

Wu, G., Sankaranarayanan, S., Wong, J., Tugusheva, K., Michener, M. S., Shi, X., et al. (2012). Characterization of plasma beta-secretase (BACE1) activity and soluble amyloid precursor proteins as potential biomarkers for Alzheimer's disease. J. Neurosci. Res. 90, 2247-2258. doi: 10.1002/jnr.23122

Xie, S., Xiao, J. X., Gong, G. L., Zang, Y. F., Wang, Y. H., Wu, H. K., et al. (2006). Voxel-based detection of white matter abnormalities in mild Alzheimer disease. Neurology 66, 1845-1849. doi: 10.1212/01.wnl.0000219625.776 25.aa

Yamada, K., Cirrito, J. R., Stewart, F. R., Jiang, H., Finn, M. B., Holmes, B. B., et al. (2011). In vivo microdialysis reveals age-dependent decrease of brain interstitial fluid tau levels in P301S human tau transgenic mice. J. Neurosci. 31, 13110-13117. doi: 10.1523/JNEUROSCI.2569-11.2011 
Yamada, K., Patel, T. K., Hochgrafe, K., Mahan, T. E., Jiang, H., Stewart, F. R., et al. (2015). Analysis of in vivo turnover of tau in a mouse model of tauopathy. Mol. Neurodegener. 10:55. doi: 10.1186/s13024-015-0052-5

Yan, P., Bero, A. W., Cirrito, J. R., Xiao, Q., Hu, X., Wang, Y., et al. (2009). Characterizing the appearance and growth of amyloid plaques in APP/PS1 mice. J. Neurosci. 29, 10706-10714. doi: 10.1523/jneurosci.2637-09.2009

Yankner, B. A., and Mesulam, M. M. (1991). Seminars in medicine of the Beth Israel Hospital, Boston. beta-Amyloid and the pathogenesis of Alzheimer's disease. N. Engl. J. Med. 325, 1849-1857. doi: 10.1056/nejm199112263252605

Yassa, M. A., Mattfeld, A. T., Stark, S. M., and Stark, C. E. (2011). Age-related memory deficits linked to circuit-specific disruptions in the hippocampus. Proc. Natl. Acad. Sci. U.S.A. 108, 8873-8878. doi: 10.1073/pnas.110156 7108

Zetterberg, H., Skillback, T., Mattsson, N., Trojanowski, J. Q., Portelius, E., Shaw, L. M., et al. (2016). Association of cerebrospinal fluid neurofilament light concentration with Alzheimer Disease progression. JAMA Neurol. 73, 60-67. doi: 10.1001/jamaneurol.2015.3037
Zimmer, D. B., Chaplin, J., Baldwin, A., and Rast, M. (2005). S100-mediated signal transduction in the nervous system and neurological diseases. Cell Mol. Biol. 51, 201-214.

Zimmer, E. R., Parent, M. J., Souza, D. G., Leuzy, A., Lecrux, C., Kim, H. I., et al. (2017). [(18)F]FDG PET signal is driven by astroglial glutamate transport. Nat. Neurosci. 20, 393-395. doi: 10.1038/nn.4492

Conflict of Interest: The authors declare that the research was conducted in the absence of any commercial or financial relationships that could be construed as a potential conflict of interest.

Copyright (c) 2020 Bjorkli, Sandvig and Sandvig. This is an open-access article distributed under the terms of the Creative Commons Attribution License (CC BY).

The use, distribution or reproduction in other forums is permitted, provided the original author(s) and the copyright owner(s) are credited and that the original publication in this journal is cited, in accordance with accepted academic practice. No use, distribution or reproduction is permitted which does not comply with these terms. 